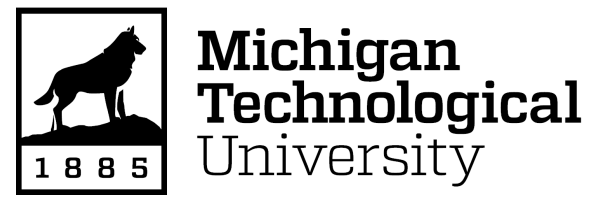

Michigan Technological University Digital Commons @ Michigan Tech

Dissertations, Master's Theses and Master's Reports

2017

\title{
Advanced Uses for Carbon Nanotubes: A Spherical Sound Source and Hot-films as Microphones
}

Micaela M. Thiery

Michigan Technological University, mmthiery@mtu.edu

Copyright 2017 Micaela M. Thiery

\section{Recommended Citation}

Thiery, Micaela M., "Advanced Uses for Carbon Nanotubes: A Spherical Sound Source and Hot-films as Microphones", Open Access Master's Report, Michigan Technological University, 2017.

https://doi.org/10.37099/mtu.dc.etdr/385

Follow this and additional works at: https://digitalcommons.mtu.edu/etdr

Part of the Acoustics, Dynamics, and Controls Commons 
ADVANCED USES FOR CARBON NANOTUBES:

A SPHERICAL SOUND SOURCE

AND

HOT-FILMS AS MICROPHONES

By

Micaela M. Thiery

\begin{abstract}
A REPORT
Submitted in partial fulfillment of the requirements for the degree of MASTER OF SCIENCE

In Mechanical Engineering
\end{abstract}

MICHIGAN TECHNOLOGICAL UNIVERSITY

2017

(C) 2017 Micaela M. Thiery 
This report has been approved in partial fulfillment of the requirements for the Degree of MASTER OF SCIENCE in Mechanical Engineering.

\author{
Department of Mechanical Engineering - Engineering Mechanics \\ Report Advisor: $\quad$ Dr. Andrew R. Barnard
}

Committee Member: $\quad$ Dr. Jason R. Blough

Committee Member: $\quad$ Charles Van Karsen

Committee Member: $\quad$ Dr. Darrell Robinette

Department Chair: $\quad$ Dr. William W. Predebon 


\section{Table of Contents}

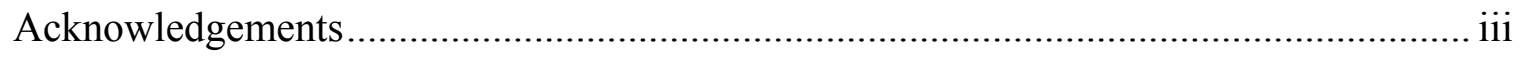

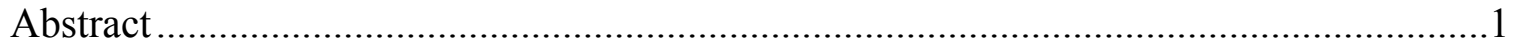

Part I - Spherical CNT Thermophone .......................................................................

1 Introduction - Spherical CNT Thermophone ...................................................

2 Methods \& Materials - Spherical CNT Thermophone...........................................5

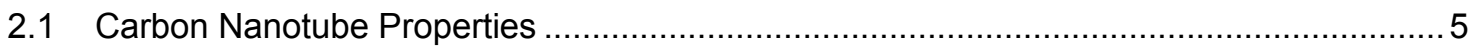

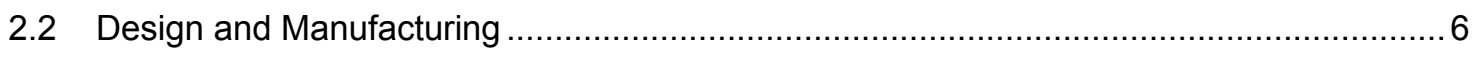

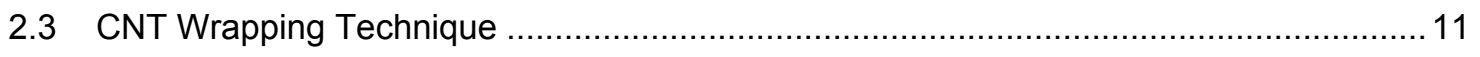

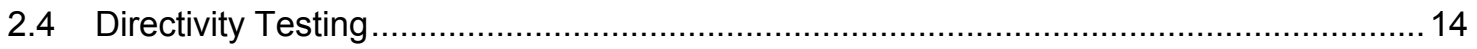

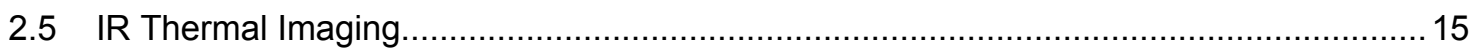

3 Results \& Discussion - Spherical CNT Thermophone .......................................16

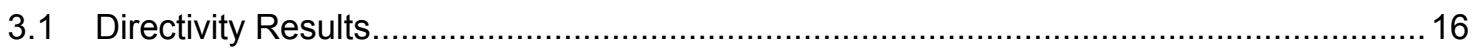

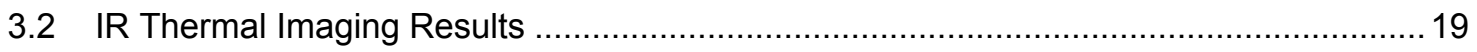

4 Conclusions \& Future Work - Spherical CNT Thermophone ................................21

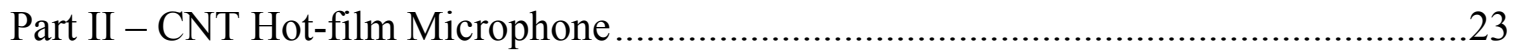

5 Introduction - CNT Hot-film Microphone …................................................23

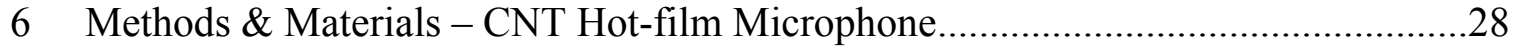

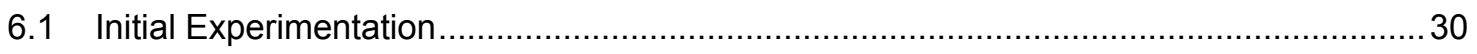

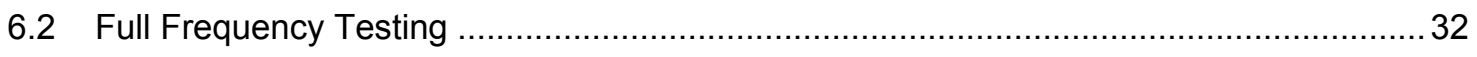

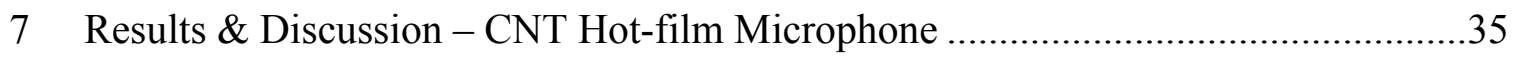

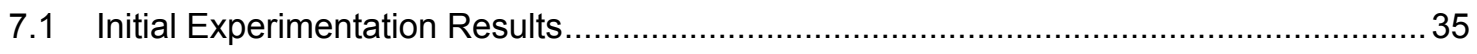


8 Conclusions \& Future Work - CNT Hot-film Microphone ....................................41

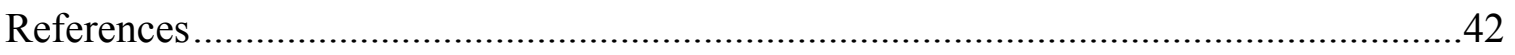

Appendix A — Spherical Base CAD Model/Detail Part Drawings .................................45

Appendix B - Overall Resistance Estimates for Spherical CNT Thermophone .............55

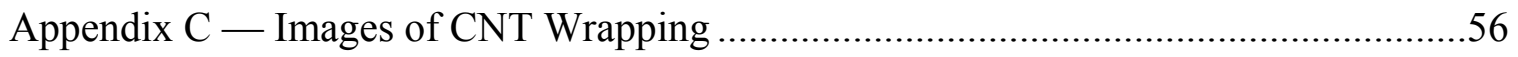

Appendix D — Directivity Testing Setup ...........................................................58

Appendix E — Spherical CNT Thermophone Directivity Results ...............................60

Appendix F — CNT Hot-film Microphone Experimentation Results............................82 


\section{Acknowledgements}

I would like to thank all those who assisted me throughout the course of my research. First, I would like to thank Dr. William Shapton for introducing me to my faculty advisor, Dr. Andrew Barnard, and for encouraging me to get involved in research while I completed my Master's degree. I would like to thank Dr. Andrew Barnard for allowing me the opportunity to complete this research and for his support throughout the project. Thank you to Dr. Jason Blough, Professor Charles Van Karsen, and Dr. Darrell Robinette for your support and for agreeing to serve on my defense committee. Thank you to all of my peers working on other research for your continuous assistance. Especially, thank you to Mahsa Asgarisabet, Stephania Vaglica, and Steven Senczyszyn for your help in working the CNT film to construct the CNT assemblies. Thank you Steve Lehman for your assistance in soldering and configuring electrical components. A special thanks to Marty Toth for working with me on the design of the spherical base and for the expert manufacturing of the final design. 


\begin{abstract}
Super-aligned carbon nanotube (CNT) thin-film is used to create thermophones. The thermal properties of CNT film allow it to rapidly heat and cool when supplied AC power producing temperature and pressure gradients and, therefore, audible sound. The advantages of CNT thermophones include eliminating all moving components of traditional speakers and reducing the weight of the speaker itself by using CNT film, which is nearly weightless. Additionally, the flexibility of CNT film provides the unique opportunity to construct loudspeakers of various sizes and geometries. In this work, a spherical CNT thermophone is designed, manufactured, and tested for directivity with the overall goal of creating a perfectly omnidirectional sound source over a wide frequency band. The spherical CNT thermophone is found to have significant directivity associated with it at the lowest and highest audible frequency bands, while performance is nearly omnidirectional at middle frequency bands.

The second part of this work uses of the same CNT thin-film as a microphone through hot-film anemometry sensing the particle velocity in acoustic waves of pure frequency tones. The advantages of a CNT hot-film microphone are similar to those of CNT thermophones and include the ability to construct microphones of various sizes and shapes because the film is ultra-lightweight and flexible. The microphone's sensitivity, power requirements, and frequency response were investigated. Results indicate that it may be feasible to use a CNT hot-film anemometer configuration as a microphone for detecting pure frequency tones across a large frequency range.
\end{abstract}




\section{Part I - Spherical CNT Thermophone}

\section{Introduction - Spherical CNT Thermophone}

Super-aligned carbon nanotube (CNT) thin-film can be used to create thermophone loudspeakers. The extremely low heat capacity per unit area (HCPUA) of CNT allows for the rapid heating and cooling of the thin-film, creating a temperature gradient in the air directly adjacent to the CNT thin-film. This temperature gradient is inherently accompanied by a pressure gradient and therein audible acoustic waves are produced when the CNT thin-film is heated and cooled at frequencies within the audible frequency range. The theory of the thermophone was first described by Braun in $1898[1,2]$. The implementation was further explored in 1917 by Arnold and Crandall using platinum as they attempted to create a telephone $[1,3]$. Platinum was used because it was available as a thin foil and known to have a low and stable HCPUA [3]. Limited by the HCPUA of the platinum, they were unsuccessful in creating a thermophone that could produce audible sound comparable to resonant mechanical speakers [3]. Since then, the discovery of CNT and development of CNT thin-films has provided a material well suited for rapid heating and cooling at frequencies across the entire audible frequency range. The HCPUA of CNT is significantly less than that of platinum with approximate values being $7.7 \times 10^{-3} \mathrm{~J} / \mathrm{m}^{2} \cdot \mathrm{K}$ for a single layer of CNT thin-film and $2.0 \mathrm{~J} / \mathrm{m}^{2} \cdot \mathrm{K}$ for platinum foil [4]. Over one hundred years after Braun detailed the thermophone theory, CNT thin-film has been used to create thermophones creating audible sound $[4,5,6]$. 
CNT thermophones can provide several advantages over traditional speakers in specific applications. CNT thin-films are nearly weightless and the architecture of CNT thermophone requires only a positive and negative electrode configuration to lay the CNT thin-film across for powering. Therefore, CNT thermophones could provide significant weight reductions compared to traditional speakers, making them well suited for weightsensitive applications such as use in aerospace and automotive systems. The architecture of the CNT thermophone requires no moving parts compared to traditional speakers that require the movement of a cone and coil and adequate space for this movement to produce sound. This elimination of moving parts along with the fact that CNT thin-films are flexible could allow CNT thermophones to also be more space efficient than traditional speakers in these applications.

Previous research at Michigan Technological University and elsewhere has focused on the development of CNT thermophones in regards to acoustic sound power, audible response, and true efficiency [6, 7]. All of this work has been done using planar CNT thermophones, which have high directivity associated with them [8]. While the flexible and stretchable nature of the CNT thin-film is observed in creating these planar CNT thermophones, CNT thermophones of complex geometries have not been created before this work. In this work, a spherical CNT thermophone was designed, manufactured, and tested.

A spherical speaker could have many uses in acoustics testing, mainly if the speaker is omnidirectional. An omnidirectional sound source has no directivity associated with it meaning that sound spreads from the source in a perfectly spherical pattern. The standard procedures for many structural acoustics measures call for the use of sound sources that 
are as nearly omnidirectional as possible according to ISO 3382 [9]. In most structural acoustics testing, dodecahedron speakers are used as close approximations to omnidirectional sound sources. These speakers are a configuration of twelve traditional moving coil speakers where each speaker is the side of a dodecahedron [10]. Generally, dodecahedron speakers give acceptable directionality at frequencies less than $3 \mathrm{kHz}$ (Figure 1.1) [11, 12]. Nevertheless, measurements made using dodecahedron speakers are found to be more accurate when measurements are averaged over several equal angle rotations of the speakers [10]. This means tests can require at least eight times as many measurements as would be required with a truly omnidirectional source.

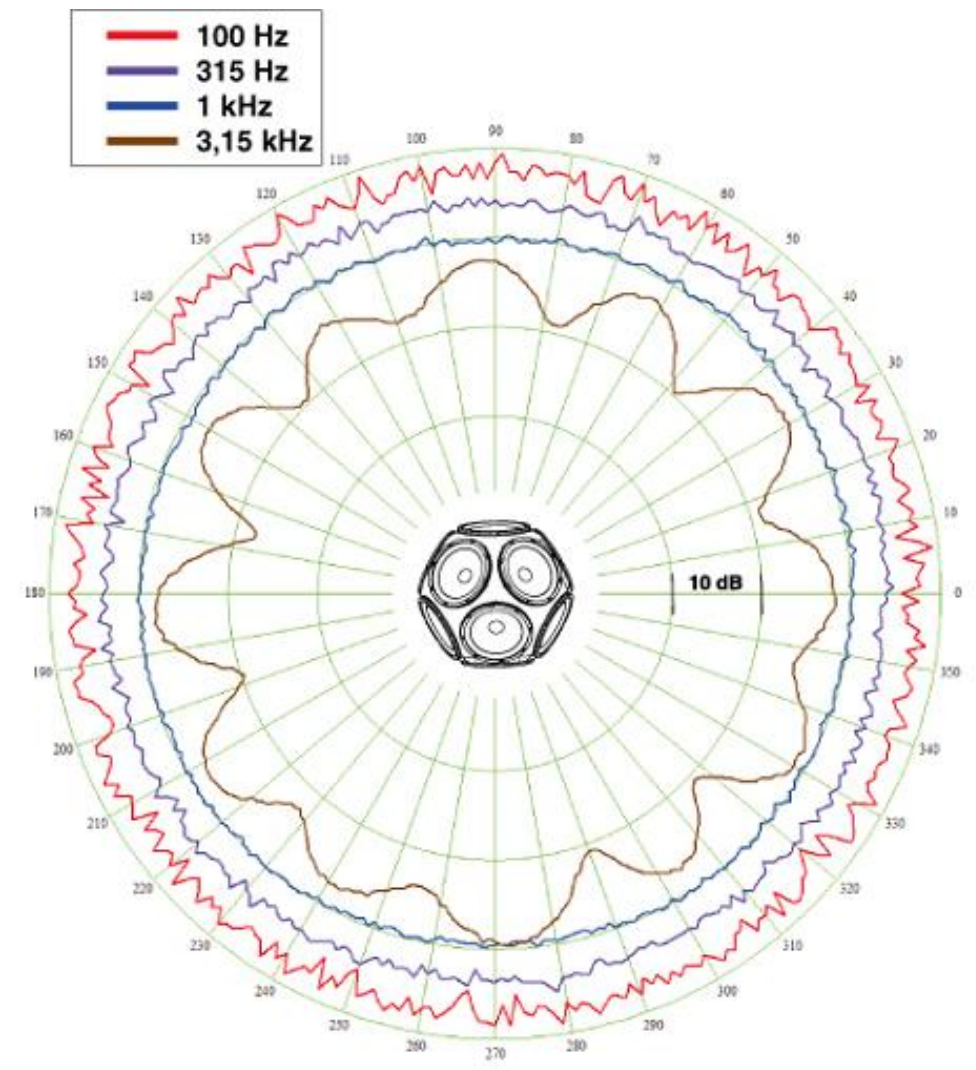

Figure 1.1: Directivity plot of commercial dodecahedron speaker, Nor276. 
Although work towards perfecting an omnidirectional speaker for acoustics testing is ongoing, the architecture of speakers has remained relatively consistent, resulting in little progress toward replacing dodecahedron speaker configurations with a more omnidirectional sound source. In this work, a spherical CNT thermophone is designed and manufactured with the goal of creating an omnidirectional sound source that operates over an extended frequency range versus traditional omnidirectional sound source approximations. The spherical CNT thermophone is tested for directivity in order to quantify how well it approximates an omnidirectional sound source.

\section{Methods \& Materials - Spherical CNT Thermophone}

\subsection{Carbon Nanotube Properties}

The carbon nanotubes (CNT) used to create the spherical CNT thermophone in this work are pulled into a thin-film from CNT forests. The CNT forests consist of multi-walled carbon nanotubes approximately $100 \mathrm{~nm}$ tall that are grown by chemical vapor deposition (CVD) on a silicon layer. These are purchased from NanoWorld Laboratories at the University of Cincinnati. Researchers at Michigan Technological University pull CNT from the purchased CNT forests resulting in a super-aligned CNT thin-film. The film is stretched over copper electrodes so that it can be powered to create CNT thermophones.

The CNT film used in this work, which results from drawing CNT from purchased CNT forests, has a consistent resistance of $750 \Omega$ per square area for one layer of CNT film. Several layers of CNT film are used in the thermophone constructions described here for increased stability and for reducing the overall resistance of the thermophone. To use 
standard audio amplifiers for powering the thermophone, the resistance of the entire construction should be a few orders of magnitude lower than the per-square-area resistance of one layer of CNT film. Ideally, the entire construction resistance should be near 2-4 $\Omega$. Layering the CNT film is the same as theoretically placing resistors in a parallel circuit and, therefore, reduces the resistance of a square area of CNT. Five layers of CNT film are used in creation of the planar thermophones, since this number of layers provides additional stability without significant degradation to the acoustic sound power [6]. When using five layers of CNT, the material has a resistance of $150 \Omega$ per square area of CNT. The entire thermophone construction resistance can be further reduced by electrode configuration decisions. Electrode spacing can be manipulated such that squares of CNT film are placed as resistors in a parallel circuit configuration.

\subsection{Design and Manufacturing}

The design of a spherical CNT thermophone begins with finding a material that has a high temperature rating, is electrically insulating, and can be machined into a spherical geometry. In the construction of planar CNT thermophones, the CNT film can be freely suspended between electrodes. Yet, to maintain the desired geometry of a spherical thermophone, the CNT film must lay over a spherical base. Additionally, a solid base is preferred over a wireframe base in this application to prevent acoustic waves from passing through the geometry and destructively interfering with acoustic waves produced on the other side of the sphere. Teflon ${ }^{\circledR}$ PTFE is identified as the most viable material for this application for its high temperature rating relative to other materials, its electrically 
insulating properties, and its machinability.

The low HCPUA of CNT film not only allows the material to heat and cool rapidly, but also allows the CNT film to reach maximum temperatures of around $300^{\circ} \mathrm{C}$ when sufficiently powered. Therefore, the material used for creating a spherical base for the thermophone must be able to handle these high temperatures without melting or deformation. Teflon ${ }^{\circledR}$ PTFE has a temperature rating of $250^{\circ} \mathrm{C}$, which is lower than the maximum temperatures of the CNT film in thermophone operation. However, the CNT film is not maintained at these maximum temperatures, so the Teflon ${ }^{\circledR}$ PTFE does not have time to heat to the CNT film's maximum temperature and the Teflon ${ }^{\circledR}$ PTFE temperature rating is found sufficient for the application of manufacturing a sphere base for the thermophone.

Many metals have higher temperature ratings than Teflon ${ }^{\circledR}$ PTFE; however, metals cannot be used as the structural material of the spherical base because they are electrically conductive. Thermophone operation requires an AC current to run through the CNT film. If the CNT film were to lay on an electrically conductive material, then powering the thermophone would result in a short circuit. Furthermore, to power the CNT film with an AC current, the film must extend from a positively wired electrode to a negatively wired electrode. To ensure this is true over a maximum surface area of the sphere, the Teflon ${ }^{\circledR}$ PTFE sphere is manufactured as separate vertical slices and copper disc electrodes are located between each slice of Teflon ${ }^{\circledR}$ PTFE. This arrangement creates two poles on the sphere, one in each of the vertical slices located at the ends of the configuration. Copper dot electrodes are included at each of these poles to complete the circuit for CNT film in these end slices. Copper is selected as the electrode material for its high electrical 
conductivity and because it is also cost efficient.

To design a spherical base with electrodes adequately incorporated into the surface, separate cylindrical Teflon ${ }^{\circledR}$ PTFE slices and copper discs are designed such that they can be sandwiched together and machined on a lathe into a sphere. Figure 2.1 contains annotated assembly and exploded views of the 3D CAD model of the sphere base. Additional images of the CAD model and detail drawings are included in Appendix A.

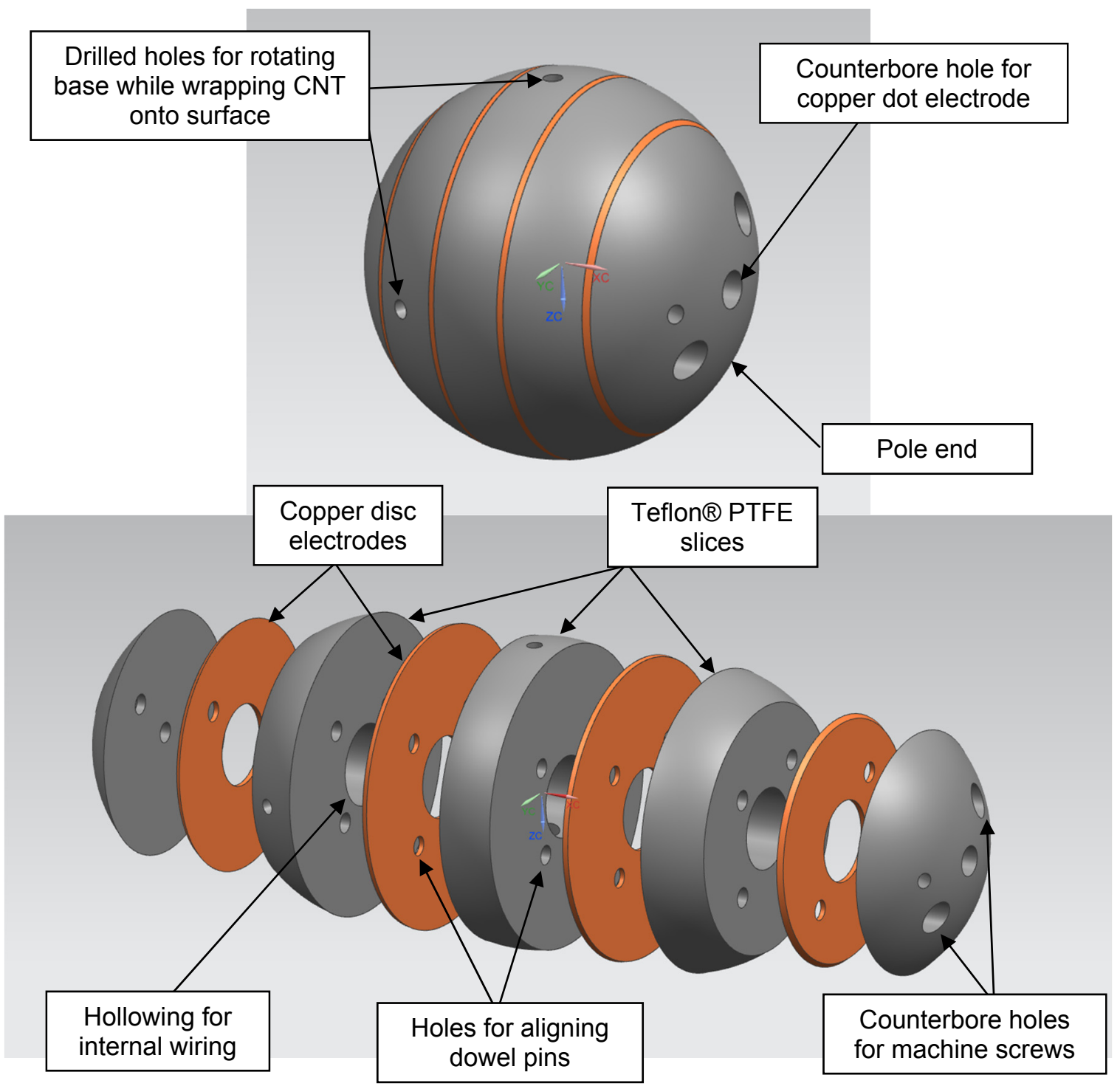

Figure 2.1: Annotated CAD model of full sphere base assembly and exploded view. 
Each of the Teflon® PTFE slices and copper discs are hollowed out such that the final sphere contains a hollow cylindrical space in the middle. This allows space for wiring the appropriate electrodes together internally, which can be seen in the exploded view of the CAD model in Figure 2.1. In order to practically assemble the Teflon ${ }^{\circledR}$ PTFE sphere slices and copper electrodes, dowel pins are used for alignment and four machine screws are threaded into counterbore holes that run through all of the Teflon ${ }^{\circledR}$ PTFE slices and copper discs. An additional hole is drilled from the outer surface of the middle Teflon® PTFE slice to the center of the sphere such that the positive and negative wire leads can be routed out of the sphere through a hollow rod used as the stand for the spherical CNT thermophone.

While a larger diameter sphere appeared theoretically easier to cover in CNT film after manufacturing, increasing the diameter of the sphere subsequently increases the cost of the Teflon ${ }^{\circledR}$ PTFE material required to make it. As a compromise in considering the ease of manufacturing the sphere, the cost and availability of the Teflon® PTFE material, and the practicality of pulling the CNT film over the sphere surface, a diameter of 3.75 inches was chosen for the spherical design.

For compatibility with standard audio amplifiers, a target overall resistance of $2 \Omega$ is selected for the design of the spherical CNT thermophone. Calculations were performed to determine the optimum number of electrodes to use. In this configuration each slice of the sphere can be considered a resistor. This gives $\mathrm{n}-1$ resistors in a series configuration across the sphere, where $\mathrm{n}$ is the number of electrodes in the sphere including the two dot electrodes.

Choosing an electrode spacing such that each of the slices has the same resistance 
when covered in CNT film will prevent current from accumulating in lower resistance areas of the sphere. The resistance of each slice was assumed to be the same when the surface area of each slice is the same, since the resistance of the CNT film is per-square-area. The surface area of any vertical slice of a sphere is given by Equation 2.1, where $r$ is the radius of the sphere and $\mathrm{h}$ is the width of the slice along the horizontal axis of the sphere.

$$
S A_{\text {slice }}=2 \pi * r * h
$$

Equation 2.1

From Equation 2.1 it was determined that each slice will have the same surface area when each slice has the same width along the horizontal axis of the sphere. The number of squares in each slice and the total resistance of the thermophone design is estimated for different numbers of electrodes. The results are included in Table 2.1. With a 3.75-inch diameter sphere, using six electrodes results in five slices, a manufacturable design, and an estimated overall resistance for the thermophone closest to $2 \Omega$.

Table 2.1: Estimates of thermophone resistance dependent on number of electrodes in design.

\begin{tabular}{|c|c|c|c|c|}
\hline $\begin{array}{c}\mathrm{n}, \# \text { of } \\
\text { electrodes }\end{array}$ & $\begin{array}{c}\text { \# of sphere } \\
\text { slices }\end{array}$ & $\begin{array}{c}\mathrm{h}, \text { width per } \\
\text { slice (inches) }\end{array}$ & $\begin{array}{c}\text { Estimated resistance } \\
\text { per slice }(\Omega)\end{array}$ & $\begin{array}{c}\text { Estimated total } \\
\text { resistance }(\Omega)\end{array}$ \\
\hline 4 & 3 & 1.25 & 15.9 & 5.3 \\
\hline 6 & 5 & 0.75 & 9.5 & 1.9 \\
\hline 8 & 7 & 0.54 & 6.9 & 1.0 \\
\hline 10 & 9 & 0.42 & 5.3 & 0.6 \\
\hline
\end{tabular}

A 3D CAD model and detail part drawings of the Teflon ${ }^{\circledR}$ PTFE and copper electrode assembly was created in Siemens NX. The design was then manufactured in the machine shop on the sixth floor of the R.L. Smith Building at Michigan Technological University. After all parts of the assembly were manufactured, wires were soldered to the copper electrodes and all positive electrodes and all negative electrodes were wired together such that these connections could be contained within the hollow portion of the sphere. The 
result of this design and manufacturing is a robust spherical base wired such that CNT film can be wrapped onto the surface repeatedly as needed. Figure 2.2 contains an image of the manufactured spherical base partially disassembled to show the inside wiring.

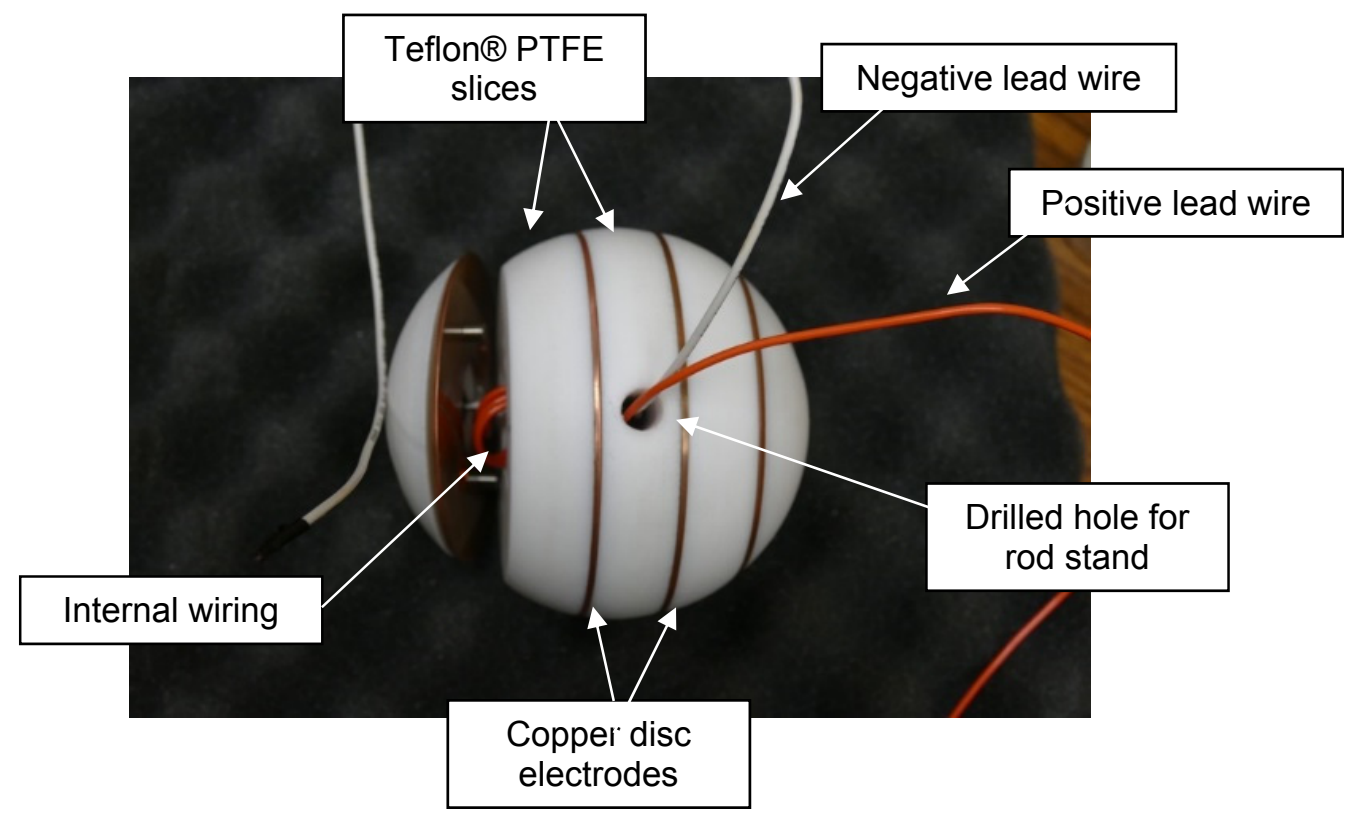

Figure 2.2: Manufactured sphere base with Teflon ${ }^{\circledR}$ PTFE and copper electrodes. One end of the sphere is partially disassembled to show internal wiring.

\subsection{CNT Wrapping Technique}

Uniformly covering the spherical base in CNT film is a main challenge. The CNT film is inherently tedious to work with because it is fragile and the CNT forests can be ruined if film is not pulled from them properly. The tension within the CNT film must remain constant as it is being pulled from the forest. For this reason, CNT film cannot be adequately wrapped around the entire sphere in one wrapping direction. Although the CNT film is flexible and can conform to the contour of the sphere surface, as the poles of the sphere are approached, tension in the CNT film becomes uneven due to the sharp angle of 
the sphere surface. This causes the CNT film to roll together. When wrapping in one direction, it is found that the CNT film can be wrapped to cover a band of approximately 2.5-3 inches in the middle of the 3.75-inch diameter sphere.

To fully cover the sphere with a uniform number of CNT film layers, CNT film is wrapped in three directions by spinning the sphere base about three orthogonal axes. Figure 2.3 contains images of the CNT film being pulled from a CNT forest and wrapped onto the spherical base. When laying three layers of CNT film per axis wrapping, this technique results in six layers of CNT film on a majority of the sphere. There are small wedges at the edges of each wrapped band and thin strips in the middle of each wrapped band that are not fully covered with all six layers and instead have only three layers of coverage. Additionally, the layers of CNT film that cover the sphere using this wrapping technique lay over one another in a crisscrossing fashion. Since the CNT thermophones constructed in previous research have been made such that the CNT film layers align in the same direction, it is unclear before testing if this crisscrossing pattern will have adverse effects on the performance of the spherical CNT thermophone. Figure 2.4 shows the final fully wrapped spherical CNT thermophone. 


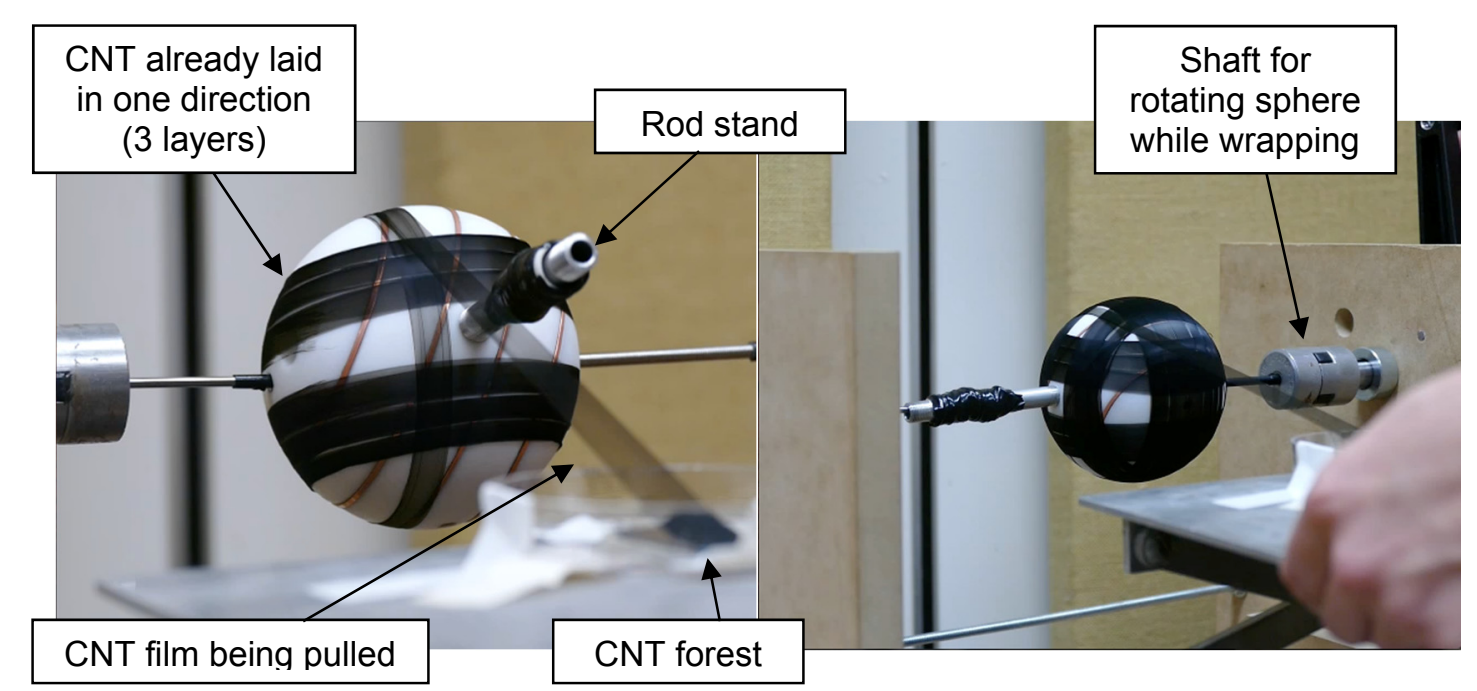

Figure 2.3: CNT film being pulled from a CNT forest. CNT film is laid and wrapped onto the surface of the spherical base simultaneously.

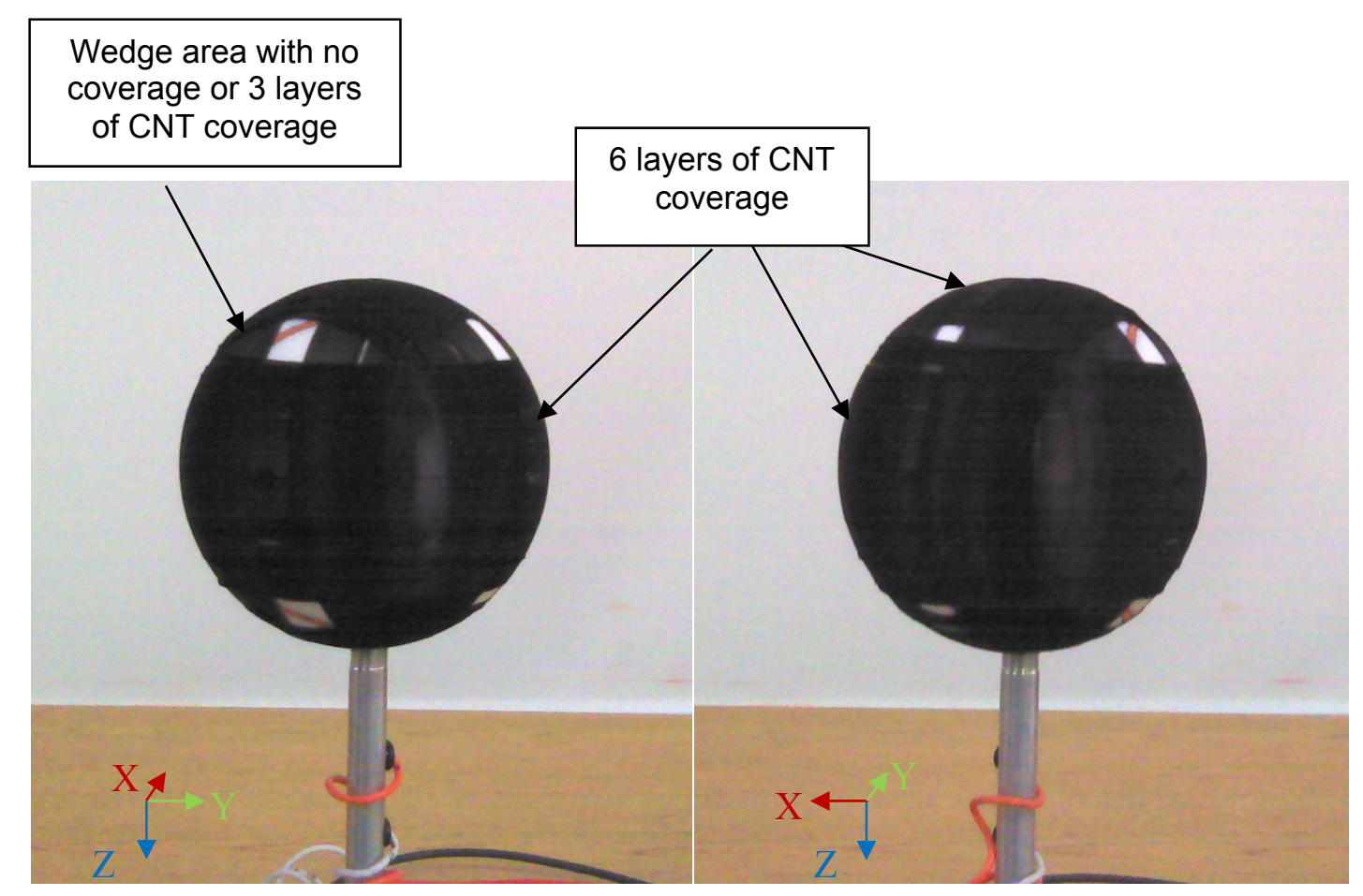

Figure 2.4: Final fully wrapped spherical CNT thermophone. 


\subsection{Directivity Testing}

The directivity of the spherical CNT thermophone is tested by measuring the sound pressure level at several points over an imaginary hemisphere with a radius of half a meter from the thermophone sound source. The test is performed in a fully anechoic environment in the anechoic chamber located on the sixth floor of the R.L. Smith Building at Michigan Technological University. The spherical CNT thermophone is placed on a turntable for this test so that measurements around the hemisphere can be made by rotating the thermophone instead of moving the microphones used to acquire data.

An array of eight microphones in an arc is used to make sound pressure level measurements over the hemisphere. Four PCB 130A23 array microphones are used along with two PCB 378B20 random incidence microphones and two PCB 378B02 free field microphones. A National Instruments PXIe-4497 module and LabVIEW code is used for data acquisition. The sound source is rotated by manually rotating the turntable between measurements to acquire measurements over the entire hemisphere with rotation increments of $20^{\circ}$. Figure 2.5 shows an image of the directivity test setup. Additional details of the directivity test such as the coordinates of the microphones are included in Appendix D.

The directivity index is defined at each measurement location as the normalized difference between the sound pressure level measured at that point and the maximum sound pressure level determined from all measurements over the hemisphere [13]. Directivity is frequency dependent and therefore the test is performed while playing white noise from the spherical CNT thermophone in order to excite a broadband range of audio frequencies 
from $40 \mathrm{~Hz}$ to $10 \mathrm{kHz}$. The input power supplied to the thermophone is held constant throughout the test such that the sound power output of the thermophone is theoretically constant throughout the test at each frequency band.

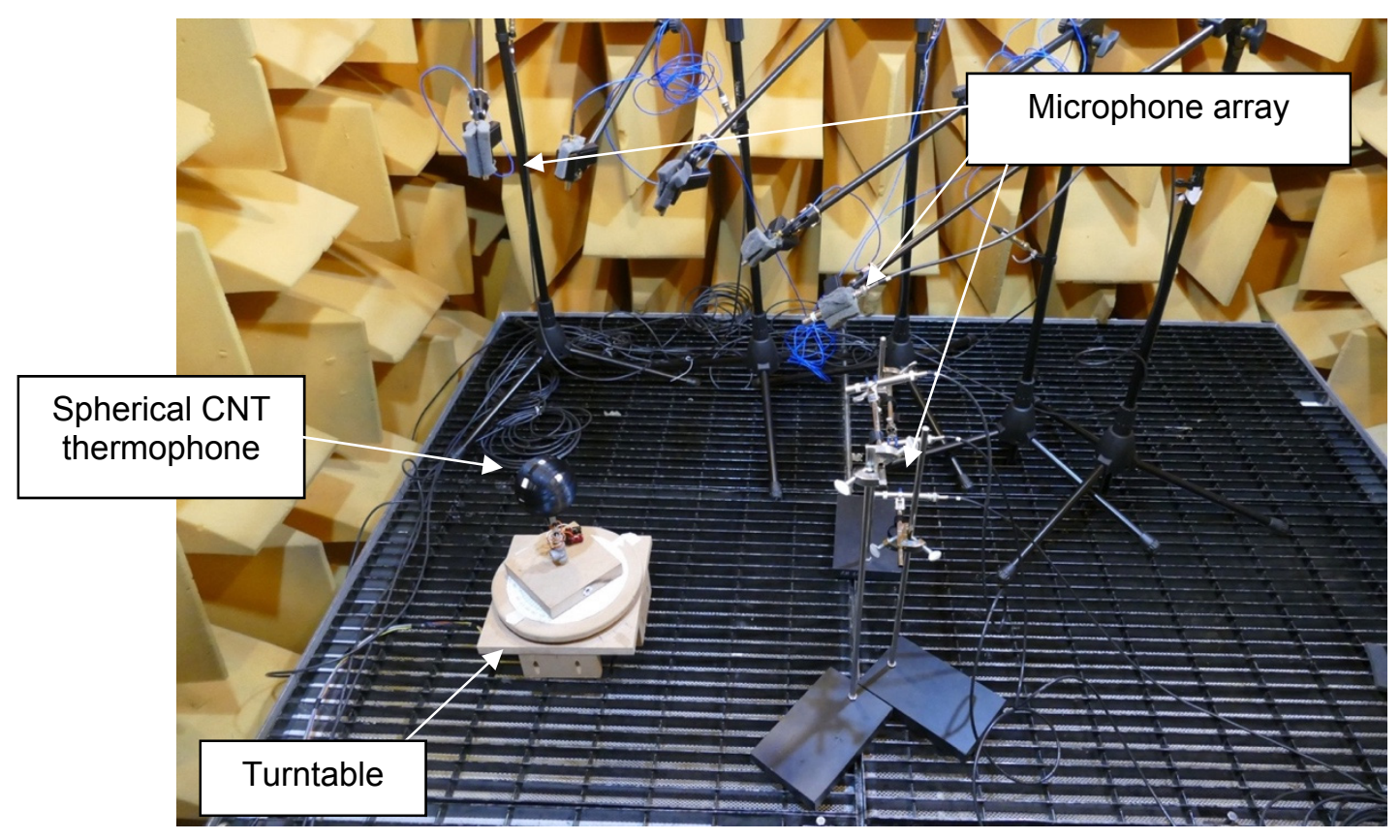

Figure 2.5: Directivity test setup within anechoic chamber.

\subsection{IR Thermal Imaging}

IR thermal imaging of the spherical CNT thermophone was performed at ThermoAnalytics, Inc. in Calumet, Michigan. This imaging was done with a high speed FLIR thermal camera equipped to record video and still images. A single frequency tone of $2 \mathrm{kHz}$ was played through the spherical CNT thermophone with an input power of $30 \mathrm{~W}$. The thermal emissivity of the CNT thin-film is assumed to be 0.80 for this test. This value is an approximate value obtain from research performed by Aliev et al. at the University of Texas at Dallas [14]. 


\section{Results \& Discussion - Spherical CNT Thermophone}

\subsection{Directivity Results}

A spherical CNT thermophone was designed and manufactured with the goal of creating an omnidirectional sound source that can replace or compete with current omnidirectional sound source approximations used in structural acoustics testing. A directivity test was performed to determine the actual directivity of the final spherical CNT thermophone by playing white noise from the thermophone with a constant sound power output. The thermophone was rotated a full $360^{\circ}$ and sound pressure level measurements were recorded with an eight microphone arc array, such that measurements were taken over the surface of a hemisphere surrounding the thermophone. The completed directivity test provides sound pressure level measurements at 144 points over the surface the hemisphere. Sound pressure levels are frequency dependent, therefore measurements were filtered into $1 / 3$ octave frequency bands. The directivity index at each measurement location was determined for each $1 / 3$ octave frequency band. The directivity index results are organized visually to represent the imaginary hemisphere over which measurements were taken. A plot was created for each $1 / 3$ octave frequency band resulting in 28 polar plots. Since the directivity index values were calculated as values normalized with the maximum sound pressure level recorded within each $1 / 3$ octave frequency band, calculated directivity index values are all less than or equal to zero. Overall directivity of the thermophone may be considered low when a majority of directivity index values are within $\pm 1 \mathrm{~dB}$ of one another. High directivity is associated with the lowest directivity index values calculated. 
Some of the most representative directivity plots are included in this section, while all of the directivity plots are included in Appendix E along with tables containing all calculated directivity index values used to create the plots.

At low frequency bands, $630 \mathrm{~Hz}$ and below, the directivity of the spherical CNT thermophone is undetermined. While CNT thermophones inherently exhibit poor performance at low frequencies since the sound pressure level produced at each frequency is proportional to the frequency, the low signal-to-noise ratios at these frequencies in the anechoic chamber used for testing also leads to sound pressure level measurements that cannot be distinguished as being sound produced from the spherical CNT thermophone and background noise [15]. However, at these low frequencies the spherical CNT thermophone is expected to be nearly omnidirectional because wavelengths are significantly larger than the source.

At frequency bands, $800 \mathrm{~Hz}$ to $4 \mathrm{kHz}$, the directivity of the spherical CNT thermophone is low over the entire hemisphere surface with hardly any locations having directivity indices less than $-10 \mathrm{~dB}$. The lowest directivity index values were measured at the 3.15 $\mathrm{kHz}$ frequency band, where the minimum directivity index value was $-5 \mathrm{~dB}$ and the average directivity index value over the hemisphere was $-2 \mathrm{~dB}$. These directivity measurements are comparable to the directivity of commercial dodecahedron speakers at frequencies of acceptable directional performance. Figure 3.1 includes four plots of these higher frequency bands directivity displaying less directivity associated with the spherical CNT thermophone. 

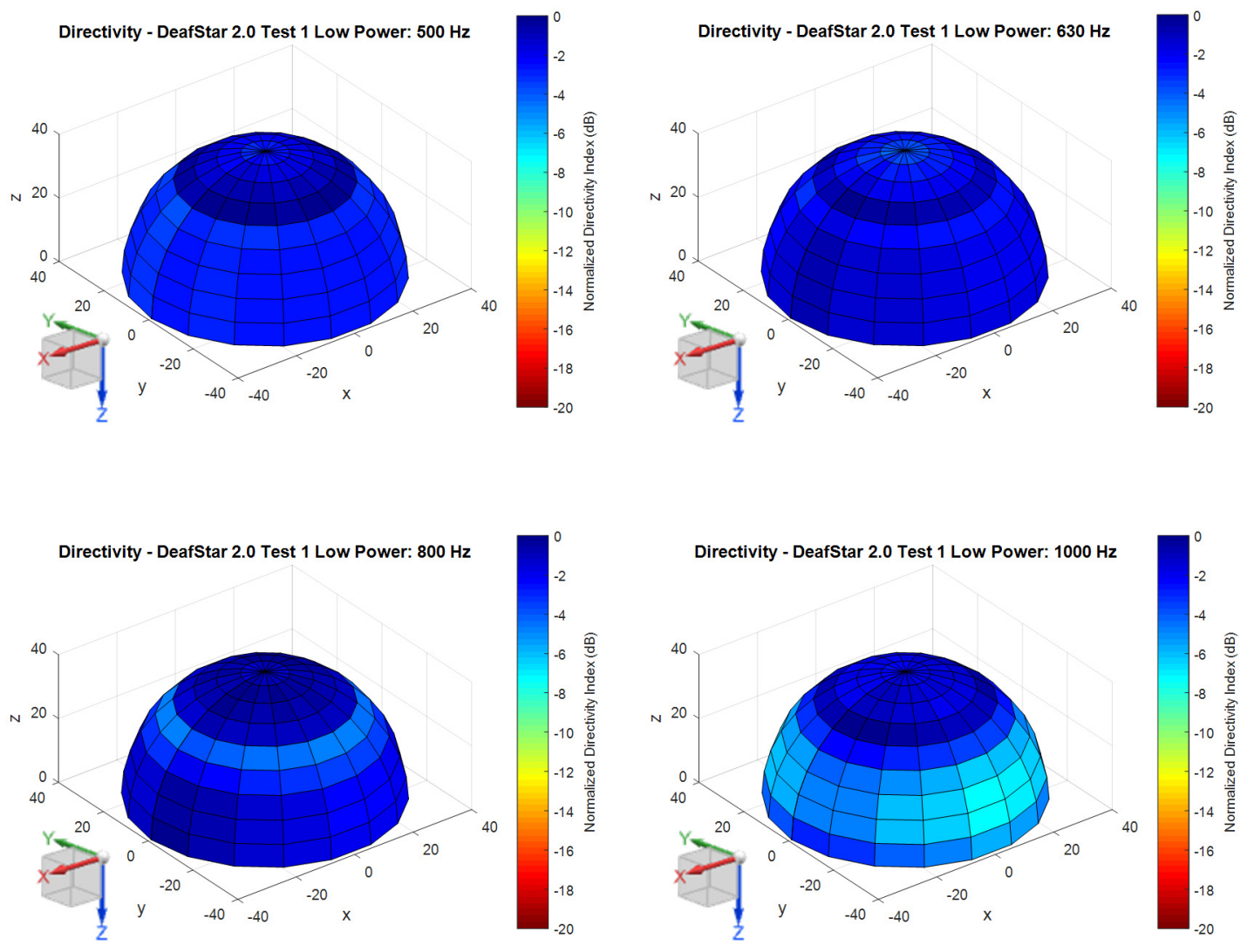

Figure 3.1: Polar plots displaying directivity calculated over an imaginary hemisphere surface for $1 / 3$ octave frequency bands, $500 \mathrm{~Hz}, 630 \mathrm{~Hz}, 800 \mathrm{~Hz}$, and $1 \mathrm{kHz}$.

However, at higher frequency bands, $5 \mathrm{kHz}$ and greater, the spherical CNT thermophone exhibits more directivity at certain locations on the hemisphere. Figure 3.2 includes four directivity plots for these highest frequency bands that show areas of increased directivity. The areas of highest directivity in these highest frequency bands appear to correlate to the two end Teflon ${ }^{\circledR}$ PTFE slices that are each powered by a copper dot electrode when considering the orientation of the spherical CNT thermophone in the directivity results. 

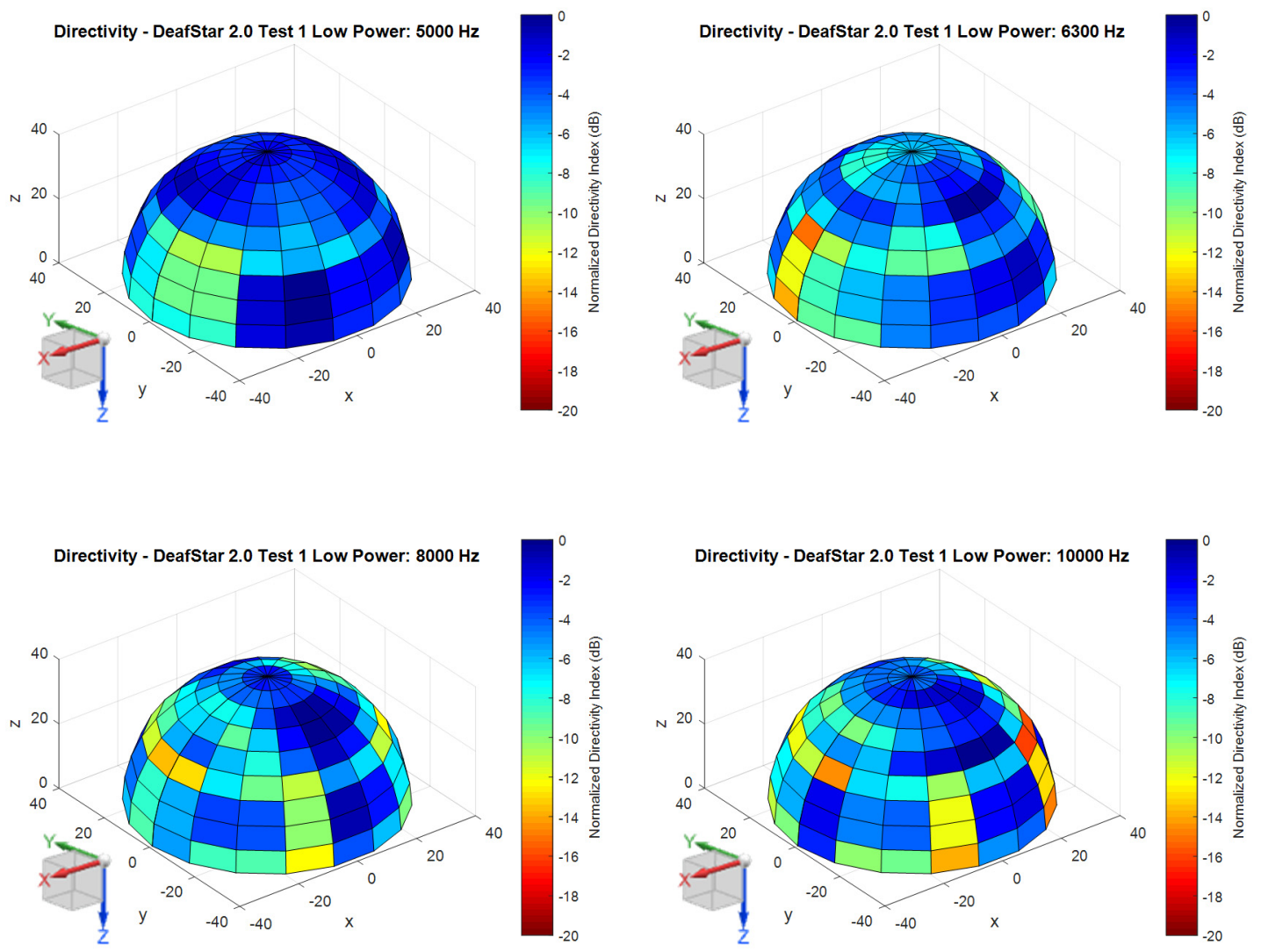

Figure 3.2: Polar plots displaying directivity calculated over imaginary hemisphere surface for $1 / 3$ octave frequency bands, $5 \mathrm{kHz}, 6.3 \mathrm{kHz}, 8 \mathrm{kHz}$, and $10 \mathrm{kHz}$.

\subsection{IR Thermal Imaging Results}

Since the spherical CNT thermophone was found to have some significant directivity associated with it at the lowest and highest $1 / 3$ octave frequency bands, IR thermal imaging of the spherical CNT thermophone was done to assist in identifying why the thermophone is directional instead of omnidirectional. IR thermal imaging was performed while operating the thermophone by playing a pure tone of $4 \mathrm{kHz}$. The spherical CNT thermophone was rotated while operating to obtain four IR thermal images that fully 
capture the temperature gradient over the entire sphere surface of the thermophone. The IR thermal images are included in Figure 3.4. The images show that the temperature of the CNT on the surface of the thermophone is not uniform but varies from approximately $24^{\circ} \mathrm{C}$ to $40^{\circ} \mathrm{C}$. This drastic variation in temperature is different from that observed for a planar CNT thermophone in operation, which exhibits a mostly uniform temperature over the entirety of the CNT film in the assembly.

Several features of the spherical base underneath the CNT film can be identified in these images, while these features are not as easily seen by the naked eye in operation of the thermophone. Hotter spots on the sphere appear to occur near the electrodes, however the electrodes themselves are not as hot as some of the nearby CNT film. The hottest spots on the sphere are where six layers CNT lay atop one another and the CNT film is laid and aligned perpendicular to the copper disc electrodes. The two end Teflon ${ }^{\circledR}$ PTFE slices to be powered by the copper dot electrodes are clearly cooler than the middle slices indicating that the CNT film in these portions of the sphere is not adequately powered. This information provides an explanation as to why high directivity and low directivity index values are calculated and associated with these two end slices. 

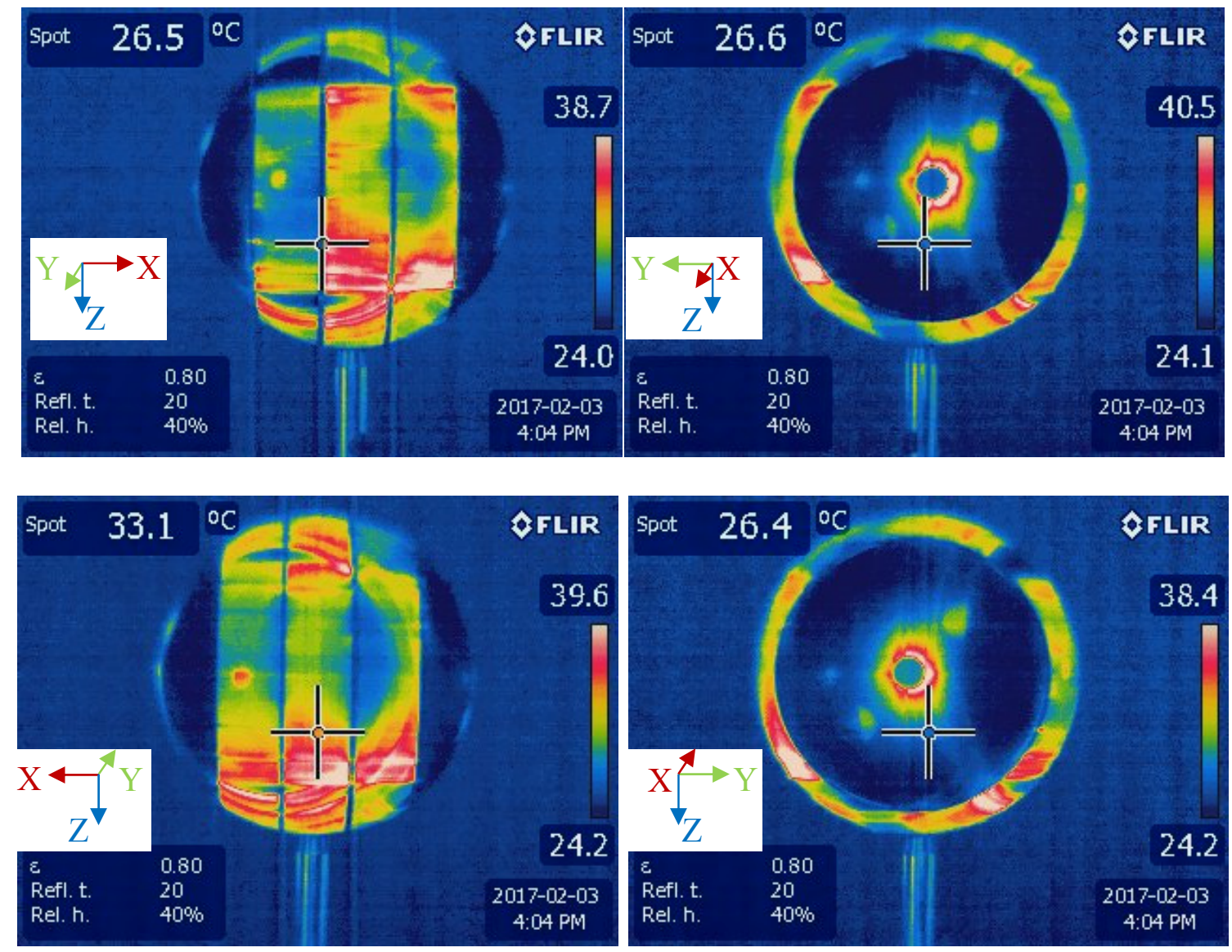

Figure 3.4: IR thermal images of spherical CNT thermophone while operating.

\section{Conclusions \& Future Work - Spherical CNT Thermophone}

A functional spherical CNT thermophone was manufactured and tested to quantify how closely it approximates an omnidirectional sound source. The design took advantage of the flexibility of the CNT film, which allowed it to be pulled and wrapped onto a spherical base made of Teflon ${ }^{\circledR}$ PTFE with copper electrodes incorporated into the surface. The spherical CNT thermophone was found to have significant directivity associated with it, particularly at the lowest and highest $1 / 3$ octave frequency bands. However, at several of the middle $1 / 3$ octave frequency bands between $500 \mathrm{~Hz}$ and $4 \mathrm{kHz}$ the spherical CNT 
thermophone exhibited less directivity over the entire imaginary hemisphere over which measurements were made.

The spherical CNT thermophone is nearly omnidirectional at frequency bands from $800 \mathrm{~Hz}$ to $4 \mathrm{kHz}$, slightly outperforming traditional dodecahedron speakers that are nearly omnidirectional at frequency bands below $3 \mathrm{kHz}$. The poor performance of the spherical CNT thermophone at low frequencies is attributed to the poor performance of thermphones in general at low frequencies and low signal-to-noise ratios in the testing facility. The areas of high directivity from the spherical CNT thermophone in the highest frequency bands were found to be related to observations made from IR thermal imaging. The poor powering of the two end Teflon® PTFE slices on the sphere leads to the conclusion that hardly any sound is produced from these areas. It is assumed that the spherical CNT thermophone would be nearly omnidirectional through a higher frequency range if the entire sphere were adequately powered.

The future work for this research would focus on improving the method for wrapping the CNT onto the spherical base in order to ensure that the CNT is aligned such that ends of the CNT connect from positive to negative electrodes across the entire surface of the sphere. The wrapping method used in this work did not allow all of the CNT film in the two end slices to come in contact with the copper dot electrodes placed in these ends to power the CNT. Winders for yarn, baseballs, and golf balls could be used as manufacturing examples. A total redesign of the spherical base could also be considered that may involve a piece-by-piece assembly of the thermophone. Cues could be taken from the structure of a spherical Rubik's ${ }^{\circledR}$ cube, while the electrical resistance of each piece when covered in CNT film should be considered. 


\section{Part II - CNT Hot-film Microphone}

\section{Introduction - CNT Hot-film Microphone}

The discovery of the thermal-acoustic properties of CNT thin-film has sparked interest in the material and specifically if it can be used in an inverse manner to not only create sound, but also to detect, sense, or record sound as a microphone. The interest in this application is similar to that of the CNT thermophone. A CNT thin-film microphone could be added to systems in unique locations due to the light-weight and flexible nature of the CNT.

In order to use CNT thin-film in a microphone application, some characteristic of the acoustic waves must affect the film in a consistent and measurable way. Previous research with CNT thermophones has revealed that the resistance of the film dependably varies with changes in the film temperature [14]. It is expected that this may be the most promising property to exploit in the creation of a CNT microphone since hot-film anemometry is an already well-established technology that utilizes this phenomenon of resistance changing with temperature changes with different materials.

Anemometers have been commonly used to measure wind speeds for several decades. The basic theory of hot-wire anemometry is that the wire is heated well above room temperature in operation allowing convection from air passing over the wire to cause a significant change in the wire temperature. Then this change in wire temperature causes a corresponding change in wire resistance that can be observed and measured [16]. Some of the first work in using platinum wires in a hot-wire configuration to measure fluctuations 
in wind speeds was performed by NASA in 1929 [17]. The platinum wires used in this work by NASA were originally $0.075 \mathrm{~mm}$ in diameter, while throughout their work it was found that the functionality and sensitivity of the hot-wire anemometer significantly increased by decreasing the diameter of the platinum wire [17]. Since the proven viability of using hot-wire anemometers to measure wind speeds, research has focused on perfecting the design configuration, sensitivity, and measurements made by this method [18, 19]. Some research has also successfully used platinum film instead of platinum wire in a hotfilm anemometry configuration for monitoring wind speeds [20,21]. One advantage described by Mailly et al. of using platinum film is that it is of no consequence if the film is parallel or perpendicular to the air flow compared to using a hot-wire configuration where orientation is crucial [20]. These factors lead to increased interest in the possibility of using CNT film in a hot-film configuration as the diameter of nanotubes within the film are several orders of magnitude smaller than that of platinum wire and the use of film itself may be advantageous in increasing the versatility of such a device.

Few hot-wire or hot-film anemometers have been extended in application to detect acoustic waves [22]. However, this is not the typical architecture of a microphone. A traditional microphone includes a diaphragm that is affected by the acoustic pressure wave. The movement of the diaphragm then induces movement in an attached coil that lies in a magnetic field. This creates a varying current that can be measured. In a hot-wire or hotfilm microphone, the particle velocity associated with the incident acoustic wave stimulates changes in the film temperature through convection in the same way that hot-wire and hotfilm anemometers detect wind speed. This microphone architecture requires no capacitive circuit to operate. 
The first hot-wire microphone was developed and tested by Tucker and Paris in 1921 [23]. This microphone employed a platinum wire grid at the base of a Helmholtz resonator and was utilized and tuned to detect select frequencies that resonated within the resonator dimensions. Utilizing the resonator and an amplifier in their configuration they were able to connect headphones to the output signal from the anemometer and hear low pure tones. In more recent work done by Huelsz et al. a hot-wire anemometer has been used to detect acoustic waves [22].

In their work, Huelsz et al. used tungsten wires $5 \mu \mathrm{m}$ in diameter with an electrical resistance of approximately $3 \Omega$ as the sensing material in a hot-wire anemometer microphone. This anemometer accurately detected audible tones of frequency $35 \mathrm{~Hz}, 46$ $\mathrm{Hz}$, and $130 \mathrm{~Hz}$. Several significant observations are made in this work. It is expected that the measured response signal from the anemometer have frequency content of even multiples of the tone frequency because the anemometer is not predicted to distinguish between cooling caused by the outward pressure oscillation of the acoustic wave and the inward pressure oscillation. However, Huelsz et al. observe the response signal from their anemometer to have significant frequency content at the tone frequency and harmonics [22]. Additionally, Huelsz et al noticed a decline in anemometer performance at higher frequency tones due to the thermal inertia of the tungsten wire. This bodes well for a CNT hot-film anemometer microphone that may operate over a higher frequency range because the thermal inertia of CNT is known to be ultralow [24].

Chiefly, the relationship between the film temperature and film resistance must be well known and significant in order for the film to work successfully as a sensor in a hot-film anemometer design. This limits the film materials that can be used for such sensing. The 
relationship between temperature and resistance for common anemometer materials, platinum and tungsten, is characterized by the following expression, where $R_{o}$ is the original film resistance at temperature $\mathrm{T}_{\mathrm{o}}, \mathrm{R}_{\mathrm{T}}$ is the film resistance at the final temperature $\mathrm{T}$, and $\alpha$ is the material's temperature coefficient of resistivity (TCR) $[17,19,25]$.

$$
\mathrm{R}_{\mathrm{T}}=\mathrm{R}_{\mathrm{o}}\left[1+\alpha\left(\mathrm{T}-\mathrm{T}_{\mathrm{o}}\right)\right]
$$

Both of these materials exhibit positive and relatively high TCRs. Platinum has a TCR of $3.9 \times 10^{-3} /{ }^{\circ} \mathrm{C}$ [20]. Meanwhile, the TCR of CNT film is not as definite. Aliev et al. found the TCR of CNT film similar to that used in this research to be $-7.6 \times 10^{-4} /{ }^{\circ} \mathrm{C}$, which is an order of magnitude lower than that of platinum and negative instead of positive raising some concerns with the practicality of CNT hot-film anemometry [14]. However, several researchers have been successful in using CNT films in the hot-film anemometry application as temperature sensors and wind speed detectors $[25,26,27,28]$. Some of these researchers use the expression in Equation 5.1 to fit their results and determine the TCR of the specific CNT material used, however some assert a different relationship between temperature and resistance for CNT. Martins et al. claims that thermoresistive materials with negative TCRs exhibit a relationship between temperature and resistance approximated to follow Equation 5.2 [19].

$$
\mathrm{R}_{\mathrm{T}}=\mathrm{R}_{o} e^{\alpha((1 / \mathrm{T})-(1 / \mathrm{To}))}
$$

Equation 5.2

Meanwhile, Xiao et al. states that the super-aligned multi-walled CNT used in their experimentation exhibits a relationship between temperature and resistance approximated by Equation 5.3 [27].

$$
\mathrm{R}_{\mathrm{T}}=\mathrm{R}_{\mathrm{o}} \mathrm{T}^{1 / 2} e^{\left((\mathrm{To} / \mathrm{T})^{\wedge}(1 / 4)\right)}
$$


All three expressions, Equations 2.1-2.3, indicate that the change in resistance of the CNT film is proportional to the base resistance of the CNT film. Therefore, theoretically a higher base resistance of the CNT assembly is desired for increased sensitivity in the anemometer.

There are three basic architectures operated as hot-wire and hot-film anemometers in literature. These are a constant current architecture, a constant voltage architecture, and a constant temperature architecture. In the constant current architecture, the anemometer is supplied a constant DC current and changes in temperature of the wire or film lead to changes in the resistance of the wire or film that correspond to changes in the voltage across the anemometer assembly. Similarly, in a constant voltage architecture, the anemometer is supplied a constant DC voltage and changes in the temperature of the wire or film lead to changes in the resistance of the wire or film that correspond to changes in the current through the anemometer assembly. In both of these cases, the resulting changes in voltage or current are measured directly. Constant temperature architectures are also discussed in the literature, which include feedback systems to ensure that the wire or film returns to a base temperature after a change in temperature is observed.

In this work, a CNT hot-film anemometer microphone is created and tested for functionality. Despite the rarity of hot-film microphones, several properties of CNT suggest the film may work well in this application. The CNT film exhibits a relatively consistent relationship between temperature and resistance of the film [24]. Additionally, CNT film has an ultralow thermal inertia and heat capacity suggesting that it can be used to create a hot-film microphone that operates over a higher frequency range than other anemometer microphones [24]. A constant voltage architecture was used in this work, 
where the CNT was supplied a constant voltage and the changes in temperature of the film ultimately result in changes in the current through the film. The CNT is expected to rapidly heat and cool in this application due to the constantly supplied voltage and convection from the incident acoustic wave, the resulting current signal is expected to have significant frequency content related to the frequency of the tone being played. While in other work the wire or film used does not return to the base resistance in use, here the CNT is expected to return to the base resistance between oscillations in operation due to the ultralow thermal inertia of the CNT.

\section{Methods \& Materials - CNT Hot-film Microphone}

The same CNT thin-film is used for the construction of a CNT hot-film microphone as is used for the construction of the CNT thermophones at Michigan Technological University. This CNT is purchased as multi-walled CNT forests that are grown through chemical vapor deposition at NanoWorld Laboratories at the University of Cincinnati. The CNT film is created by drawing CNT from the forests such that they stretch into a thin film of super-aligned CNT. To create the CNT hot-film microphone assembly CNT film is pulled across two copper rods. The two copper rods act as leads to place the film in a circuit as a resistor and the CNT film remains freely suspended between the two electrodes in operation.

Several CNT hot-film assemblies of various sizes and dimensions were created to test and determine if the size or dimensions of the assembly affect the sensitivity of the microphone. A single layer CNT hot-film assembly was created first for testing, however, 
this assembly quickly deteriorated before obtaining any results from the assembly operating as a microphone. Therefore, five layers of CNT film was used in all the following CNT hot-film anemometer assemblies in order to increase their stability and durability. Three five layer CNT hot-film assemblies were created. Dimensions of these assemblies were $5 \mathrm{~cm} \times 12 \mathrm{~cm}, 3 \mathrm{~cm} \mathrm{x} 4 \mathrm{~cm}$, and $1 \mathrm{~cm} \times 4 \mathrm{~cm}$. Figure 6.1 includes an images of these three assemblies. The electrical resistance of each of the CNT hot-film anemometer assemblies is determined directly while the assembly is heated. The CNT assembly is supplied a DC voltage that is measured using a digital multimeter and the DC current through the assembly is measured using a Fluke current probe, a National Instruments PXIe-4497 module, and the National Instruments Sound and Vibration Assistant software.

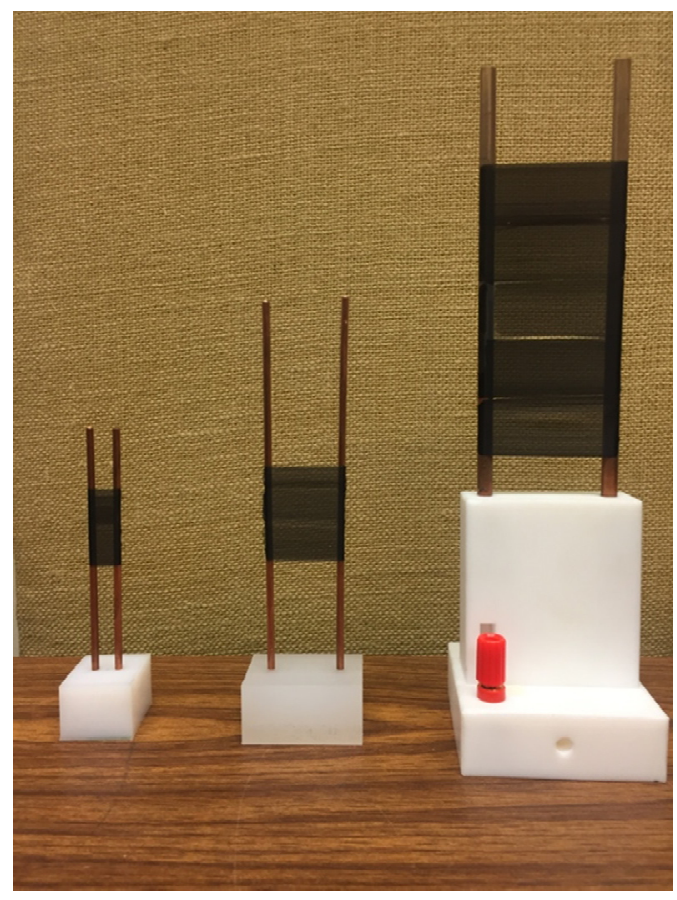


Figure 6.1: Five layer CNT hot-film assemblies used in testing the feasibility of a CNT film microphone. From left to right the CNT assemblies have dimensions of $1 \mathrm{~cm} \mathrm{x} 4 \mathrm{~cm}, 3 \mathrm{~cm} \mathrm{x} 4 \mathrm{~cm}$, and $5 \mathrm{~cm} \times 12 \mathrm{~cm}$. The assemblies are powered by supplying a constant DC voltage across the assembly with either alligator clips or banana plugs connected to the copper electrodes.

\subsection{Initial Experimentation}

Several experiments were performed to determine the feasibility of using CNT film as a microphone in a hot-film anemometer configuration. Initial experiments were performed in no specific environment in the sound laboratory room on the sixth floor of the R.L. Smith Building at Michigan Technological University. These initial experiments were performed with both a single layer CNT assembly and a $5 \mathrm{~cm}$ x $9 \mathrm{~cm}$, double-sided five layer CNT assembly. The CNT assemblies were supplied a constant DC voltage from a desktop voltage supply and the current through the CNT was measured with a Fluke current probe, a National Instruments single slot chassis and 9234 module, and the National Instruments Sound and Vibration Assistant software. Originally, the single layer of CNT film was considered preferable to multiple layers in order to minimize the heat capacity of the CNT and not complicate the convection over the assembly with several layers of film. The base resistance of this CNT assembly was approximately $640 \Omega$ when powered and the CNT was supplied a maximum power level of $0.7 \mathrm{~W}$. The $5 \mathrm{~cm} \times 9 \mathrm{~cm}$, double-sided five layer CNT assembly had a base resistance of $29 \Omega$ when powered and could be supplied more power than the single layer CNT assembly because of the lower resistance. The maximum power level supplied to the five layer CNT assembly was $11 \mathrm{~W}$ in this initial testing. The testing was performed using a single frequency tone of $1 \mathrm{kHz}$. This tone was played from 
a cell phone at full volume approximately 6 inches from the surface of the CNT film in the assembly.

Ultimately, through all initial testing of CNT hot-film assemblies in the sound laboratory room, no correlation was observed between the frequency content of the acquired current signals through the CNT assemblies and the pure frequency tone which was played. It is suspected that neither CNT assembly was able to be sufficiently heated due to limitations associated with the total resistance of the assemblies and the voltage supply used. Additionally, it is thought that the sound pressure level from the pure frequency tone was too low to be detected by the CNT hot-film as a microphone.

Further experimentation was moved into the anechoic chamber on the sixth floor of the R.L. Smith Building at Michigan Technological University and two compression driven speakers were used to play pure frequency tones in order to increase the sound pressure level at the surface of the CNT assemblies from the tones being played. The $5 \mathrm{~cm} \times 9 \mathrm{~cm}$, double-sided five layer CNT assembly was used. The speakers were located $1 \mathrm{~m}$ from the CNT assembly and a $1 \mathrm{kHz}$ tone was played at the speaker's maximum volume. A constant DC voltage was supplied using a function generator coded in LabVIEW, a National Instruments PXIe-6733 analog output module, and an amplifier. The use of the amplifier allowed the CNT to be supplied more power than it was supplied in previous experiments with a desktop voltage supply. Several tests were performed with the CNT assembly supplied various amounts of power, $31 \mathrm{~W}, 55 \mathrm{~W}$, and $86 \mathrm{~W}$. 


\subsection{Full Frequency Testing}

Additional testing was performed in the anechoic chamber to better quantify the response of the CNT hot-film microphone assembly across a larger range of frequency tones. Three single-sided five layer CNT assemblies ranging in dimensions and size were tested in this final experimentation. The CNT assemblies had dimensions of $5 \mathrm{~cm} \mathrm{x} 12 \mathrm{~cm}$, $3 \mathrm{~cm} \times 4 \mathrm{~cm}$, and $1 \mathrm{~cm} \times 4 \mathrm{~cm}$. A full frequency range QSC K12 loudspeaker was used to play pure frequency tones covering a frequency range of $40 \mathrm{~Hz}$ to $16 \mathrm{kHz}$. The speaker and the CNT hot-film microphone assemblies were located in the anechoic chamber for testing at a maximum possible distance of $2.4 \mathrm{~m}$ apart. Figure 6.2 contains images from inside the anechoic chamber while testing the $5 \mathrm{~cm} \times 12 \mathrm{~cm}$ CNT assembly. 

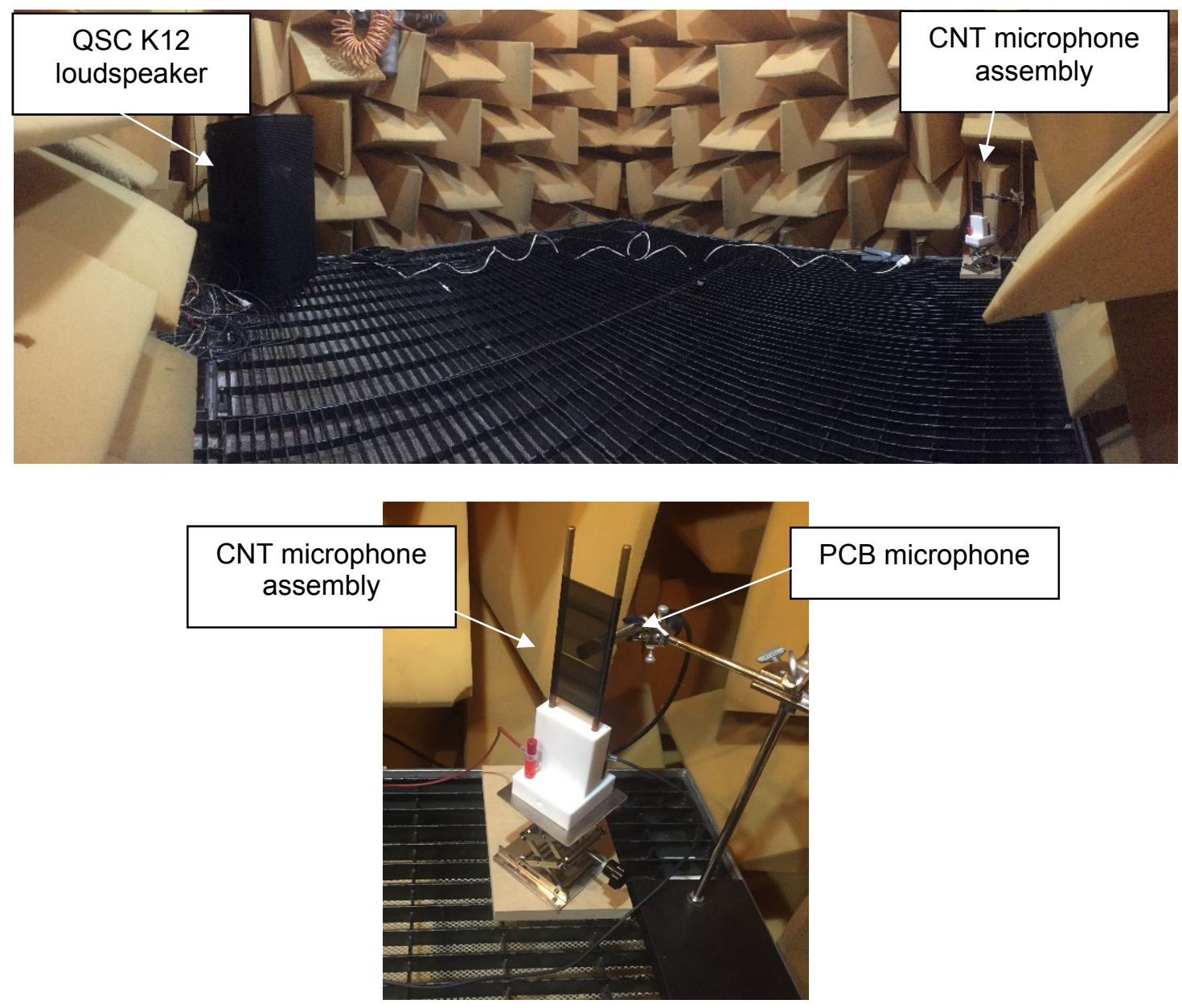

Figure 6.2: Test setup for CNT microphone inside anechoic chamber with QSC K12 loudspeaker located far left and CNT microphone assembly located far right.

A function generator coded in LabVIEW was used in conjunction with a National Instruments 9269 analog output module to provide single frequency tone signals to the speaker through an amplifier for maximum sound output. The same function generator software was used on another computer with a National Instruments PXIe-6733 analog output module and an amplifier to supply a constant voltage to the CNT assemblies. The amplifier allowed for an increased amount of power to be supplied to the CNT assemblies. 
A half-inch free field PCB 378B02 microphone was placed directly behind the CNT film at a distance of less than $1 \mathrm{~cm}$ to record baseline sound pressure levels at the surface of the CNT. The alternating current signal resulting from the change in resistance of the CNT film as the acoustic wave passes over it was recorded using a Fluke current probe. A National Instruments PXIe-4497 analog input was used for data acquisition of the measurement signals from the PCB microphone and the current probe. A schematic of the setup and data acquisition is included in Figure 6.3.

Testing is performed on each of the three CNT assemblies separately. Three tests were performed using the $5 \mathrm{~cm} \times 12 \mathrm{~cm}$ CNT assembly, one with no power supplied to the assembly, one with $30 \mathrm{~W}$ supplied to the assembly, and one with $80 \mathrm{~W}$ supplied to the assembly. Two tests were performed using the $3 \mathrm{~cm} \times 4 \mathrm{~cm}$ CNT assembly, one with no power supplied and one with $30 \mathrm{~W}$ supplied. The $1 \mathrm{~cm} \times 4 \mathrm{~cm}$ CNT assembly was used in two tests, one with no power supplied and one with 10W supplied. 


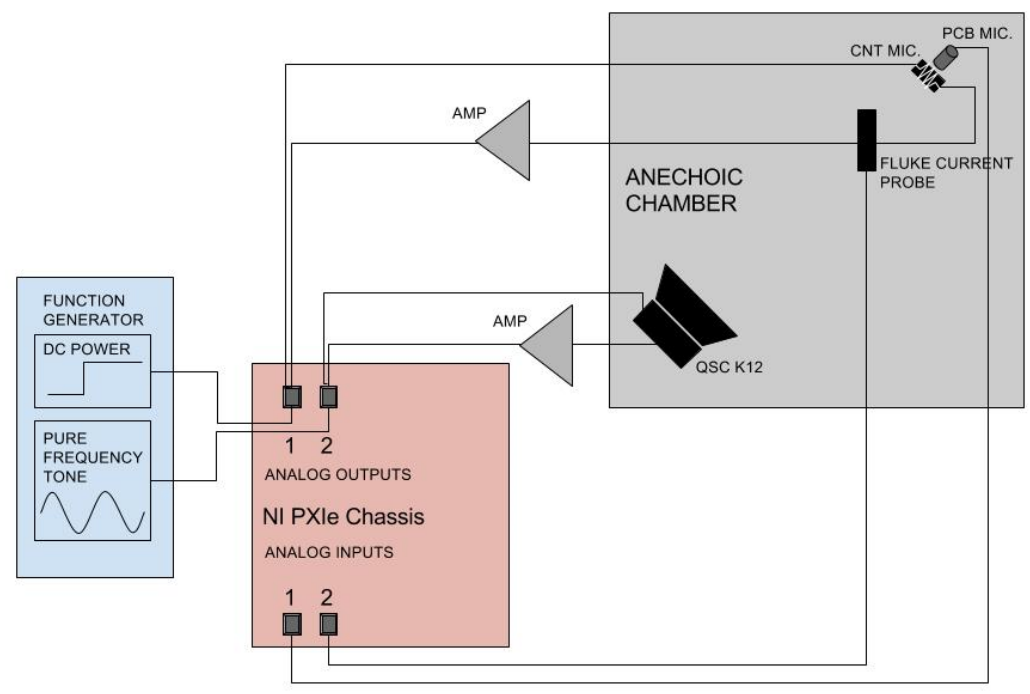

Figure 6.3: Schematic of experimental setup for testing CNT hot-film microphone assemblies in anechoic chamber. *Wire connections in the image are spaced for clarity, however, only one hole is available to run cables into and out of the anechoic chamber, therefore all cables run side by side through this one hole.

\section{Results \& Discussion - CNT Hot-film Microphone}

\subsection{Initial Experimentation Results}

Testing of a CNT hot-film microphone was performed in the anechoic chamber and two compression driven speakers with increased sound power outputs were utilized. The 5 $\mathrm{cm}$ x $12 \mathrm{~cm}$, double-sided five layer CNT assembly was used and supplied various amounts of power, $31 \mathrm{~W}, 55 \mathrm{~W}$, and $86 \mathrm{~W}$, which was more power than that supplied to the CNT assemblies in previous experiments. A $1 \mathrm{kHz}$ tone was played. The averaged autopower frequency spectra of the acquired current signals were examined and no significant frequency content was observed at $1 \mathrm{kHz}$, the tone played, or harmonics of the tone in the 
two lower power tests. However, when the CNT assembly was supplied the highest power, $86 \mathrm{~W}$, significant frequency content was observed at $1 \mathrm{kHz}$. The autopower frequency spectrum for this experiment is displayed in Figure 7.1. The presence of frequency content in the acquired current signal that was related to the tone being played suggests that the CNT hot-film assembly was operating as a microphone. This result was particularly encouraging because the frequency content was not present in previous tests and the only alteration to this test was an increase in the power supplied to the CNT assembly.

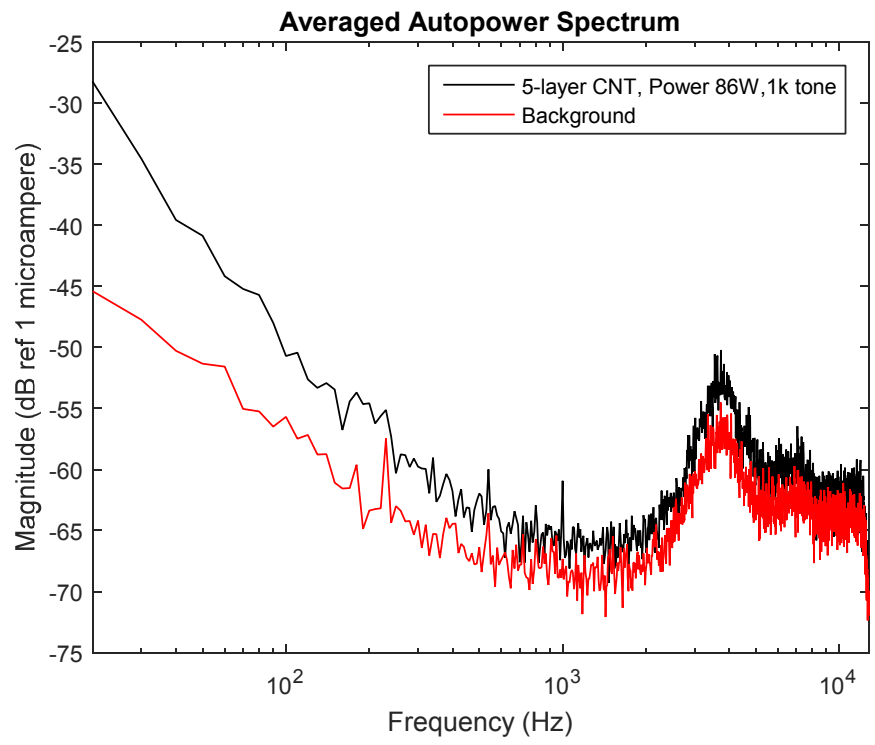

Figure 7.1: Autopower frequency spectrum of acquired current signal from initial experimentation in anechoic chamber using a five layer CNT hot-film assembly supplied $86 \mathrm{~W}$ and subjected to a 1 $\mathrm{kHz}$ tone. Significant frequency content is observed at the tone frequency.

\subsection{Full Frequency Testing Results}

After observing a measurable response from the CNT hot-film assembly as a microphone, testing was extended to investigate if the CNT hot-film microphone could be used over a wider frequency range and to investigate how several other factors such as 
dimensions and size of the CNT assembly and input power supplied may affect the performance of the CNT hot-film microphone. The testing setup remained similar to the previous experimentation with the exception that the two compression driven speakers were replaced with a full frequency range QSC K12 loudspeaker. Three CNT assemblies with dimensions of $5 \mathrm{~cm} \times 12 \mathrm{~cm}, 3 \mathrm{~cm} \mathrm{x} 4 \mathrm{~cm}$, and $1 \mathrm{~cm} \mathrm{x} 4 \mathrm{~cm}$ were used to experiment if the assemblies could detect pure frequency tones from $40 \mathrm{~Hz}$ to $16 \mathrm{kHz}$. Several tests were performed on each individual CNT assembly with various amounts of power supplied.

Overall, the results from testing showed that all three of the CNT assemblies responded to a majority of the pure frequency tones played. Some representative frequency spectrum plots are included in Figures 7.2 and 7.3. Figure 7.2 displays frequency spectra of acquired current signals through the CNT assemblies when an $800 \mathrm{~Hz}$ tone was played. There is a significant peak at $800 \mathrm{~Hz}$ in nearly all of the pictured frequency spectra, however amplitude of the peak does differ with different CNT assemblies used and different input power levels supplied. The amplitude of the peak appears greatest when the $1 \mathrm{~cm} \times 4 \mathrm{~cm}$ CNT assembly was used and least when the $5 \mathrm{~cm} \times 12 \mathrm{~cm}$ CNT assembly was used. Meanwhile, Figure 7.3 displays frequency spectra of acquired current signals through the CNT assemblies when an $8 \mathrm{kHz}$ tone was played. Once again, in these plots a significant peak at $8 \mathrm{kHz}$, the frequency of the tone played, is apparent in all of them. However, unlike the response to the lower frequency, $800 \mathrm{~Hz}$ tone, the amplitudes of the peaks at $8 \mathrm{kHz}$ in response to an $8 \mathrm{kHz}$ tone appear to be almost the same regardless of which CNT assembly was used and the input power level supplied. The testing was performed over a large frequency range, playing single frequency tones from $40 \mathrm{~Hz}$ to $16 \mathrm{kHz}$. The recorded 
current response from all three of the CNT assemblies supplied various power levels are tabulated and included in Appendix F.
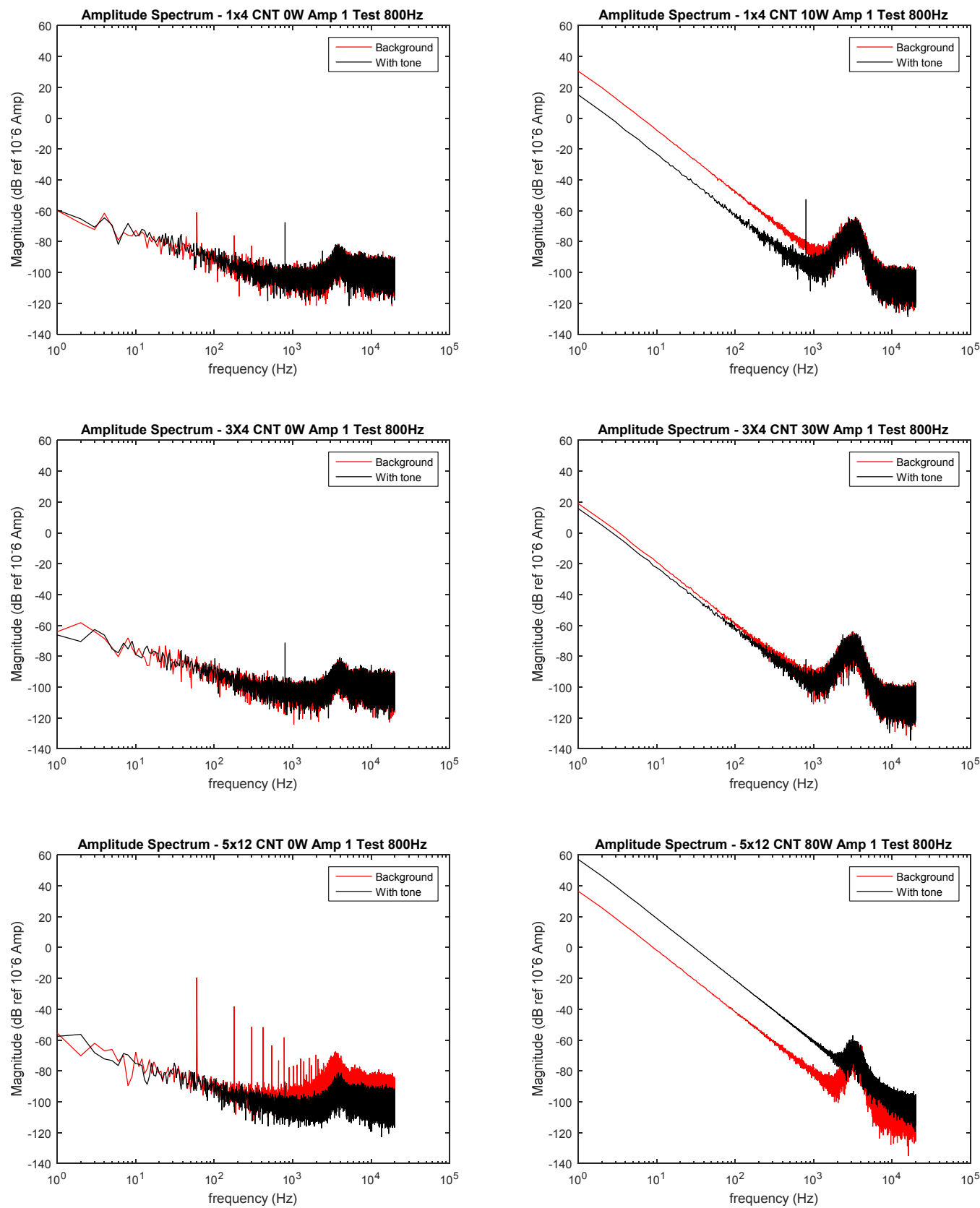

Figure 7.2: Frequency spectra from experimentations when an $800 \mathrm{~Hz}$ tone was played with all three CNT assemblies with various supplied power levels. 

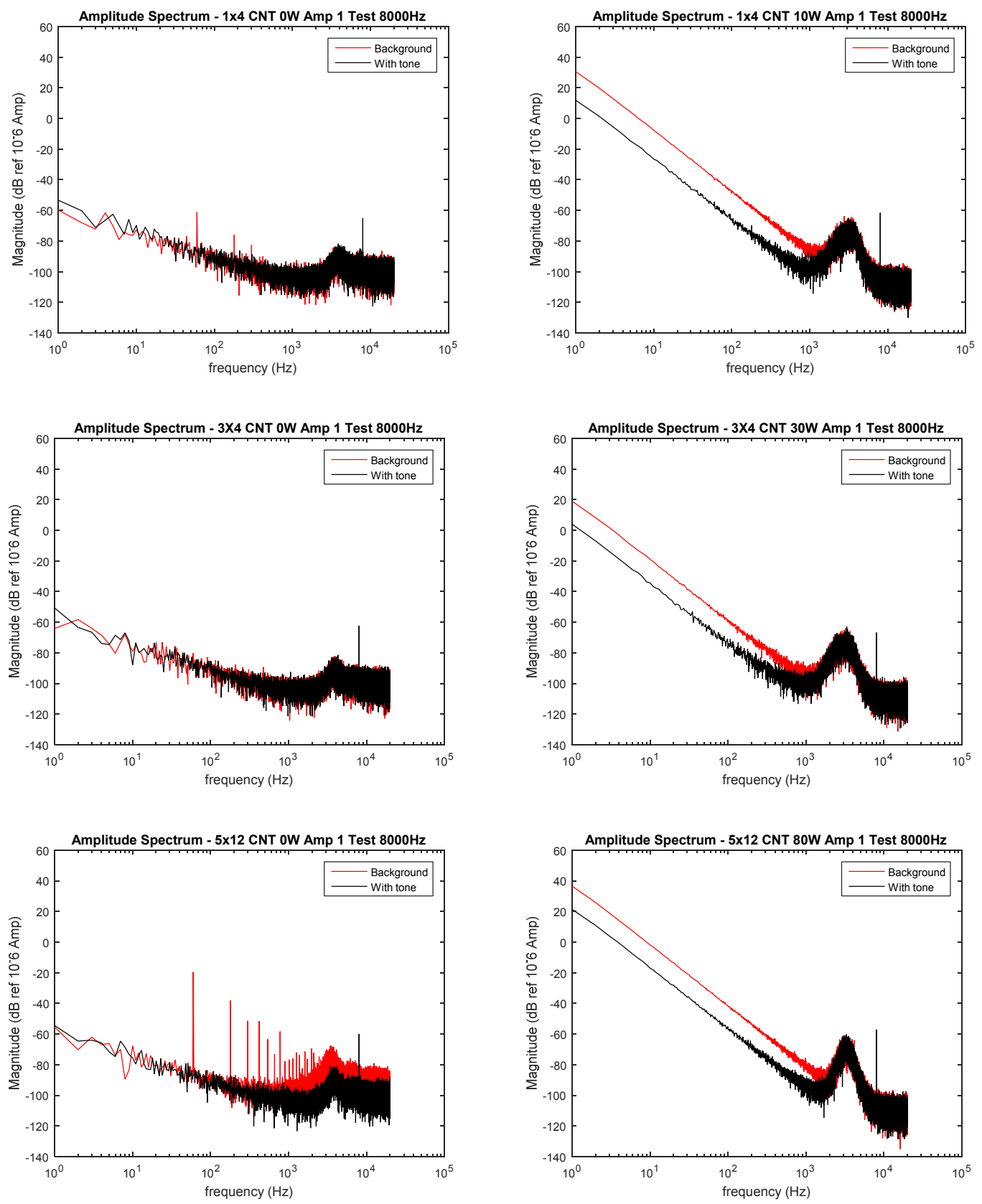

Figure 7.3: Frequency spectra from experimentations when an $8 \mathrm{kHz}$ tone was played with all three CNT assemblies with various supplied power levels. 
Again, the presence of frequency content in the acquired current signals that is related to the tone being played suggests that the CNT hot-film assembly is operating as a microphone. Therefore, the results indicate that CNT film may be used in a hot-film anemometer configuration as a microphone as predicted at the start of this work. The results also indicate that the CNT hot-film microphone can detect frequency tones much greater than frequency tones that have been detected and recorded with platinum or tungsten hotwire or hot-film microphones presented in other works, as a response is recorded in tests at even the highest frequencies tested up to $16 \mathrm{kHz}$.

Yet, certain aspects of the results raise questions about the response that is observed. The results seem to validate the feasibility of a CNT hot-film microphone that functions over a large frequency range because the frequency content observed in the acquired current response signals consistently corresponded to the frequency tone that was played in testing and without playing the frequency tone this frequency content was not present in the current signal. However, the results also show significant responses from the CNT assemblies at the frequency tone played when no power was supplied to them in testing. These results are unexpected when considering the theory of anemometry that states sensitivity increases when the base temperature of the wire or film is higher. These unexpected results suggest that the response exhibited by the CNT assemblies in some or all of these tests could be due to electrical interference between various cables within the experimental setup. 


\section{Conclusions \& Future Work - CNT Hot-film Microphone}

The feasibility of a CNT hot-film anemometer in a microphone application was researched and explored. Pure frequency tones were played and the change in the CNT film resistance due to changes in temperature caused by convection from the acoustic pressure wave was measured by measuring the current through the CNT film assembly while the film was supplied a constant DC voltage. After the results of several initial experiments displayed no measurable response from the CNT assembly, testing in the anechoic chamber was performed using speakers with higher sound power outputs. It was found that the acquired current response signal from the CNT hot-film microphone assembly consistently had frequency content at the same frequency of pure tones that were played through the loudspeaker.

Although a considerable amount of research has been and is currently being performed using CNT film in the acoustic thermophone application, hardly any research has been completed on using CNT film as a microphone to sense sounds or frequency tones. This work shows that it may be possible that CNT thin-film can be used in a hot-film anemometer configuration as a microphone to detect pure frequency tones. Future work for this research would include further validating that the frequency content that appears in the acquired current response signals from the CNT assemblies is a result of the CNT resistance changing due to changes in temperature caused by convection from the acoustic pressure waves and not simply a result of electrical interference. Additionally, further investigation could determine the sensitivity of the CNT hot-film microphone and the governing equations associated with the phenomenon. 


\section{References}

[1] T. Bouman, M. Asgarisabet \& A. Barnard. "Experimental quantification of the true efficiency of carbon nanotube thin-film thermophones." The Journal of the Acoustical Society of America. 139.3, 1353-1363 (2016). http://dx.doi.org/10.1121/1.4944688

[2] F. Braun. "Notiz über Thermophonie (Note on thermophonie)". Annalen Der Physik 65, 358-360 (1898). http://dx.doi.org/10.1002/andp.18983010609

[3] H. Arnold \& I. Crandall. "The thermophone as a precision source of sound," Physical Review. 10, $22-38$ (1917). http://dx.doi.org/10.1103/PhysRev.10.22

[4] L. Xiao, Z. Chen, C. Feng, L. Liu, Z. Bai, Y. Wang, L. Qian, Y. Zhang, Q. Li, K. Jiang \& S. Fan. "Flexible, stretchable, transparent carbon nanotube thin-film loudspeakers." Nano Letters. 8(12), 4539-4545 (2008). http://dx.doi.org/10.1021/n1802750z

[5] X. Yu, R. Rajamani, K. Stelson \& T. Cui. "Carbon nanotube-based transparent thin film acoustic actuators and sensors." Sensors and Actuators A: Physical. 132(2), 626-631 (2006) http://dx.doi.org/10.1016/j.sna.2006.02.045

[6] A. Barnard, T. Brungart, T. McDevitt, A. Aliev, D. Jenkins, B. Kline \& R. Baughman. "Advancements toward a high-power, carbon nanotube, thin-film loudspeaker." Noise Control Engineering Journal. 62(5), 360-367 (2014). http://dx.doi.org/10.3397/1/376235

[7] A. Aliev, Y. Gartstein \& R. Baughman. "Increasing the efficiency of thermoacoustic carbon nanotube sound projectors." Nanotechnology. 24(23), 235501 (2013). http://dx.doi.org/10.1088/0957-4484/24/23/235501

[8] M. Asgarisabet, A. Barnard, \& T. Bouman. "Near field acoustic holography measurements of carbon nanotube thin film speakers." The Journal of the Acoustical Society of America, 140(6), 4237-4245. (2016).

[9] ISO 3382. "Acoustics - Measurements of room acoustic parameters." International Organization for Standardization. (2012). Print.

[10] H. Constant, R. Wenmaekers, J. Hak, \& R. Luxemburg. "The Source Directivity of a Dodecahedron Sound Source determined by Stepwise Rotation." Proceedings of Forum Acusticum, Aalborg. (2011).

[11] Noise Excitation Equipment for Building Acoustics Measurements. Norsonic. (2017). http://www.norsonic.com/en/products/noise_sources/nor276_loudspeaker/ 
[12] T. Leishman, S. Rollins, \& H. Smith. "An experimental evaluation of regular polyhedron loudspeakers as omnidirectional sources of sound," The Journal of the Acoustical Society of America 120, 1411 (2006). http://dx.doi.org/10.1121/1.2221552

[13] H. Lord, W. Gatley, W. S., \& Evensen, H. A. Noise Control for Engineers. Malibar, FL: R.E. Krieger Pub. Co. (1987).

[14] A. Aliev, N. Mayo, R. Baughman, D. Avirovik, S. Priya, M. Zarnetske, \& J. Blottman. "Thermal management of thermoacoustic sound projectors using a free-standing carbon nanotube aerogel sheet as a heat source". Nanotechnology. 25(40), 405704. (2014).

[15] L. Xiao, P. Liu, L. Liu, Q. Li, Z. Feng, S. Fan, \& K. Jiang. "High frequency response of carbon nanotube thin film speaker in gases." Journal of Applied Physics, 110(8), 084311. (2011).

[16] A. Perry. Hot Wire Anemometry. Clarendon Press, Oxford. (1982).

[17] H. Dryden, \& A. Kuethe. "The measurement of fluctuations of air speed by the hotwire anemometer." NASA. (1930).

[18] G. Sarma. "Analysis of a constant voltage anemometer circuit." Instrumentation and Measurement Technology Conference, 1993. IMTC/93. Conference Record. IEEE. (1993).

[19] V. Martins, R. Freire, \& S. Catunda. "Sensitivity analysis and automatic adjustment of a controlled-temperature thermoresistive-based anemometer." Instrumentation and Measurement Technology Conference (I2MTC), 2012 IEEE International. IEEE. (2012).

[20] F. Mailly, A. Giani, R. Bonnot, P. Temple-Boyer, F. Pascal-Delannoy, A. Foucaran, $\&$ A. Boyer. "Anemometer with hot platinum thin film." Sensors and Actuators A: Physical, 94(1), 32-38. (2001).

[21] X. Jing, J. Lu, J. Miao, H. Hans, H. Rahman, S. Pan, \& L. Norford. "An aerodynamically efficient sphere anemometer with integrated hot-film sensors for 2-D environmental airflow monitoring." Solid-State Sensors, Actuators and Microsystems Conference (TRANSDUCERS), 2011 16th International (pp. 96-99). IEEE. (2011).

[22] G. Huelsz, \& F. Lopez-Alquicira. "Hot-wire anemometry in acoustic waves." Experiments in Fluids, 30(3), 283-285. (2001). 
[23] W. Tucker, \& E. Paris. "A Selective Hot-Wire Microphone." Philosophical Transactions of the Royal Society of London. Series A, Containing Papers of a Mathematical or Physical Character, 221, 389-430. (1921).

[24] A. Aliev, M. Lima, S. Fang, \& R. Baughman. "Underwater sound generation using carbon nanotube projectors." Nano Letters, 10(7), 2374-2380. (2010).

[25] M. Hsu, \& G. Lee. "Carbon nanotube-based hot-film and temperature sensor assembled by optically-induced dielectrophoresis". IET Nanobiotechnology, 8(1), 44-50. (2014).

[26] C. Fung, \& W. Li. "Ultra-low-power and high frequency-response carbon nanotube based MEMS thermal sensors." Intelligent Robots and Systems, 2003.(IROS 2003). Proceedings. 2003 IEEE/RSJ International Conference on (Vol. 3, pp. 2371-2376). IEEE. (2003).

[27] L. Xiao, Y. Zhang, Y. Wang, K. Liu, Z. Wang, T. Li, \& Y. Zhao. “A polarized infrared thermal detector made from super-aligned multiwalled carbon nanotube films." Nanotechnology, 22(2), 025502. (2010).

[28] X. Yang, Z. Zhou, F. Zheng, \& Y. Wu. "High sensitivity temperature sensor based on a long, suspended single-walled carbon nanotube array." IET Micro \& Nano Letters, 5(2), 157-161. (2010). 


\section{Appendix A - Spherical Base CAD Model/Detail Part Drawings}

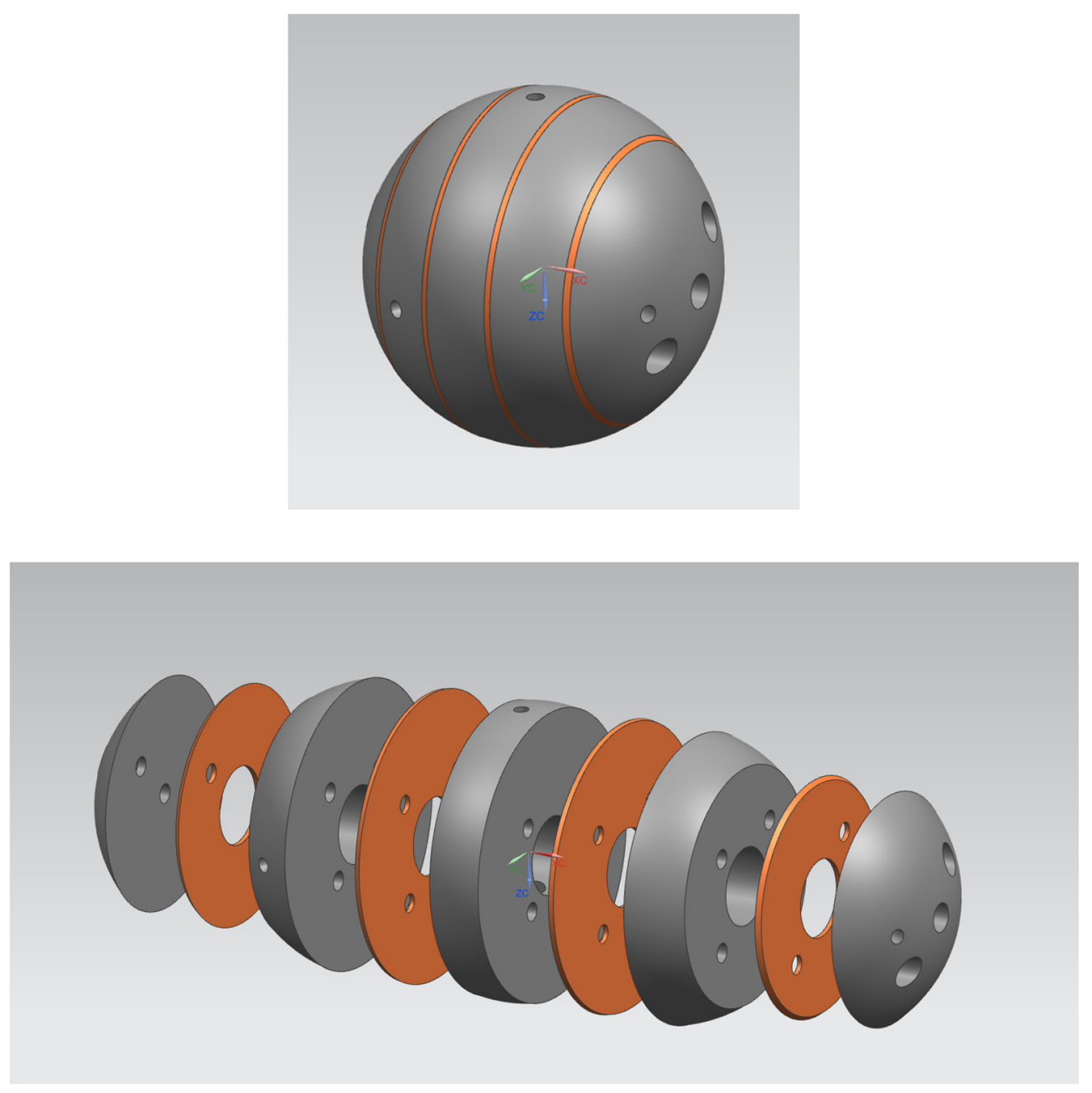

Figure A.1: CAD model of full sphere base assembly and exploded view. 

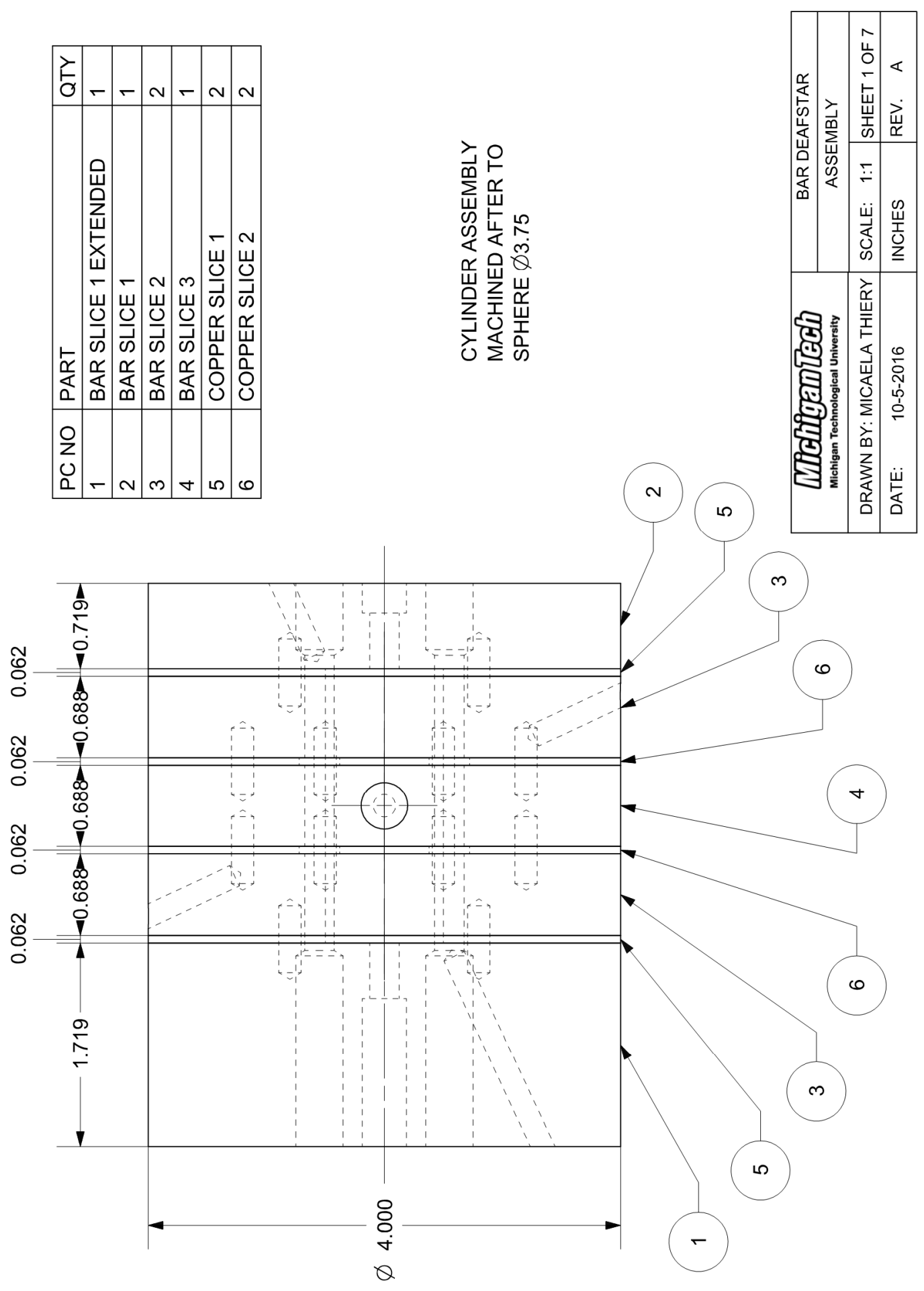

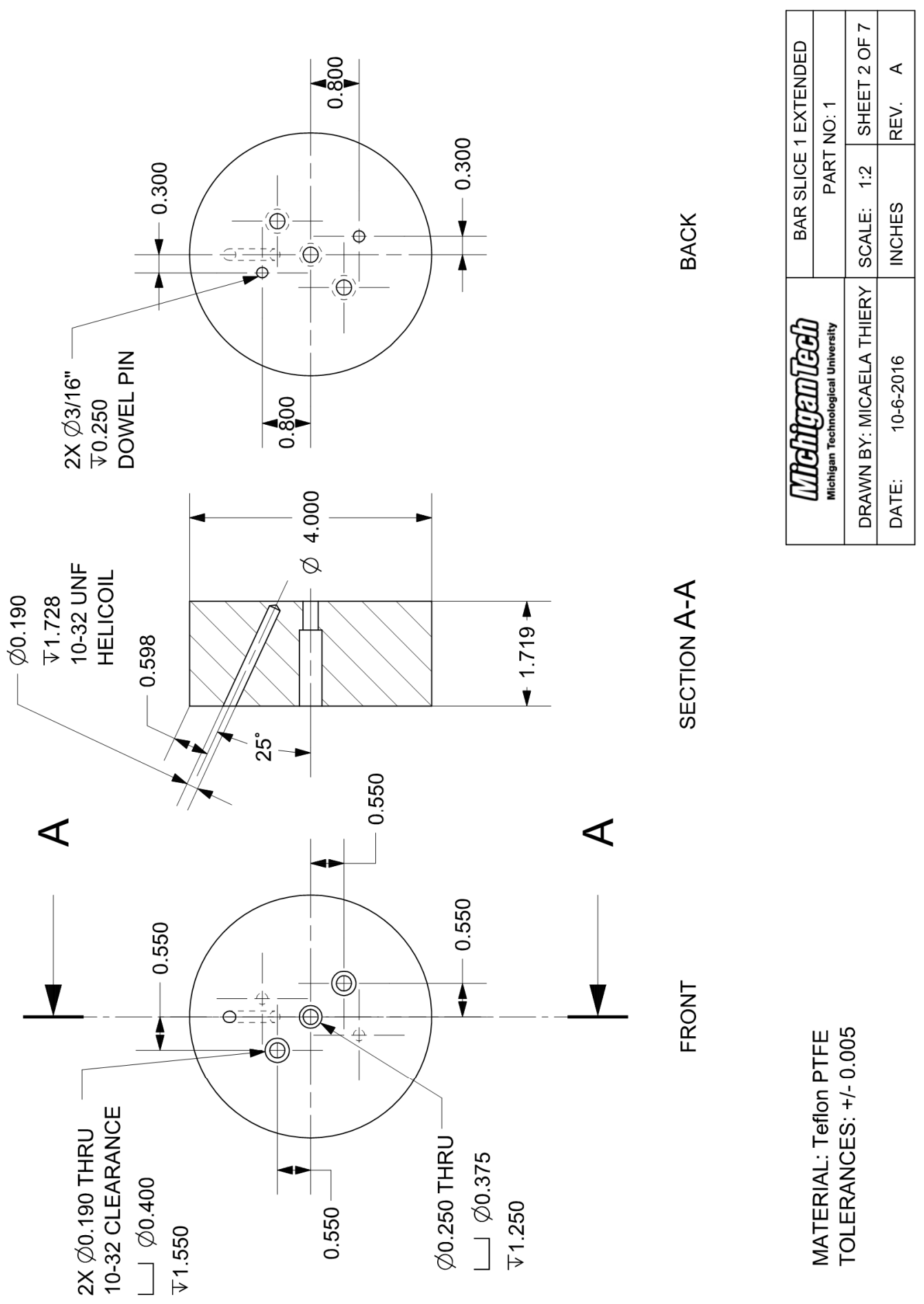

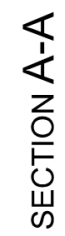

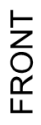

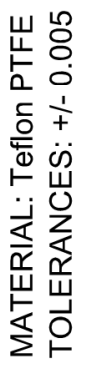



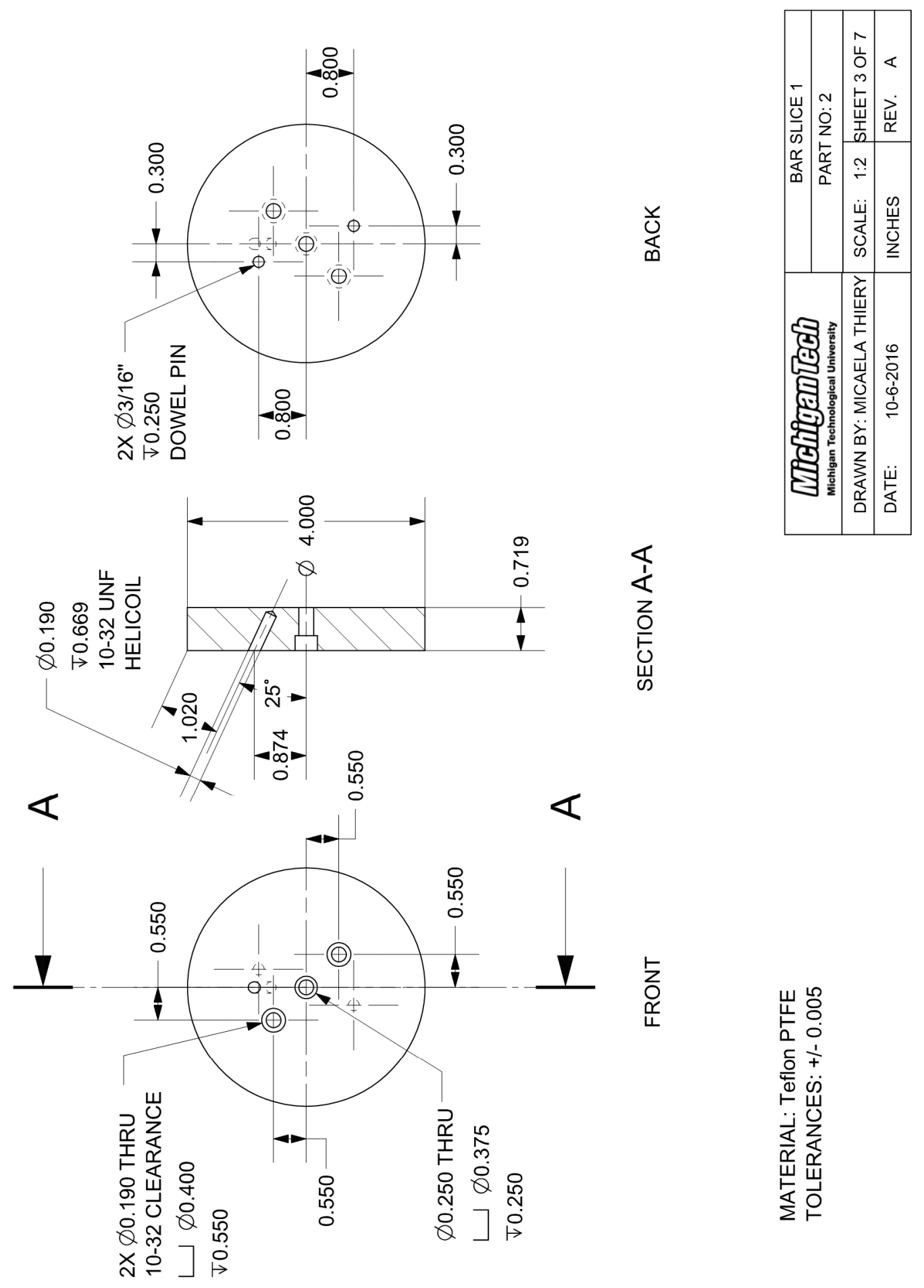

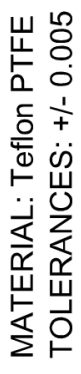



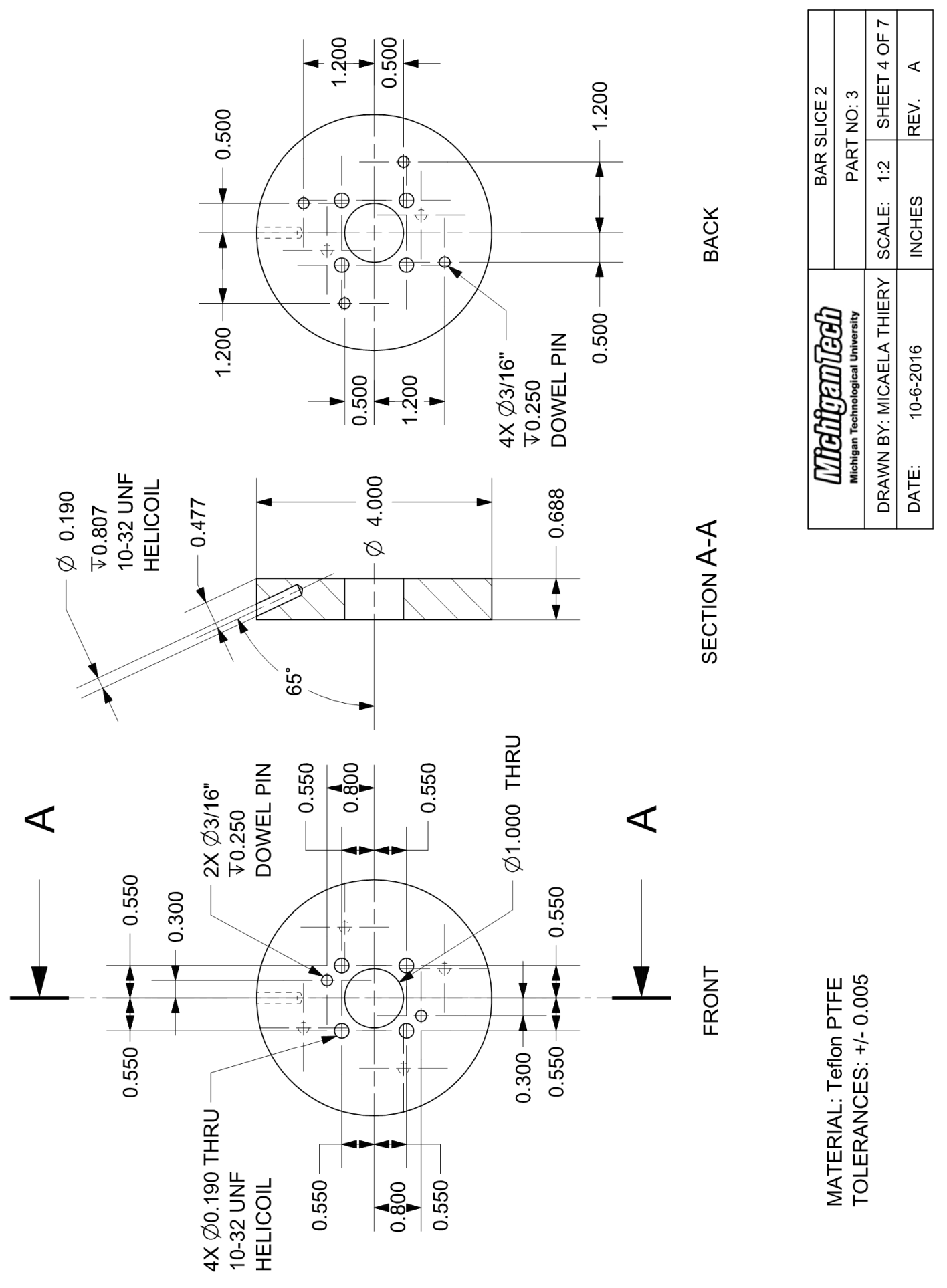

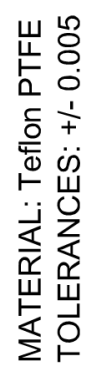




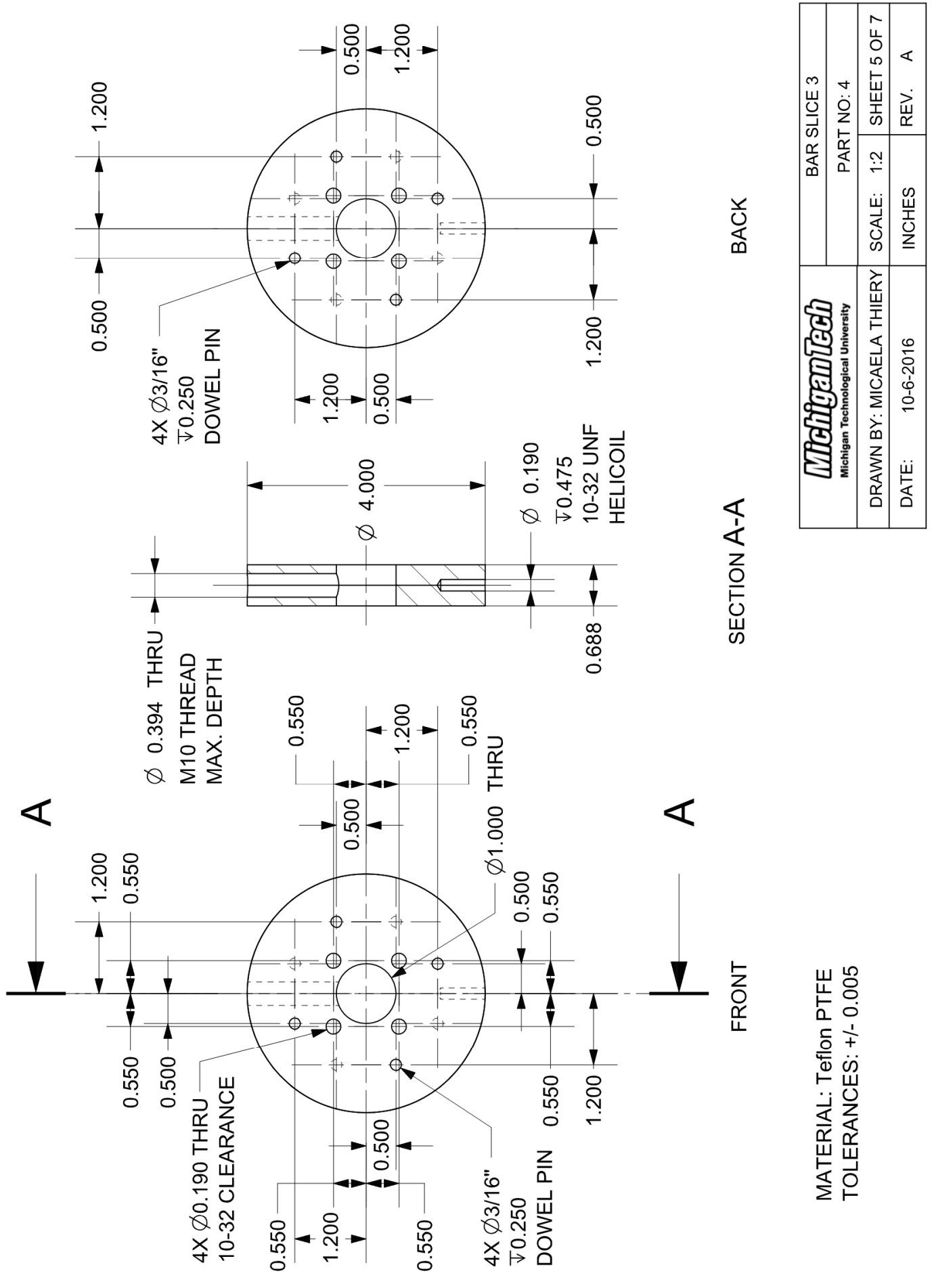




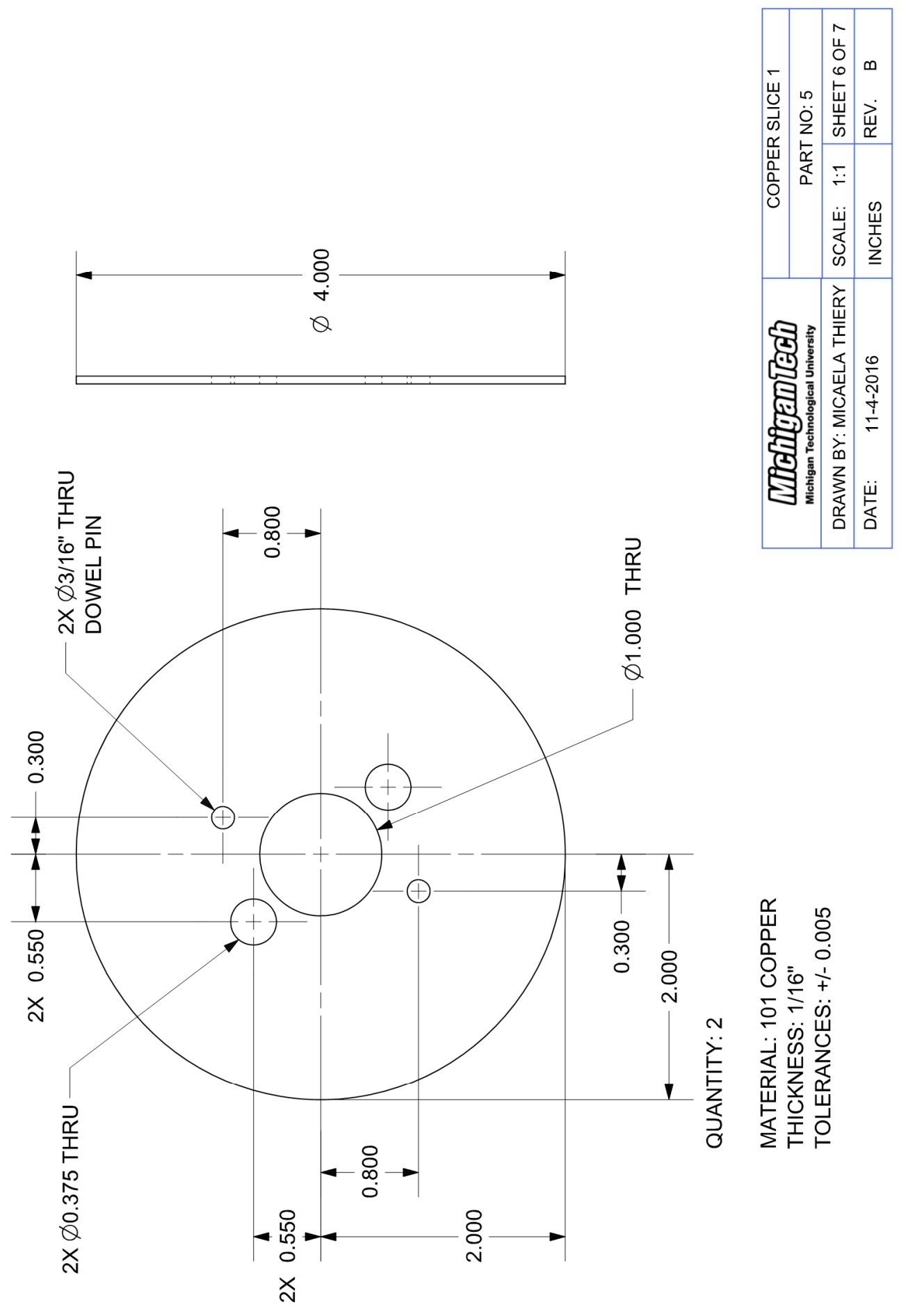




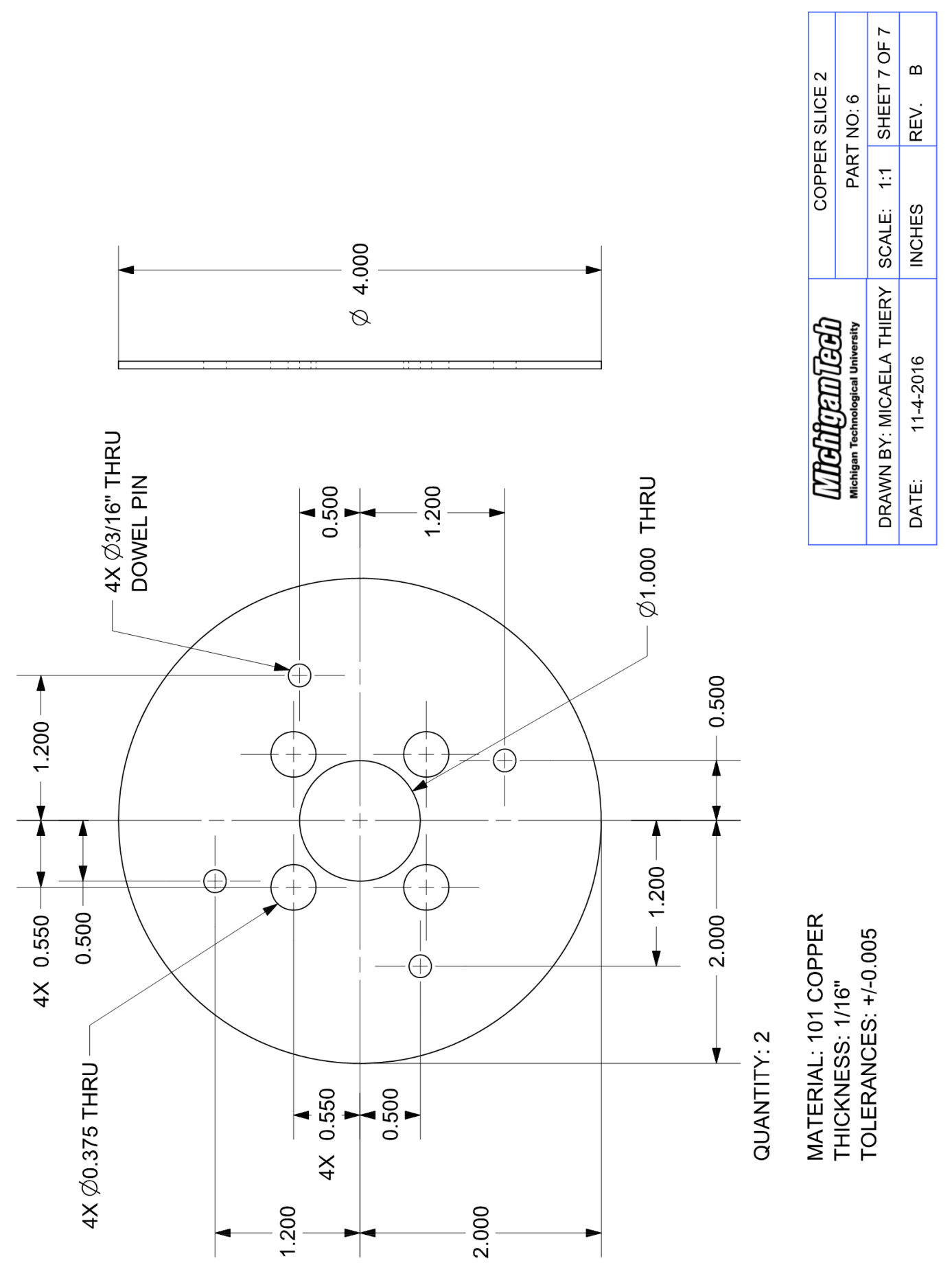



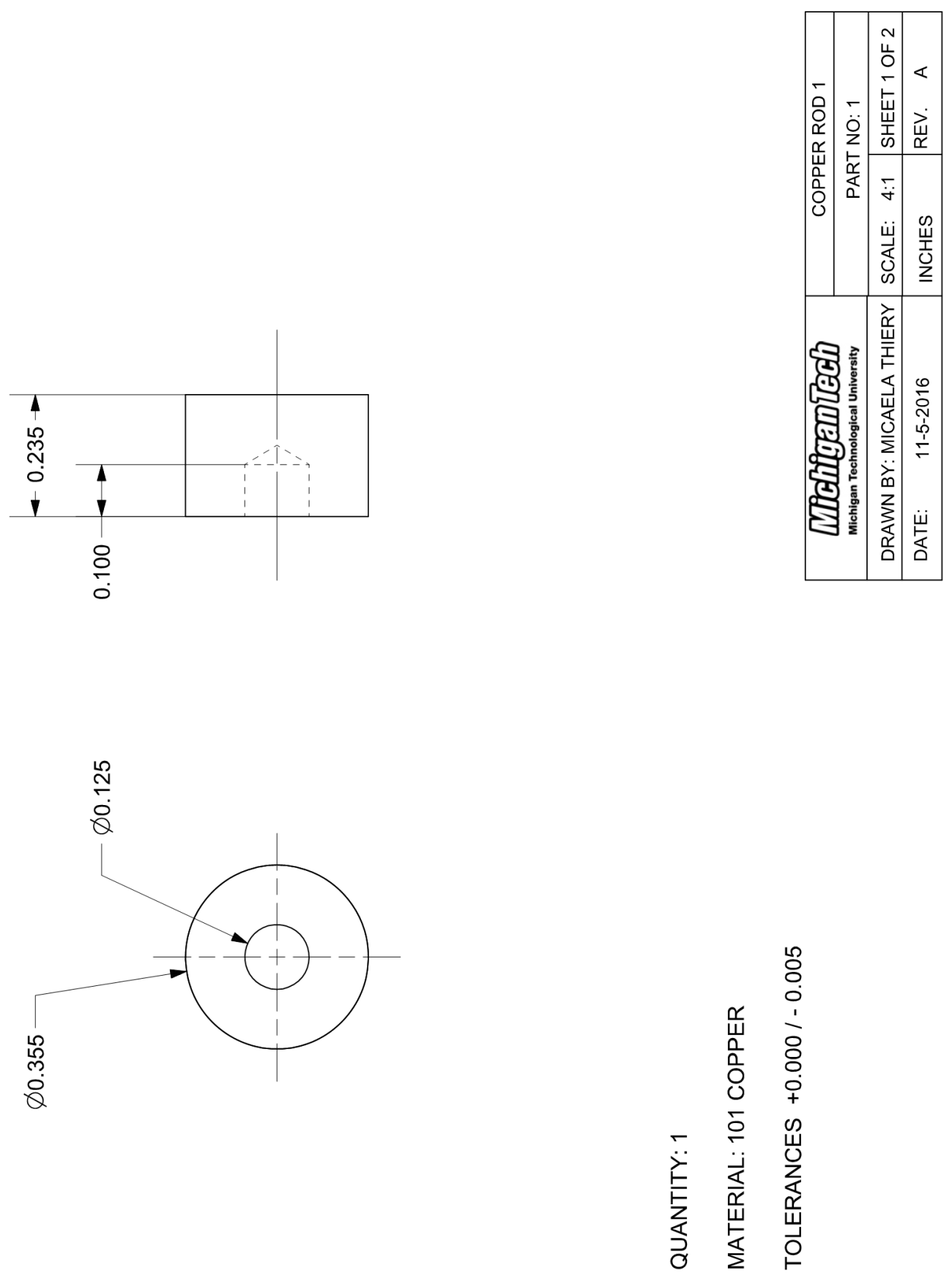

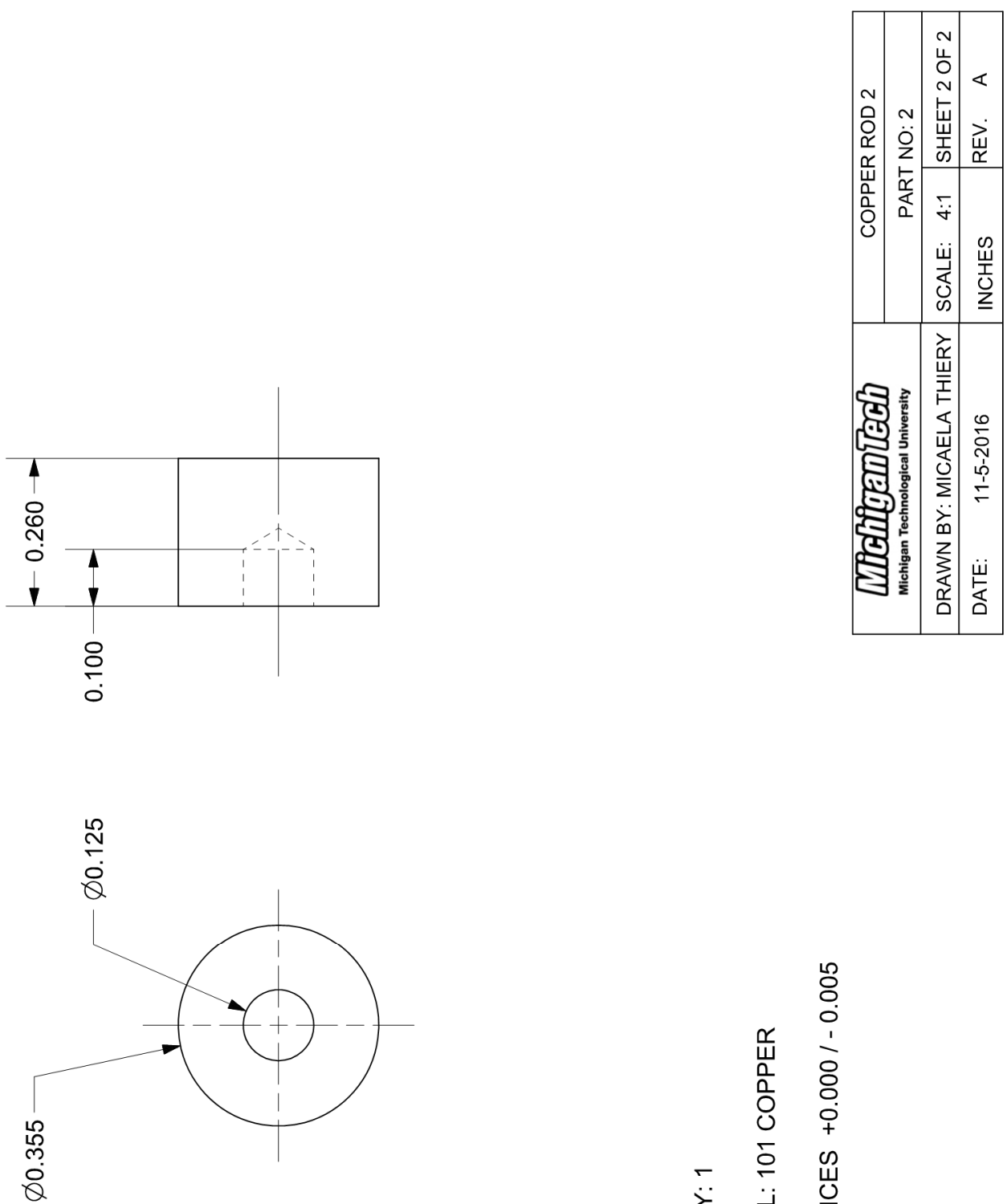

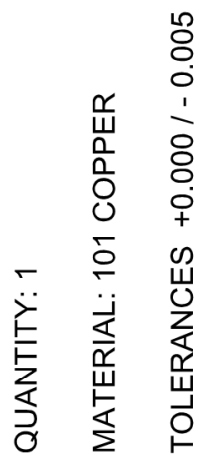




\section{Appendix B — Overall Resistance Estimates for Spherical CNT}

\section{Thermophone}

$S A_{\text {slice }}$, surface area of one Teflon ${ }^{\circledR}$ PTFE slice

$r$, radius of spherical base

$h$, width of Teflon ${ }^{\circledR}$ PTFE slice along horizontal axis

$$
S A_{\text {slice }}=2 \pi * r * h
$$

$n_{\text {squares }}$, number of squares of CNT film in a parallel configuration per Teflon ${ }^{\circledR}$ PTFE slice each with a resistance of $150 \Omega$ assuming 5-layers of CNT film used

$$
\begin{gathered}
n_{\text {squares }}=\frac{S A_{\text {slice }}}{h^{2}} \\
R_{T, \text { slice }} \text {, resistance of each Teflon } \AA \text { PTFE slice } \\
R_{T, \text { slice }}=\frac{150 \Omega}{n_{\text {squares }}} \\
R_{T, \text { sphere }}, \text { overall resistance of spherical CNT construction } \\
n_{\text {slices }}, \text { number of Teflon® PTFE slices } \\
R_{T, \text { sphere }}=\frac{R_{T, \text { slice }} \Omega}{n_{\text {slices }}}
\end{gathered}
$$

Each Teflon ${ }^{\circledR}$ PTFE slice is assumed to act as a resistor in all slices are wired such that they are in a parallel configuration with one another

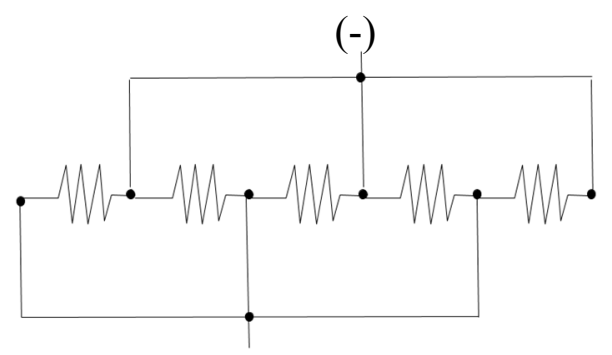

$(+)$ 
Appendix C - Images of CNT Wrapping
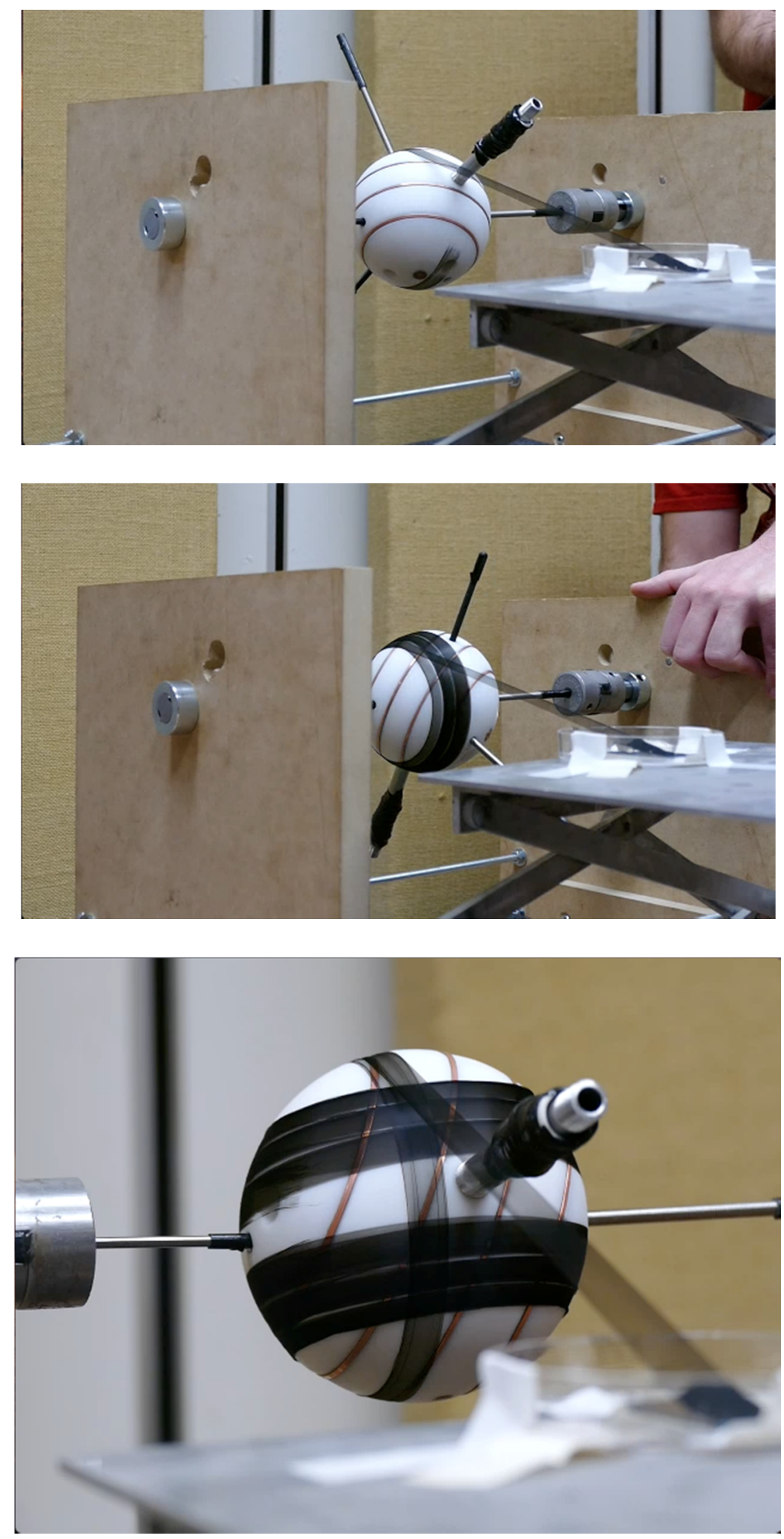

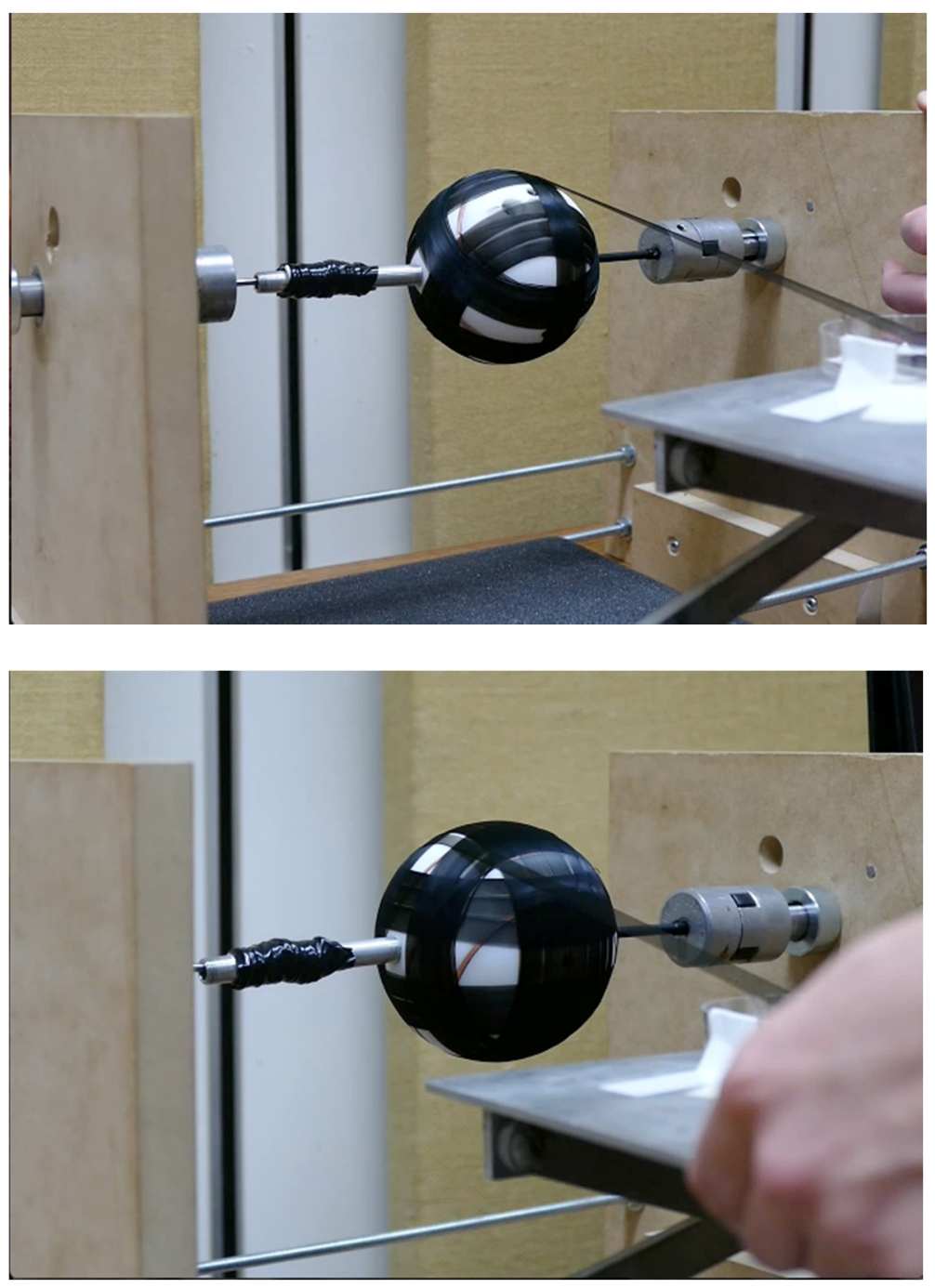


\section{Appendix D - Directivity Testing Setup}

Table D.1: Coordinates for microphone locations in directivity test.

\begin{tabular}{|c|c|c|c|}
\hline $\begin{array}{c}\text { Mic. } \\
\text { Location }\end{array}$ & Microphone Model & $\begin{array}{c}\text { X-direction coordinate } \\
(\mathrm{m})\end{array}$ & $\begin{array}{c}\text { y-direction coordinate } \\
(\mathrm{m})\end{array}$ \\
\hline 1 & PCB 130A23 & 0.000 & 1.200 \\
\hline 2 & PCB 130A23 & 0.208 & 1.178 \\
\hline 3 & PCB 130A23 & 0.423 & 1.106 \\
\hline 4 & PCB 130A23 & 0.616 & 0.988 \\
\hline 5 & PCB 378B20 & 0.777 & 0.829 \\
\hline 6 & PCB 378B02 & 0.899 & 0.638 \\
\hline 7 & PCB 378B20 & 0.974 & 0.425 \\
\hline 8 & PCB 378B02 & 1.000 & 0.200 \\
\hline
\end{tabular}



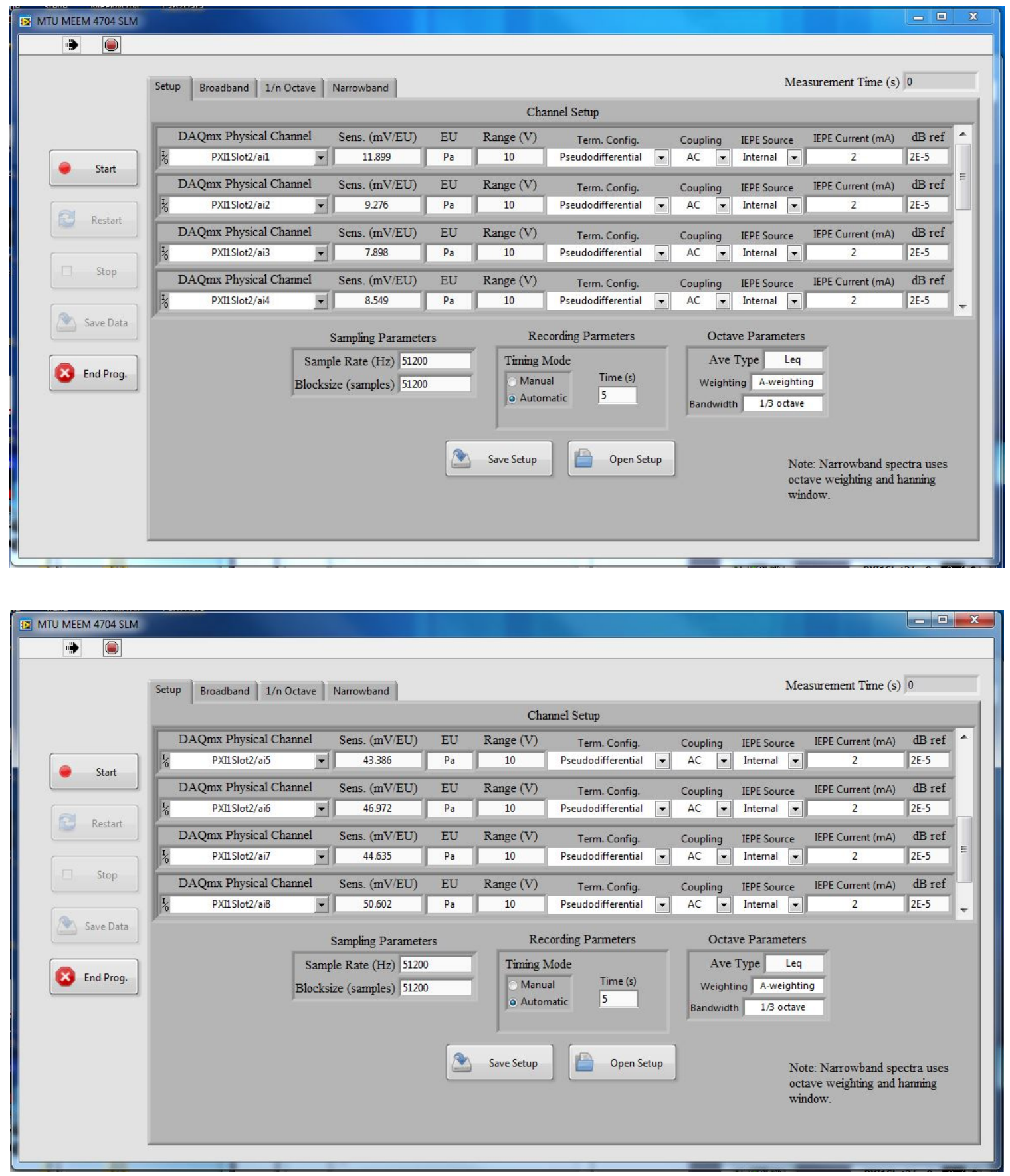

Figure D.1: Screenshot of data acquisition setup of directivity testing in LabVIEW coded SLM software. 
Appendix E - Spherical CNT Thermophone Directivity Results
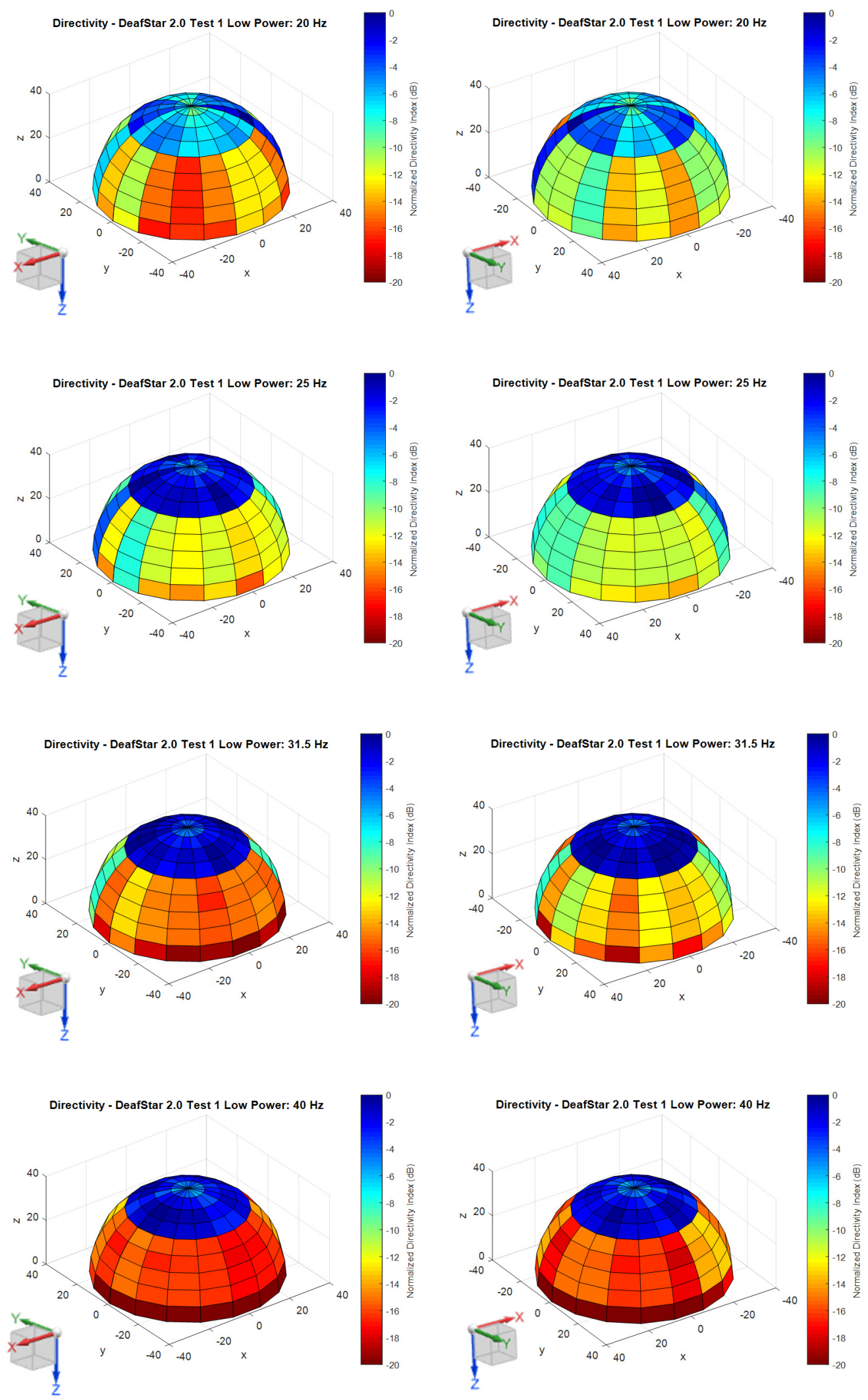


$$
\begin{array}{lll}
0 & 0 \\
0 & 0 \\
0 & 1 & 1 \\
0 & 1
\end{array}
$$



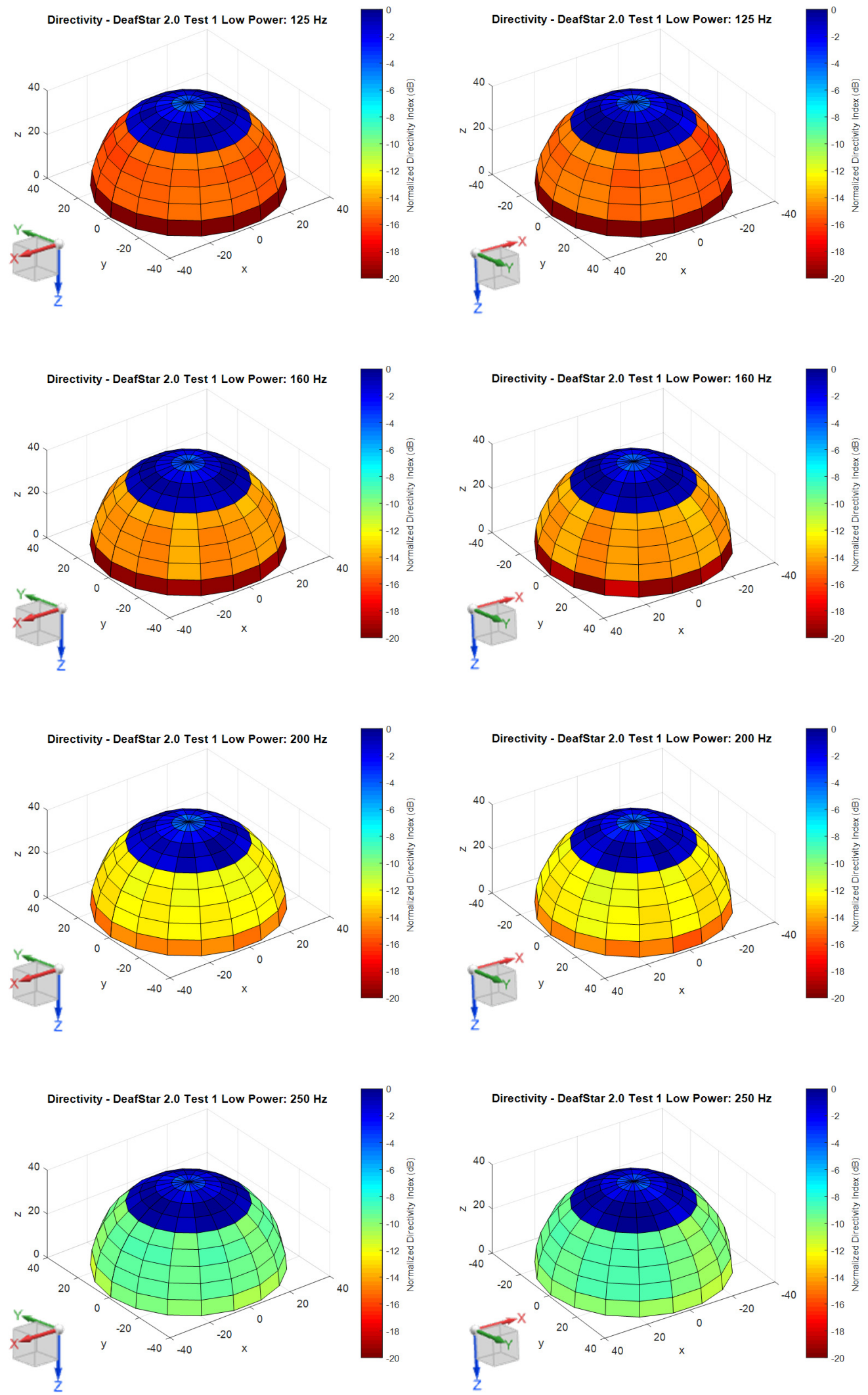

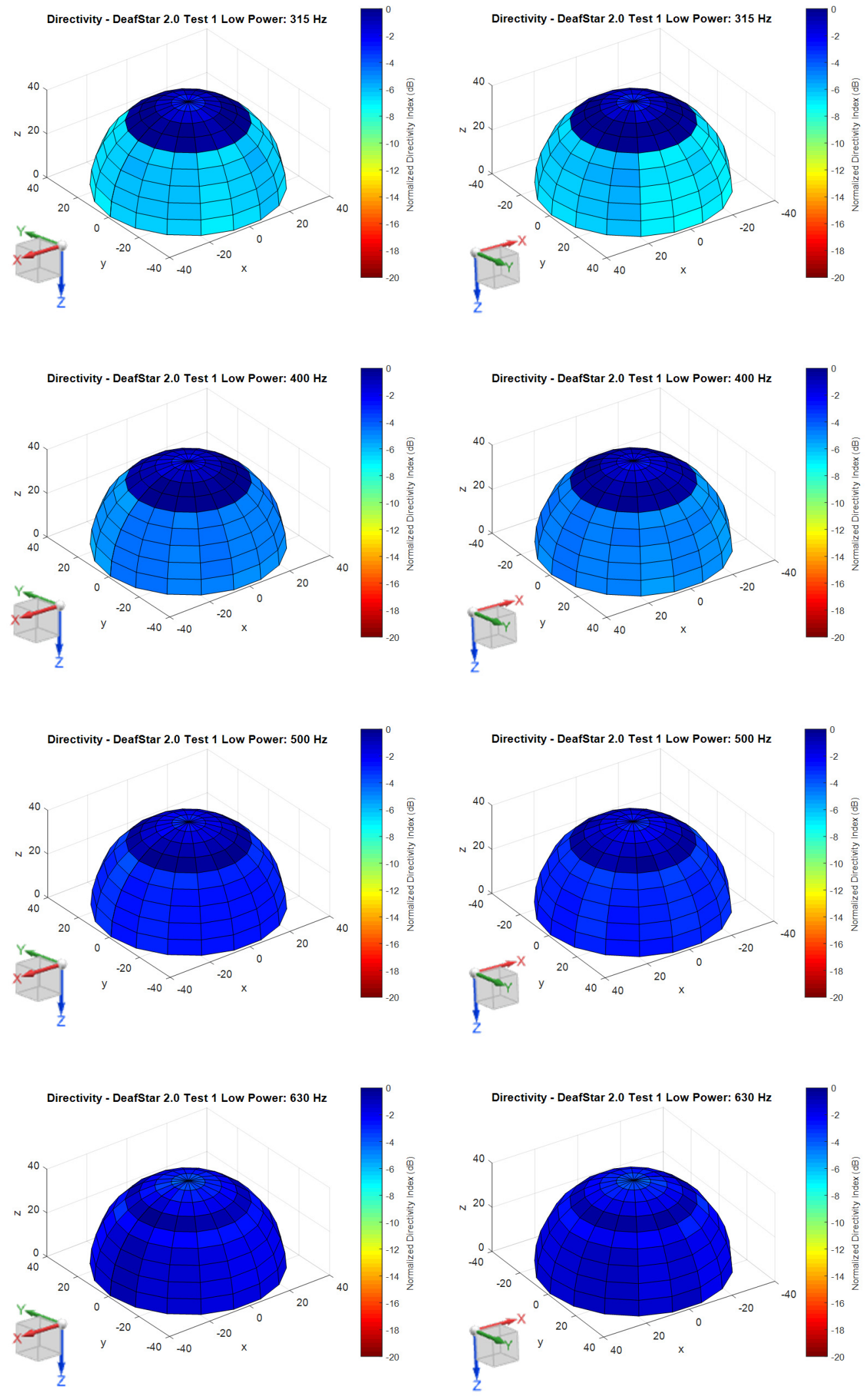

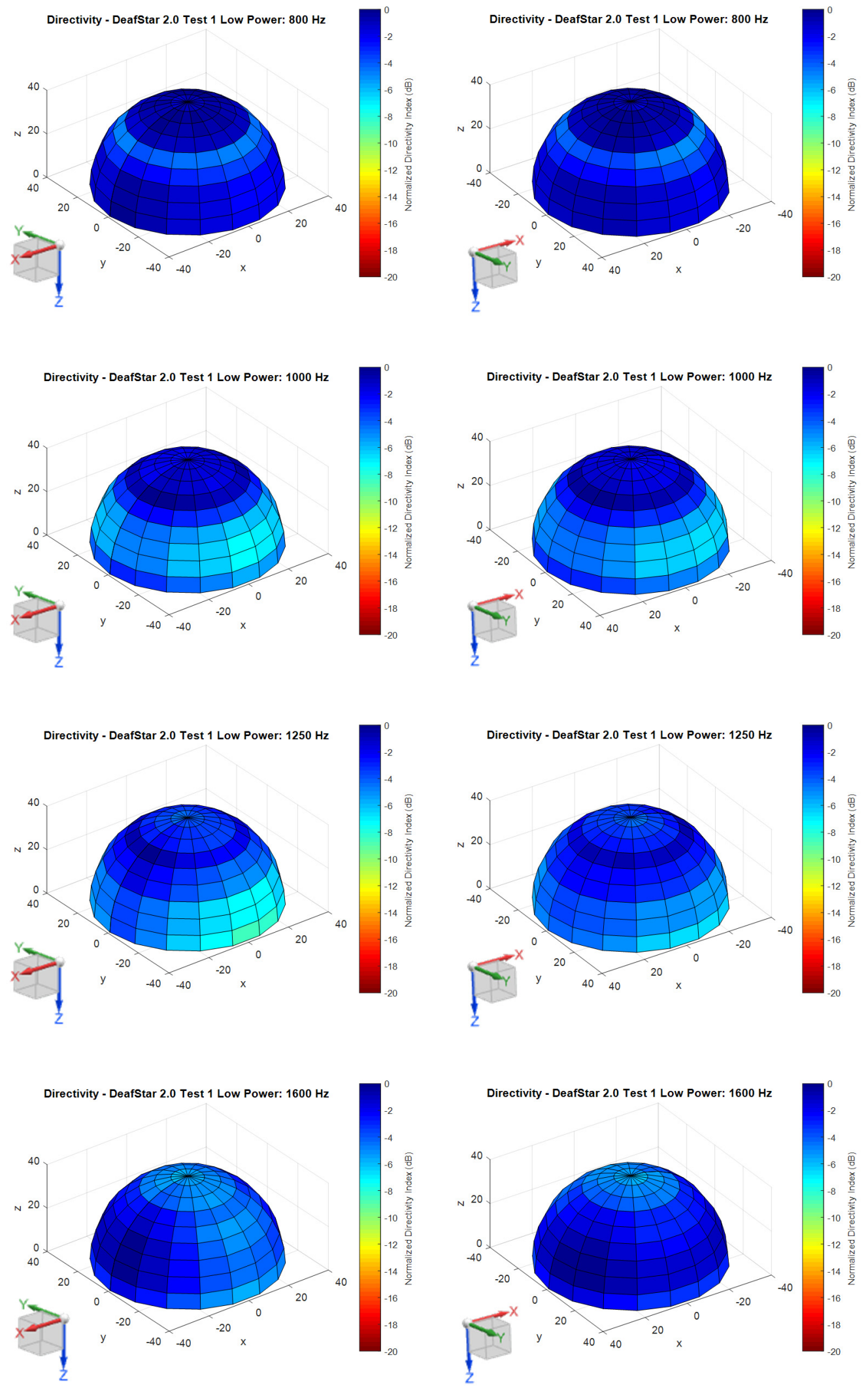

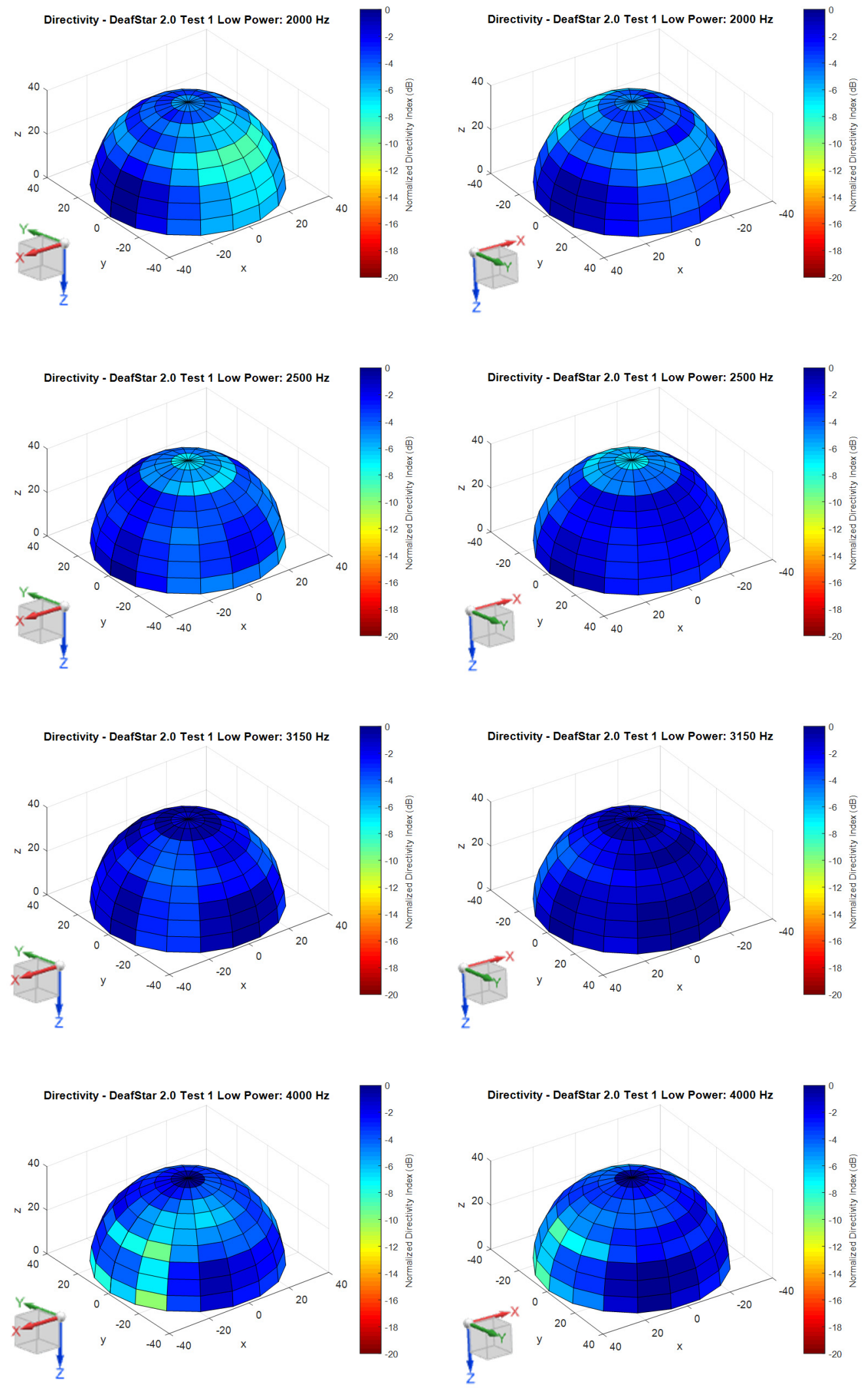

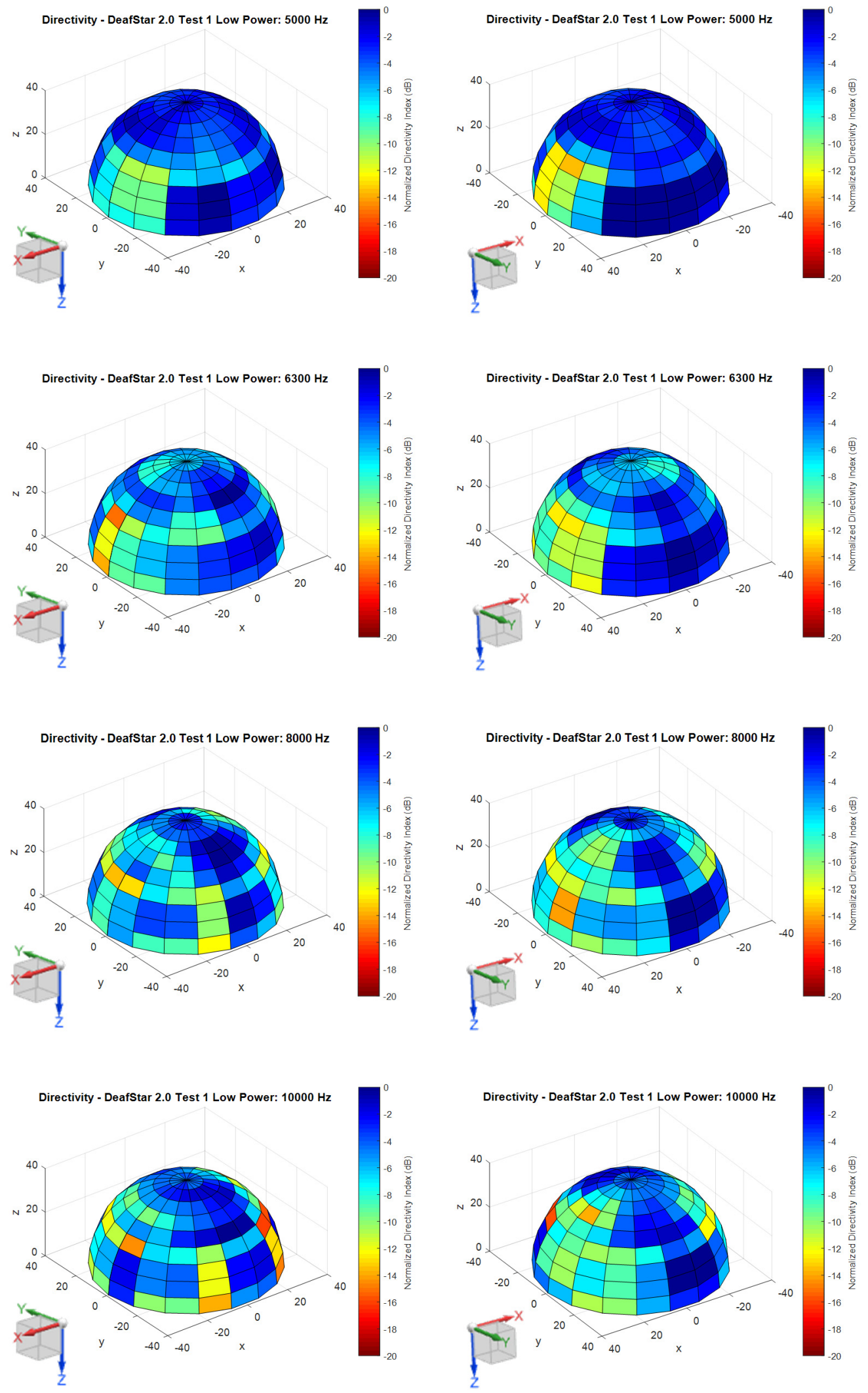
Table E.1: Directivity index values (dB) at all microphone locations, $1 / 3$ octave band center frequency: $20 \mathrm{~Hz}$, maximum SPL in $1 / 3$ octave frequency band: $52 \mathrm{~dB}$ ref $20 \mu \mathrm{Pa}$.

\begin{tabular}{|c|c|c|c|c|c|c|c|c|c|}
\hline $\begin{array}{c}\text { Mic. } \\
\text { Location }\end{array}$ & DI $0^{\circ}$ & DI $20^{\circ}$ & DI $40^{\circ}$ & DI $60^{\circ}$ & DI $80^{\circ}$ & $\begin{array}{c}\text { DI } \\
100^{\circ}\end{array}$ & $\begin{array}{c}\text { DI } \\
120^{\circ}\end{array}$ & $\begin{array}{c}\text { DI } \\
140^{\circ}\end{array}$ & $\begin{array}{c}\text { DI } \\
160^{\circ}\end{array}$ \\
\hline 1 & -6.99 & -7.96 & -9.87 & -9.40 & -8.99 & -7.66 & -9.30 & -2.59 & -6.76 \\
\hline 2 & -5.68 & -6.17 & -7.86 & -7.63 & -7.17 & -6.30 & -7.56 & -1.72 & -5.14 \\
\hline 3 & -4.84 & -4.92 & -6.37 & -7.04 & -6.77 & -5.41 & -6.66 & -1.86 & -4.79 \\
\hline 4 & -4.56 & -5.40 & -6.97 & -6.62 & -6.16 & -5.28 & -6.70 & 0.00 & -3.92 \\
\hline 5 & -10.91 & -14.89 & -16.69 & -14.58 & -12.45 & -12.56 & -14.79 & -2.94 & -10.56 \\
\hline 6 & -10.97 & -15.16 & -16.78 & -14.84 & -12.64 & -12.65 & -15.06 & -2.90 & -10.64 \\
\hline 7 & -10.81 & -15.10 & -16.75 & -14.81 & -12.61 & -12.56 & -14.87 & -2.69 & -10.39 \\
\hline 8 & -11.96 & -17.12 & -16.56 & -16.27 & -12.82 & -14.09 & -16.29 & -3.24 & -11.22 \\
\hline Mic. & DI & DI & DI & DI & DI & DI & DI & DI & DI \\
Location & $180^{\circ}$ & $200^{\circ}$ & $220^{\circ}$ & $240^{\circ}$ & $260^{\circ}$ & $280^{\circ}$ & $300^{\circ}$ & $320^{\circ}$ & $340^{\circ}$ \\
\hline 1 & -6.30 & -5.77 & -9.32 & -8.30 & -9.41 & -5.37 & -6.42 & -4.53 & -7.45 \\
\hline 2 & -4.96 & -4.39 & -7.99 & -6.89 & -7.51 & -3.97 & -4.92 & -3.59 & -7.29 \\
\hline 3 & -3.82 & -4.25 & -7.06 & -6.07 & -6.66 & -3.48 & -4.35 & -3.67 & -6.45 \\
\hline 4 & -3.98 & -3.25 & -6.89 & -5.81 & -6.80 & -2.99 & -3.92 & -2.44 & -6.49 \\
\hline 5 & -10.72 & -8.81 & -13.51 & -11.81 & -14.14 & -9.80 & -10.42 & -6.61 & -13.29 \\
\hline 6 & -10.73 & -8.79 & -13.70 & -11.93 & -14.28 & -10.03 & -10.58 & -6.58 & -13.51 \\
\hline 7 & -10.66 & -8.59 & -13.45 & -11.73 & -14.30 & -10.05 & -10.41 & -6.40 & -13.38 \\
\hline 8 & -11.43 & -9.68 & -14.23 & -12.62 & -14.44 & -11.50 & -11.36 & -7.15 & -14.32 \\
\hline
\end{tabular}

Table E.2: Directivity index values $(\mathrm{dB})$ at all microphone locations, $1 / 3$ octave band center frequency: $25 \mathrm{~Hz}$, maximum SPL in $1 / 3$ octave frequency band: $48 \mathrm{~dB}$ ref $20 \mu \mathrm{Pa}$.

\begin{tabular}{|c|c|c|c|c|c|c|c|c|c|}
\hline $\begin{array}{c}\text { Mic. } \\
\text { Location }\end{array}$ & DI $0^{\circ}$ & DI $20^{\circ}$ & DI $40^{\circ}$ & DI $60^{\circ}$ & DI $80^{\circ}$ & $\begin{array}{c}\text { DI } \\
100^{\circ}\end{array}$ & $\begin{array}{c}\text { DI } \\
120^{\circ}\end{array}$ & $\begin{array}{c}\text { DI } \\
140^{\circ}\end{array}$ & $\begin{array}{c}\text { DI } \\
160^{\circ}\end{array}$ \\
\hline 1 & -4.35 & -4.06 & -4.37 & -4.86 & -3.45 & -5.08 & -5.60 & -4.61 & -3.78 \\
\hline 2 & -2.59 & -2.32 & -2.25 & -3.13 & -1.39 & -3.08 & -3.95 & -2.81 & -2.51 \\
\hline 3 & -1.54 & -0.94 & -1.12 & -1.70 & 0.00 & -1.70 & -2.67 & -1.88 & -1.53 \\
\hline 4 & -1.35 & -1.24 & -1.34 & -2.08 & -0.50 & -2.34 & -2.93 & -1.84 & -1.51 \\
\hline 5 & -8.72 & -11.46 & -12.20 & -11.62 & -12.78 & -12.33 & -11.80 & -8.42 & -8.94 \\
\hline 6 & -8.32 & -11.58 & -12.48 & -11.65 & -13.12 & -12.27 & -11.73 & -8.17 & -9.09 \\
\hline 7 & -7.89 & -11.32 & -12.21 & -11.34 & -12.84 & -12.05 & -11.55 & -7.95 & -8.89 \\
\hline 8 & -8.36 & -13.96 & -14.64 & -13.09 & -15.71 & -12.39 & -12.17 & -8.03 & -10.12 \\
\hline Mic. & DI & DI & DI & DI & DI & DI & DI & DI & DI \\
Location & $180^{\circ}$ & $200^{\circ}$ & $220^{\circ}$ & $240^{\circ}$ & $260^{\circ}$ & $280^{\circ}$ & $300^{\circ}$ & $320^{\circ}$ & $340^{\circ}$ \\
\hline 1 & -4.95 & -4.11 & -5.55 & -3.66 & -3.26 & -5.69 & -4.88 & -1.68 & -4.57 \\
\hline 2 & -2.94 & -2.30 & -3.27 & -1.71 & -1.13 & -3.88 & -3.48 & -0.64 & -2.56 \\
\hline 3 & -2.06 & -0.91 & -2.36 & -0.34 & -0.02 & -2.23 & -2.55 & -0.16 & -1.12 \\
\hline 4 & -1.94 & -1.36 & -2.50 & -0.76 & -0.31 & -3.14 & -2.46 & 0.53 & -1.62 \\
\hline 5 & -9.22 & -10.99 & -11.72 & -11.31 & -11.20 & -11.95 & -8.93 & -4.36 & -12.60 \\
\hline 6 & -9.05 & -10.92 & -11.79 & -11.45 & -11.39 & -12.01 & -8.87 & -4.19 & -12.78 \\
\hline 7 & -8.84 & -10.65 & -11.54 & -11.18 & -11.15 & -11.81 & -8.62 & -4.01 & -12.31 \\
\hline 8 & -8.96 & -11.79 & -12.65 & -13.13 & -14.02 & -11.42 & -9.01 & -4.28 & -14.52 \\
\hline
\end{tabular}


Table E.3: Directivity index values (dB) at all microphone locations, $1 / 3$ octave band center frequency: $31.5 \mathrm{~Hz}$, maximum SPL in $1 / 3$ octave frequency band: $48 \mathrm{~dB}$ ref $20 \mu \mathrm{Pa}$.

\begin{tabular}{|c|c|c|c|c|c|c|c|c|c|}
\hline $\begin{array}{c}\text { Mic. } \\
\text { Location }\end{array}$ & DI $0^{\circ}$ & DI $20^{\circ}$ & DI $40^{\circ}$ & DI $60^{\circ}$ & DI $80^{\circ}$ & $\begin{array}{c}\text { DI } \\
100^{\circ}\end{array}$ & $\begin{array}{c}\text { DI } \\
120^{\circ}\end{array}$ & $\begin{array}{c}\text { DI } \\
140^{\circ}\end{array}$ & $\begin{array}{c}\text { DI } \\
160^{\circ}\end{array}$ \\
\hline 1 & -4.09 & -4.95 & -4.39 & -4.90 & -3.45 & -4.41 & -4.75 & -3.41 & -3.47 \\
\hline 2 & -2.19 & -3.04 & -2.36 & -2.85 & -1.38 & -2.21 & -2.73 & -1.78 & -1.45 \\
\hline 3 & -0.74 & -1.63 & -1.06 & -1.49 & 0.00 & -0.76 & -1.43 & -0.95 & 0.00 \\
\hline 4 & -1.20 & -2.24 & -1.48 & -1.89 & -0.56 & -1.33 & -1.97 & -1.17 & -0.67 \\
\hline 5 & -12.74 & -14.46 & -14.83 & -16.05 & -14.76 & -14.82 & -15.16 & -8.96 & -14.17 \\
\hline 6 & -12.96 & -14.71 & -15.27 & -16.61 & -15.22 & -15.10 & -15.54 & -8.61 & -14.52 \\
\hline 7 & -12.92 & -14.57 & -15.25 & -15.68 & -15.06 & -14.59 & -15.61 & -8.29 & -14.27 \\
\hline 8 & -14.98 & -18.33 & -19.62 & -19.09 & -21.31 & -18.74 & -20.40 & -7.94 & -18.93 \\
\hline Mic. & DI & DI & DI & DI & DI & DI & DI & DI & DI \\
Location & $180^{\circ}$ & $200^{\circ}$ & $220^{\circ}$ & $240^{\circ}$ & $260^{\circ}$ & $280^{\circ}$ & $300^{\circ}$ & $320^{\circ}$ & $340^{\circ}$ \\
\hline 1 & -3.06 & -4.13 & -3.99 & -4.52 & -3.02 & -3.29 & -3.12 & -2.54 & -4.37 \\
\hline 2 & -1.29 & -2.29 & -1.83 & -2.45 & -1.01 & -1.25 & -1.33 & -0.71 & -2.59 \\
\hline 3 & -0.24 & -1.13 & -0.36 & -1.28 & 0.42 & 0.07 & -0.34 & 0.47 & -0.99 \\
\hline 4 & -0.35 & -1.48 & -0.84 & -1.59 & -0.11 & -0.50 & -0.80 & 0.37 & -1.78 \\
\hline 5 & -10.81 & -12.72 & -14.93 & -12.25 & -13.36 & -12.80 & -10.86 & -8.97 & -15.17 \\
\hline 6 & -10.93 & -12.66 & -15.34 & -12.31 & -13.74 & -13.05 & -10.97 & -8.69 & -15.45 \\
\hline 7 & -10.78 & -12.88 & -14.79 & -12.20 & -13.52 & -12.75 & -10.89 & -8.41 & -15.27 \\
\hline 8 & -12.91 & -15.40 & -18.91 & -14.18 & -17.45 & -14.67 & -12.02 & -10.00 & -17.91 \\
\hline
\end{tabular}

Table E.4: Directivity index values $(\mathrm{dB})$ at all microphone locations, $1 / 3$ octave band center frequency: $40 \mathrm{~Hz}$, maximum SPL in $1 / 3$ octave frequency band: $48 \mathrm{~dB}$ ref $20 \mu \mathrm{Pa}$.

\begin{tabular}{|c|c|c|c|c|c|c|c|c|c|}
\hline $\begin{array}{c}\text { Mic. } \\
\text { Location }\end{array}$ & DI $0^{\circ}$ & DI $20^{\circ}$ & DI $40^{\circ}$ & DI $60^{\circ}$ & DI $80^{\circ}$ & $\begin{array}{c}\text { DI } \\
100^{\circ}\end{array}$ & $\begin{array}{c}\text { DI } \\
120^{\circ}\end{array}$ & $\begin{array}{c}\text { DI } \\
140^{\circ}\end{array}$ & $\begin{array}{c}\text { DI } \\
160^{\circ}\end{array}$ \\
\hline 1 & -3.43 & -3.94 & -4.33 & -4.42 & -5.79 & -5.77 & -4.51 & -4.65 & -5.41 \\
\hline 2 & -1.37 & -1.84 & -2.15 & -2.29 & -3.66 & -3.76 & -2.33 & -2.61 & -3.31 \\
\hline 3 & 0 & -0.47 & -0.78 & -0.90 & -2.19 & -2.35 & -0.98 & -1.37 & -1.92 \\
\hline 4 & -0.57 & -1.02 & -1.31 & -1.48 & -2.91 & -2.84 & -1.55 & -1.90 & -2.49 \\
\hline 5 & -14.87 & -15.77 & -15.94 & -16.35 & -17.35 & -17.06 & -16.13 & -14.15 & -17.13 \\
\hline 6 & -15.33 & -16.62 & -16.50 & -16.48 & -17.79 & -17.36 & -16.48 & -14.54 & -17.82 \\
\hline 7 & -15.12 & -16.03 & -15.96 & -16.39 & -17.44 & -17.06 & -16.32 & -14.06 & -17.40 \\
\hline 8 & -25.26 & -29.13 & -28.99 & -27.22 & -28.74 & -25.04 & -28.07 & -16.33 & -27.99 \\
\hline Mic. & DI & DI & DI & DI & DI & DI & DI & DI & DI \\
Location & $180^{\circ}$ & $200^{\circ}$ & $220^{\circ}$ & $240^{\circ}$ & $260^{\circ}$ & $280^{\circ}$ & $300^{\circ}$ & $320^{\circ}$ & $340^{\circ}$ \\
\hline 1 & -4.55 & -3.54 & -4.39 & -4.55 & -5.55 & -3.83 & -3.86 & -6.22 & -4.22 \\
\hline 2 & -2.41 & -1.40 & -2.36 & -2.54 & -3.48 & -1.89 & -2.11 & -4.22 & -2.24 \\
\hline 3 & -1.17 & -0.11 & -1.03 & -0.98 & -1.97 & -0.42 & -0.78 & -2.66 & -0.85 \\
\hline 4 & -1.58 & -0.63 & -1.63 & -1.69 & -2.55 & -0.87 & -1.25 & -3.28 & -1.49 \\
\hline 5 & -14.98 & -14.82 & -16.29 & -15.99 & -17.50 & -13.60 & -13.06 & -15.17 & -16.20 \\
\hline 6 & -15.29 & -15.41 & -17.07 & -16.28 & -18.36 & -14.15 & -13.20 & -15.27 & -16.98 \\
\hline 7 & -15.03 & -15.14 & -16.39 & -16.13 & -17.57 & -13.99 & -13.35 & -14.82 & -16.54 \\
\hline 8 & -20.40 & -23.92 & -24.54 & -24.11 & -26.67 & -19.08 & -17.28 & -16.35 & -27.33 \\
\hline
\end{tabular}


Table E.5: Directivity index values (dB) at all microphone locations, $1 / 3$ octave band center frequency: $50 \mathrm{~Hz}$, maximum SPL in $1 / 3$ octave frequency band: $49 \mathrm{~dB}$ ref $20 \mu \mathrm{Pa}$.

\begin{tabular}{|c|c|c|c|c|c|c|c|c|c|}
\hline $\begin{array}{c}\text { Mic. } \\
\text { Location }\end{array}$ & DI $0^{\circ}$ & DI $20^{\circ}$ & DI $40^{\circ}$ & DI $60^{\circ}$ & DI $80^{\circ}$ & $\begin{array}{c}\text { DI } \\
100^{\circ}\end{array}$ & $\begin{array}{c}\text { DI } \\
120^{\circ}\end{array}$ & $\begin{array}{c}\text { DI } \\
140^{\circ}\end{array}$ & $\begin{array}{c}\text { DI } \\
160^{\circ}\end{array}$ \\
\hline 1 & -4.24 & -3.66 & -4.67 & -4.52 & -4.21 & -4.73 & -4.77 & -3.46 & -3.48 \\
\hline 2 & -2.10 & -1.62 & -2.61 & -2.37 & -2.11 & -2.61 & -2.69 & -1.39 & -1.44 \\
\hline 3 & -0.64 & -0.16 & -1.04 & -1.00 & -0.70 & -1.21 & -1.33 & 0.00 & -0.04 \\
\hline 4 & -1.34 & -0.79 & -1.74 & -1.57 & -1.31 & -1.76 & -1.88 & -0.57 & -0.63 \\
\hline 5 & -15.94 & -15.43 & -16.53 & -16.47 & -15.79 & -16.57 & -16.36 & -13.20 & -15.46 \\
\hline 6 & -16.68 & -16.05 & -17.21 & -17.19 & -16.44 & -17.34 & -16.90 & -13.09 & -16.13 \\
\hline 7 & -16.15 & -15.52 & -16.81 & -16.67 & -15.96 & -17.01 & -16.46 & -12.34 & -15.68 \\
\hline 8 & -29.24 & -30.24 & -31.99 & -29.60 & -29.96 & -29.86 & -28.27 & -14.55 & -30.46 \\
\hline Mic. & DI & DI & DI & DI & DI & DI & DI & DI & DI \\
Location & $180^{\circ}$ & $200^{\circ}$ & $220^{\circ}$ & $240^{\circ}$ & $260^{\circ}$ & $280^{\circ}$ & $300^{\circ}$ & $320^{\circ}$ & $340^{\circ}$ \\
\hline 1 & -4.23 & -4.09 & -4.02 & -4.15 & -3.95 & -3.61 & -3.95 & -3.20 & -5.33 \\
\hline 2 & -2.14 & -1.99 & -1.95 & -2.13 & -1.85 & -1.57 & -1.90 & -1.10 & -3.28 \\
\hline 3 & -0.68 & -0.63 & -0.52 & -0.70 & -0.37 & -0.23 & -0.46 & 0.28 & -1.89 \\
\hline 4 & -1.22 & -1.23 & -1.05 & -1.26 & -1.05 & -0.86 & -1.01 & -0.33 & -2.49 \\
\hline 5 & -15.85 & -16.12 & -15.36 & -15.88 & -15.93 & -15.40 & -14.71 & -14.65 & -16.87 \\
\hline 6 & -16.50 & -16.85 & -15.96 & -16.61 & -16.51 & -15.92 & -14.59 & -15.35 & -17.59 \\
\hline 7 & -16.05 & -16.26 & -15.45 & -16.06 & -16.22 & -15.30 & -13.59 & -15.17 & -17.18 \\
\hline 8 & -26.62 & -31.12 & -28.57 & -30.18 & -29.08 & -21.42 & -17.16 & -23.67 & -25.07 \\
\hline
\end{tabular}

Table E.6: Directivity index values (dB) at all microphone locations, $1 / 3$ octave band center frequency: $63 \mathrm{~Hz}$, maximum SPL in $1 / 3$ octave frequency band: $49 \mathrm{~dB}$ ref $20 \mu \mathrm{Pa}$.

\begin{tabular}{|c|c|c|c|c|c|c|c|c|c|}
\hline $\begin{array}{c}\text { Mic. } \\
\text { Location }\end{array}$ & DI $0^{\circ}$ & DI $20^{\circ}$ & DI $40^{\circ}$ & DI $60^{\circ}$ & DI $80^{\circ}$ & $\begin{array}{c}\text { DI } \\
100^{\circ}\end{array}$ & $\begin{array}{c}\text { DI } \\
120^{\circ}\end{array}$ & $\begin{array}{c}\text { DI } \\
140^{\circ}\end{array}$ & $\begin{array}{c}\text { DI } \\
160^{\circ}\end{array}$ \\
\hline 1 & -5.12 & -4.48 & -4.60 & -4.92 & -3.60 & -4.56 & -5.07 & -3.34 & -3.49 \\
\hline 2 & -3.02 & -2.39 & -2.55 & -2.84 & -1.42 & -2.46 & -2.94 & -1.46 & -1.38 \\
\hline 3 & -1.54 & -1.01 & -1.08 & -1.41 & -0.09 & -1.00 & -1.62 & -0.14 & 0.00 \\
\hline 4 & -2.20 & -1.55 & -1.73 & -2.02 & -0.68 & -1.62 & -2.08 & -0.52 & -0.60 \\
\hline 5 & -17.09 & -16.33 & -16.49 & -16.61 & -15.37 & -16.45 & -16.76 & -11.82 & -15.38 \\
\hline 6 & -17.79 & -16.96 & -17.15 & -17.29 & -16.06 & -17.09 & -17.33 & -11.03 & -15.98 \\
\hline 7 & -17.28 & -16.59 & -16.70 & -16.82 & -15.54 & -16.56 & -16.95 & -10.45 & -15.48 \\
\hline 8 & -28.57 & -29.58 & -29.39 & -28.51 & -28.86 & -29.62 & -27.91 & -11.03 & -29.07 \\
\hline Mic. & DI & DI & DI & DI & DI & DI & DI & DI & DI \\
Location & $180^{\circ}$ & $200^{\circ}$ & $220^{\circ}$ & $240^{\circ}$ & $260^{\circ}$ & $280^{\circ}$ & $300^{\circ}$ & $320^{\circ}$ & $340^{\circ}$ \\
\hline 1 & -4.34 & -4.72 & -4.79 & -5.14 & -3.90 & -3.45 & -3.22 & -3.31 & -4.21 \\
\hline 2 & -2.22 & -2.62 & -2.74 & -3.14 & -1.74 & -1.36 & -1.36 & -1.26 & -2.20 \\
\hline 3 & -0.80 & -1.15 & -1.28 & -1.64 & -0.37 & 0.04 & 0.03 & 0.17 & -0.67 \\
\hline 4 & -1.43 & -1.75 & -1.88 & -2.30 & -1.00 & -0.55 & -0.32 & -0.40 & -1.28 \\
\hline 5 & -15.52 & -16.24 & -16.58 & -17.16 & -15.87 & -15.08 & -11.21 & -15.11 & -13.55 \\
\hline 6 & -15.93 & -16.82 & -17.20 & -17.69 & -16.49 & -15.60 & -10.36 & -15.69 & -13.51 \\
\hline 7 & -15.38 & -16.37 & -16.73 & -17.16 & -15.98 & -15.12 & -9.60 & -15.11 & -13.04 \\
\hline 8 & -21.75 & -26.31 & -27.49 & -27.37 & -27.21 & -22.60 & -10.12 & -23.33 & -14.75 \\
\hline
\end{tabular}


Table E.7: Directivity index values $(\mathrm{dB})$ at all microphone locations, $1 / 3$ octave band center frequency: $80 \mathrm{~Hz}$, maximum SPL in $1 / 3$ octave frequency band: $49 \mathrm{~dB}$ ref $20 \mu \mathrm{Pa}$.

\begin{tabular}{|c|c|c|c|c|c|c|c|c|c|}
\hline $\begin{array}{c}\text { Mic. } \\
\text { Location }\end{array}$ & DI $0^{\circ}$ & DI $20^{\circ}$ & DI $40^{\circ}$ & DI $60^{\circ}$ & DI $80^{\circ}$ & $\begin{array}{c}\text { DI } \\
100^{\circ}\end{array}$ & $\begin{array}{c}\text { DI } \\
120^{\circ}\end{array}$ & $\begin{array}{c}\text { DI } \\
140^{\circ}\end{array}$ & $\begin{array}{c}\text { DI } \\
160^{\circ}\end{array}$ \\
\hline 1 & -4.99 & -3.51 & -4.34 & -3.82 & -4.96 & -3.90 & -3.80 & -4.43 & -4.82 \\
\hline 2 & -2.83 & -1.40 & -2.17 & -1.64 & -2.81 & -1.81 & -1.69 & -2.33 & -2.65 \\
\hline 3 & -1.46 & 0 & -0.81 & -0.30 & -1.41 & -0.46 & -0.30 & -0.97 & -1.31 \\
\hline 4 & -2.02 & -0.62 & -1.40 & -0.80 & -2.00 & -0.97 & -0.88 & -1.39 & -1.79 \\
\hline 5 & -16.64 & -15.54 & -16.06 & -15.53 & -16.74 & -15.55 & -15.33 & -13.77 & -16.38 \\
\hline 6 & -17.19 & -16.19 & -16.53 & -15.94 & -17.30 & -16.15 & -15.85 & -13.47 & -16.82 \\
\hline 7 & -16.21 & -15.31 & -15.56 & -14.78 & -16.59 & -15.26 & -15.02 & -12.60 & -15.70 \\
\hline 8 & -24.85 & -25.85 & -24.48 & -24.49 & -25.61 & -25.20 & -24.57 & -14.38 & -24.68 \\
\hline Mic. & DI & DI & DI & DI & DI & DI & DI & DI & DI \\
Location & $180^{\circ}$ & $200^{\circ}$ & $220^{\circ}$ & $240^{\circ}$ & $260^{\circ}$ & $280^{\circ}$ & $300^{\circ}$ & $320^{\circ}$ & $340^{\circ}$ \\
\hline 1 & -4.91 & -4.69 & -3.36 & -4.72 & -4.04 & -4.09 & -3.58 & -4.30 & -4.40 \\
\hline 2 & -2.77 & -2.60 & -1.22 & -2.53 & -1.83 & -2.02 & -1.62 & -2.17 & -2.26 \\
\hline 3 & -1.45 & -1.13 & 0.20 & -1.21 & -0.42 & -0.58 & -0.26 & -0.76 & -0.88 \\
\hline 4 & -1.96 & -1.74 & -0.42 & -1.74 & -0.97 & -1.24 & -0.60 & -1.31 & -1.44 \\
\hline 5 & -16.07 & -16.44 & -15.30 & -16.40 & -15.91 & -15.79 & -11.93 & -15.44 & -16.50 \\
\hline 6 & -16.37 & -16.98 & -15.87 & -16.85 & -16.25 & -16.44 & -11.33 & -15.64 & -17.02 \\
\hline 7 & -15.47 & -16.27 & -14.76 & -15.76 & -15.41 & -15.88 & -10.48 & -14.68 & -15.76 \\
\hline 8 & -22.19 & -23.63 & -25.64 & -24.88 & -25.83 & -22.95 & -12.14 & -20.12 & -25.01 \\
\hline
\end{tabular}

Table E.8: Directivity index values $(\mathrm{dB})$ at all microphone locations, $1 / 3$ octave band center frequency: $100 \mathrm{~Hz}$, maximum SPL in $1 / 3$ octave frequency band: $49 \mathrm{~dB}$ ref $20 \mu \mathrm{Pa}$.

\begin{tabular}{|c|c|c|c|c|c|c|c|c|c|}
\hline $\begin{array}{c}\text { Mic. } \\
\text { Location }\end{array}$ & DI $0^{\circ}$ & DI $20^{\circ}$ & DI $40^{\circ}$ & DI $60^{\circ}$ & DI $80^{\circ}$ & $\begin{array}{c}\text { DI } \\
100^{\circ}\end{array}$ & $\begin{array}{c}\text { DI } \\
120^{\circ}\end{array}$ & $\begin{array}{c}\text { DI } \\
140^{\circ}\end{array}$ & $\begin{array}{c}\text { DI } \\
160^{\circ}\end{array}$ \\
\hline 1 & -4.45 & -4.34 & -4.60 & -3.48 & -4.19 & -4.04 & -4.19 & -4.01 & -3.66 \\
\hline 2 & -2.36 & -2.26 & -2.43 & -1.40 & -2.10 & -1.95 & -2.08 & -1.89 & -1.60 \\
\hline 3 & -0.94 & -0.84 & -1.03 & 0.00 & -0.70 & -0.60 & -0.67 & -0.56 & -0.18 \\
\hline 4 & -1.56 & -1.42 & -1.64 & -0.58 & -1.25 & -1.10 & -1.27 & -1.13 & -0.80 \\
\hline 5 & -16.26 & -15.83 & -16.43 & -15.13 & -15.89 & -15.46 & -15.83 & -15.08 & -15.45 \\
\hline 6 & -16.97 & -16.42 & -17.10 & -15.70 & -16.52 & -16.03 & -16.46 & -15.60 & -16.09 \\
\hline 7 & -16.48 & -16.06 & -16.68 & -15.35 & -16.07 & -15.63 & -15.97 & -15.21 & -15.68 \\
\hline 8 & -27.69 & -25.46 & -25.82 & -26.83 & -27.36 & -26.68 & -26.19 & -21.80 & -26.60 \\
\hline Mic. & DI & DI & DI & DI & DI & DI & DI & DI & DI \\
Location & $180^{\circ}$ & $200^{\circ}$ & $220^{\circ}$ & $240^{\circ}$ & $260^{\circ}$ & $280^{\circ}$ & $300^{\circ}$ & $320^{\circ}$ & $340^{\circ}$ \\
\hline 1 & -4.60 & -4.00 & -4.46 & -3.96 & -4.51 & -4.14 & -5.16 & -5.03 & -4.52 \\
\hline 2 & -2.46 & -1.92 & -2.42 & -1.88 & -2.37 & -2.07 & -3.05 & -2.94 & -2.41 \\
\hline 3 & -1.10 & -0.47 & -1.00 & -0.46 & -0.97 & -0.67 & -1.64 & -1.58 & -1.01 \\
\hline 4 & -1.67 & -1.09 & -1.59 & -1.07 & -1.60 & -1.27 & -2.22 & -2.10 & -1.62 \\
\hline 5 & -16.04 & -15.84 & -16.39 & -15.61 & -16.37 & -15.95 & -16.29 & -15.48 & -16.20 \\
\hline 6 & -16.61 & -16.43 & -17.04 & -16.26 & -16.97 & -16.59 & -16.64 & -15.66 & -16.87 \\
\hline 7 & -16.19 & -16.01 & -16.60 & -15.83 & -16.53 & -16.18 & -16.23 & -15.32 & -16.42 \\
\hline 8 & -23.82 & -25.58 & -28.32 & -27.11 & -26.17 & -26.28 & -22.23 & -19.17 & -28.74 \\
\hline
\end{tabular}


Table E.9: Directivity index values (dB) at all microphone locations, $1 / 3$ octave band center frequency: $125 \mathrm{~Hz}$, maximum SPL in $1 / 3$ octave frequency band: $48 \mathrm{~dB}$ ref $20 \mu \mathrm{Pa}$.

\begin{tabular}{|c|c|c|c|c|c|c|c|c|c|}
\hline $\begin{array}{c}\text { Mic. } \\
\text { Location }\end{array}$ & DI $0^{\circ}$ & DI $20^{\circ}$ & DI $40^{\circ}$ & DI $60^{\circ}$ & DI $80^{\circ}$ & $\begin{array}{c}\text { DI } \\
100^{\circ}\end{array}$ & $\begin{array}{c}\text { DI } \\
120^{\circ}\end{array}$ & $\begin{array}{c}\text { DI } \\
140^{\circ}\end{array}$ & $\begin{array}{c}\text { DI } \\
160^{\circ}\end{array}$ \\
\hline 1 & -4.07 & -4.15 & -3.53 & -3.54 & -4.01 & -4.24 & -4.24 & -3.58 & -3.51 \\
\hline 2 & -1.97 & -2.09 & -1.44 & -1.47 & -1.92 & -2.17 & -2.16 & -1.49 & -1.39 \\
\hline 3 & -0.55 & -0.73 & -0.05 & -0.05 & -0.53 & -0.77 & -0.75 & -0.08 & 0.00 \\
\hline 4 & -1.16 & -1.25 & -0.64 & -0.65 & -1.16 & -1.33 & -1.32 & -0.69 & -0.55 \\
\hline 5 & -15.21 & -15.07 & -14.86 & -14.87 & -15.28 & -15.58 & -15.27 & -14.91 & -14.83 \\
\hline 6 & -15.81 & -15.61 & -15.49 & -15.48 & -15.87 & -16.12 & -15.79 & -15.46 & -15.40 \\
\hline 7 & -15.50 & -15.37 & -15.16 & -15.16 & -15.60 & -15.82 & -15.55 & -15.15 & -15.03 \\
\hline 8 & -23.67 & -22.93 & -23.22 & -23.35 & -23.42 & -23.61 & -23.80 & -22.68 & -24.33 \\
\hline Mic. & DI & DI & DI & DI & DI & DI & DI & DI & DI \\
Location & $180^{\circ}$ & $200^{\circ}$ & $220^{\circ}$ & $240^{\circ}$ & $260^{\circ}$ & $280^{\circ}$ & $300^{\circ}$ & $320^{\circ}$ & $340^{\circ}$ \\
\hline 1 & -3.14 & -3.32 & -3.58 & -3.82 & -3.93 & -3.96 & -4.82 & -3.91 & -4.48 \\
\hline 2 & -1.04 & -1.20 & -1.44 & -1.72 & -1.83 & -1.85 & -2.69 & -1.76 & -2.43 \\
\hline 3 & 0.33 & 0.15 & -0.04 & -0.36 & -0.44 & -0.48 & -1.30 & -0.36 & -1.04 \\
\hline 4 & -0.20 & -0.41 & -0.66 & -0.91 & -0.98 & -1.09 & -1.91 & -0.98 & -1.57 \\
\hline 5 & -14.51 & -14.58 & -15.05 & -14.87 & -15.17 & -15.37 & -15.95 & -15.49 & -15.69 \\
\hline 6 & -15.08 & -15.13 & -15.64 & -15.41 & -15.71 & -15.90 & -16.49 & -16.12 & -16.22 \\
\hline 7 & -14.78 & -14.86 & -15.35 & -15.15 & -15.40 & -15.66 & -16.20 & -15.78 & -15.92 \\
\hline 8 & -22.88 & -23.57 & -23.20 & -23.57 & -23.57 & -23.67 & -22.95 & -24.28 & -23.31 \\
\hline
\end{tabular}

Table E.10: Directivity index values $(\mathrm{dB})$ at all microphone locations, $1 / 3$ octave band center frequency: $160 \mathrm{~Hz}$, maximum SPL in $1 / 3$ octave frequency band: $48 \mathrm{~dB}$ ref $20 \mu \mathrm{Pa}$.

\begin{tabular}{|c|c|c|c|c|c|c|c|c|c|}
\hline $\begin{array}{c}\text { Mic. } \\
\text { Location }\end{array}$ & DI $0^{\circ}$ & DI $20^{\circ}$ & DI $40^{\circ}$ & DI $60^{\circ}$ & DI $80^{\circ}$ & $\begin{array}{c}\text { DI } \\
100^{\circ}\end{array}$ & $\begin{array}{c}\text { DI } \\
120^{\circ}\end{array}$ & $\begin{array}{c}\text { DI } \\
140^{\circ}\end{array}$ & $\begin{array}{c}\text { DI } \\
160^{\circ}\end{array}$ \\
\hline 1 & -3.98 & -3.89 & -4.06 & -4.18 & -4.10 & -3.64 & -3.53 & -3.39 & -3.61 \\
\hline 2 & -1.94 & -1.81 & -2.09 & -2.17 & -2.02 & -1.58 & -1.43 & -1.37 & -1.50 \\
\hline 3 & -0.56 & -0.46 & -0.75 & -0.80 & -0.65 & -0.18 & -0.06 & 0.00 & -0.15 \\
\hline 4 & -1.11 & -1.03 & -1.25 & -1.30 & -1.22 & -0.73 & -0.64 & -0.54 & -0.73 \\
\hline 5 & -14.05 & -14.35 & -13.52 & -14.36 & -14.20 & -13.68 & -14.12 & -13.65 & -13.99 \\
\hline 6 & -14.47 & -14.79 & -13.89 & -14.79 & -14.64 & -14.14 & -14.60 & -14.07 & -14.43 \\
\hline 7 & -14.46 & -14.72 & -13.97 & -14.74 & -14.61 & -14.10 & -14.50 & -14.02 & -14.41 \\
\hline 8 & -19.47 & -19.39 & -19.19 & -19.40 & -19.50 & -19.32 & -20.01 & -19.42 & -19.50 \\
\hline Mic. & DI & DI & DI & DI & DI & DI & DI & DI & DI \\
Location & $180^{\circ}$ & $200^{\circ}$ & $220^{\circ}$ & $240^{\circ}$ & $260^{\circ}$ & $280^{\circ}$ & $300^{\circ}$ & $320^{\circ}$ & $340^{\circ}$ \\
\hline 1 & -3.62 & -4.51 & -3.79 & -4.00 & -3.91 & -3.52 & -3.63 & -3.90 & -3.53 \\
\hline 2 & -1.55 & -2.43 & -1.71 & -1.91 & -1.87 & -1.49 & -1.59 & -1.85 & -1.47 \\
\hline 3 & -0.21 & -1.12 & -0.32 & -0.52 & -0.49 & -0.19 & -0.25 & -0.52 & -0.10 \\
\hline 4 & -0.68 & -1.59 & -0.89 & -1.01 & -1.03 & -0.63 & -0.80 & -1.01 & -0.63 \\
\hline 5 & -13.58 & -14.47 & -13.75 & -13.95 & -13.90 & -13.26 & -14.09 & -13.77 & -14.11 \\
\hline 6 & -14.03 & -14.90 & -14.11 & -14.42 & -14.34 & -13.70 & -14.57 & -14.26 & -14.63 \\
\hline 7 & -13.99 & -14.85 & -14.12 & -14.40 & -14.34 & -13.77 & -14.54 & -14.31 & -14.54 \\
\hline 8 & -18.99 & -20.14 & -18.24 & -19.44 & -19.66 & -18.89 & -19.96 & -19.53 & -19.96 \\
\hline
\end{tabular}


Table E.11: Directivity index values (dB) at all microphone locations, $1 / 3$ octave band center frequency: $200 \mathrm{~Hz}$, maximum SPL in $1 / 3$ octave frequency band: $47 \mathrm{~dB}$ ref $20 \mu \mathrm{Pa}$.

\begin{tabular}{|c|c|c|c|c|c|c|c|c|c|}
\hline $\begin{array}{c}\text { Mic. } \\
\text { Location }\end{array}$ & DI $0^{\circ}$ & DI $20^{\circ}$ & DI $40^{\circ}$ & DI $60^{\circ}$ & DI $80^{\circ}$ & $\begin{array}{c}\text { DI } \\
100^{\circ}\end{array}$ & $\begin{array}{c}\text { DI } \\
120^{\circ}\end{array}$ & $\begin{array}{c}\text { DI } \\
140^{\circ}\end{array}$ & $\begin{array}{c}\text { DI } \\
160^{\circ}\end{array}$ \\
\hline 1 & -4.09 & -4.47 & -3.73 & -4.22 & -3.34 & -4.03 & -4.36 & -3.60 & -4.44 \\
\hline 2 & -2.15 & -2.51 & -1.79 & -2.24 & -1.32 & -2.12 & -2.35 & -1.60 & -2.41 \\
\hline 3 & -0.81 & -1.11 & -0.43 & -0.94 & 0.00 & -0.80 & -0.96 & -0.28 & -1.05 \\
\hline 4 & -1.29 & -1.69 & -0.93 & -1.37 & -0.49 & -1.18 & -1.58 & -0.78 & -1.57 \\
\hline 5 & -12.12 & -12.46 & -11.93 & -12.17 & -11.88 & -11.89 & -12.59 & -12.09 & -12.53 \\
\hline 6 & -12.18 & -12.52 & -12.05 & -12.26 & -12.05 & -12.00 & -12.68 & -12.24 & -12.61 \\
\hline 7 & -12.40 & -12.76 & -12.22 & -12.52 & -12.21 & -12.21 & -12.90 & -12.42 & -12.86 \\
\hline 8 & -14.63 & -14.79 & -14.75 & -14.64 & -15.05 & -14.60 & -15.10 & -15.24 & -14.63 \\
\hline Mic. & DI & DI & DI & DI & DI & DI & DI & DI & DI \\
Location & $180^{\circ}$ & $200^{\circ}$ & $220^{\circ}$ & $240^{\circ}$ & $260^{\circ}$ & $280^{\circ}$ & $300^{\circ}$ & $320^{\circ}$ & $340^{\circ}$ \\
\hline 1 & -4.74 & -3.83 & -3.79 & -4.75 & -3.28 & -4.36 & -3.84 & -4.31 & -4.43 \\
\hline 2 & -2.82 & -1.83 & -1.80 & -2.73 & -1.33 & -2.38 & -1.84 & -2.34 & -2.48 \\
\hline 3 & -1.52 & -0.57 & -0.46 & -1.42 & -0.04 & -0.98 & -0.51 & -1.03 & -1.17 \\
\hline 4 & -1.98 & -0.89 & -0.96 & -1.88 & -0.46 & -1.53 & -1.01 & -1.46 & -1.65 \\
\hline 5 & -12.25 & -11.73 & -12.06 & -12.61 & -12.06 & -12.76 & -12.39 & -12.52 & -12.54 \\
\hline 6 & -12.30 & -11.83 & -12.18 & -12.69 & -12.28 & -12.89 & -12.54 & -12.69 & -12.65 \\
\hline 7 & -12.56 & -12.03 & -12.37 & -12.96 & -12.39 & -13.10 & -12.69 & -12.91 & -12.89 \\
\hline 8 & -14.72 & -14.58 & -15.02 & -14.79 & -15.81 & -15.29 & -15.17 & -15.61 & -15.14 \\
\hline
\end{tabular}

Table E.12: Directivity index values $(\mathrm{dB})$ at all microphone locations, $1 / 3$ octave band center frequency: $250 \mathrm{~Hz}$, maximum SPL in $1 / 3$ octave frequency band: $47 \mathrm{~dB}$ ref $20 \mu \mathrm{Pa}$.

\begin{tabular}{|c|c|c|c|c|c|c|c|c|c|}
\hline $\begin{array}{c}\text { Mic. } \\
\text { Location }\end{array}$ & DI $0^{\circ}$ & DI $20^{\circ}$ & DI $40^{\circ}$ & DI $60^{\circ}$ & DI $80^{\circ}$ & $\begin{array}{c}\text { DI } \\
100^{\circ}\end{array}$ & $\begin{array}{c}\text { DI } \\
120^{\circ}\end{array}$ & $\begin{array}{c}\text { DI } \\
140^{\circ}\end{array}$ & $\begin{array}{c}\text { DI } \\
160^{\circ}\end{array}$ \\
\hline 1 & -3.18 & -3.55 & -3.89 & -3.12 & -3.05 & -3.62 & -3.91 & -3.35 & -3.13 \\
\hline 2 & -1.34 & -1.78 & -2.17 & -1.34 & -1.24 & -1.72 & -2.13 & -1.58 & -1.30 \\
\hline 3 & -0.08 & -0.56 & -0.91 & -0.08 & 0.00 & -0.45 & -0.92 & -0.37 & -0.09 \\
\hline 4 & -0.41 & -0.88 & -1.25 & -0.41 & -0.34 & -0.80 & -1.23 & -0.61 & -0.40 \\
\hline 5 & -9.22 & -9.28 & -9.70 & -9.27 & -9.49 & -10.06 & -9.60 & -9.51 & -9.22 \\
\hline 6 & -8.97 & -9.02 & -9.41 & -9.01 & -9.29 & -9.77 & -9.31 & -9.27 & -9.01 \\
\hline 7 & -9.13 & -9.18 & -9.58 & -9.15 & -9.43 & -9.89 & -9.50 & -9.41 & -9.14 \\
\hline 8 & -9.94 & -9.88 & -10.29 & -10.30 & -10.74 & -10.71 & -10.16 & -10.57 & -10.17 \\
\hline Mic. & DI & DI & DI & DI & DI & DI & DI & DI & DI \\
Location & $180^{\circ}$ & $200^{\circ}$ & $220^{\circ}$ & $240^{\circ}$ & $260^{\circ}$ & $280^{\circ}$ & $300^{\circ}$ & $320^{\circ}$ & $340^{\circ}$ \\
\hline 1 & -3.74 & -3.25 & -2.71 & -3.01 & -3.54 & -4.38 & -3.47 & -3.74 & -3.38 \\
\hline 2 & -1.96 & -1.42 & -0.89 & -1.21 & -1.69 & -2.54 & -1.61 & -1.88 & -1.55 \\
\hline 3 & -0.73 & -0.25 & 0.33 & 0.01 & -0.41 & -1.26 & -0.36 & -0.59 & -0.31 \\
\hline 4 & -1.03 & -0.52 & 0.07 & -0.23 & -0.73 & -1.57 & -0.67 & -0.96 & -0.60 \\
\hline 5 & -9.57 & -9.13 & -9.01 & -9.21 & -9.88 & -10.44 & -9.87 & -10.25 & -9.62 \\
\hline 6 & -9.29 & -8.86 & -8.78 & -8.93 & -9.64 & -10.14 & -9.61 & -9.99 & -9.37 \\
\hline 7 & -9.39 & -9.03 & -8.90 & -9.04 & -9.82 & -10.34 & -9.73 & -10.11 & -9.53 \\
\hline 8 & -10.23 & -10.09 & -10.06 & -10.47 & -10.82 & -11.03 & -10.96 & -11.40 & -10.89 \\
\hline
\end{tabular}


Table E.13: Directivity index values (dB) at all microphone locations, $1 / 3$ octave band center frequency: $315 \mathrm{~Hz}$, maximum SPL in $1 / 3$ octave frequency band: $46 \mathrm{~dB}$ ref $20 \mu \mathrm{Pa}$.

\begin{tabular}{|c|c|c|c|c|c|c|c|c|c|}
\hline $\begin{array}{c}\text { Mic. } \\
\text { Location }\end{array}$ & DI $0^{\circ}$ & DI $20^{\circ}$ & DI $40^{\circ}$ & DI $60^{\circ}$ & DI $80^{\circ}$ & $\begin{array}{c}\text { DI } \\
100^{\circ}\end{array}$ & $\begin{array}{c}\text { DI } \\
120^{\circ}\end{array}$ & $\begin{array}{c}\text { DI } \\
140^{\circ}\end{array}$ & $\begin{array}{c}\text { DI } \\
160^{\circ}\end{array}$ \\
\hline 1 & -2.87 & -2.91 & -2.80 & -2.99 & -3.20 & -2.61 & -2.81 & -2.83 & -2.75 \\
\hline 2 & -1.40 & -1.39 & -1.33 & -1.44 & -1.70 & -1.10 & -1.24 & -1.25 & -1.14 \\
\hline 3 & -0.34 & -0.29 & -0.27 & -0.37 & -0.64 & 0.00 & -0.19 & -0.13 & -0.04 \\
\hline 4 & -0.28 & -0.39 & -0.26 & -0.45 & -0.63 & -0.05 & -0.26 & -0.22 & -0.12 \\
\hline 5 & -6.17 & -6.28 & -6.21 & -6.69 & -6.58 & -6.08 & -6.53 & -6.60 & -6.48 \\
\hline 6 & -5.88 & -5.98 & -5.97 & -6.46 & -6.30 & -5.83 & -6.26 & -6.33 & -6.19 \\
\hline 7 & -6.10 & -6.20 & -6.20 & -6.67 & -6.50 & -6.05 & -6.46 & -6.53 & -6.38 \\
\hline 8 & -6.41 & -6.37 & -6.45 & -6.99 & -6.71 & -6.15 & -6.75 & -6.77 & -6.69 \\
\hline Mic. & DI & DI & DI & DI & DI & DI & DI & DI & DI \\
Location & $180^{\circ}$ & $200^{\circ}$ & $220^{\circ}$ & $240^{\circ}$ & $260^{\circ}$ & $280^{\circ}$ & $300^{\circ}$ & $320^{\circ}$ & $340^{\circ}$ \\
\hline 1 & -2.99 & -2.40 & -2.33 & -2.92 & -2.92 & -2.30 & -2.94 & -2.53 & -2.53 \\
\hline 2 & -1.44 & -0.80 & -0.79 & -1.36 & -1.31 & -0.76 & -1.37 & -0.96 & -1.03 \\
\hline 3 & -0.31 & 0.26 & 0.30 & -0.29 & -0.24 & 0.32 & -0.30 & 0.12 & 0.00 \\
\hline 4 & -0.36 & 0.25 & 0.31 & -0.43 & -0.39 & 0.19 & -0.42 & -0.01 & -0.07 \\
\hline 5 & -6.49 & -6.06 & -5.82 & -6.97 & -7.04 & -6.68 & -7.15 & -6.77 & -6.48 \\
\hline 6 & -6.17 & -5.75 & -5.54 & -6.76 & -6.82 & -6.51 & -6.95 & -6.58 & -6.29 \\
\hline 7 & -6.39 & -5.96 & -5.74 & -6.93 & -7.01 & -6.67 & -7.14 & -6.75 & -6.48 \\
\hline 8 & -6.63 & -6.26 & -6.14 & -7.15 & -7.19 & -7.12 & -7.41 & -7.13 & -6.89 \\
\hline
\end{tabular}

Table E.14: Directivity index values $(\mathrm{dB})$ at all microphone locations, $1 / 3$ octave band center frequency: $400 \mathrm{~Hz}$, maximum SPL in $1 / 3$ octave frequency band: $47 \mathrm{~dB}$ ref $20 \mu \mathrm{Pa}$.

\begin{tabular}{|c|c|c|c|c|c|c|c|c|c|}
\hline $\begin{array}{c}\text { Mic. } \\
\text { Location }\end{array}$ & DI $0^{\circ}$ & DI $20^{\circ}$ & DI $40^{\circ}$ & DI $60^{\circ}$ & DI $80^{\circ}$ & $\begin{array}{c}\text { DI } \\
100^{\circ}\end{array}$ & $\begin{array}{c}\text { DI } \\
120^{\circ}\end{array}$ & $\begin{array}{c}\text { DI } \\
140^{\circ}\end{array}$ & $\begin{array}{c}\text { DI } \\
160^{\circ}\end{array}$ \\
\hline 1 & -2.14 & -2.12 & -1.86 & -1.97 & -2.12 & -1.93 & -2.05 & -2.00 & -2.42 \\
\hline 2 & -1.06 & -1.06 & -0.82 & -0.95 & -1.04 & -0.95 & -0.99 & -0.97 & -1.34 \\
\hline 3 & -0.30 & -0.31 & -0.09 & -0.26 & -0.33 & -0.25 & -0.28 & -0.29 & -0.54 \\
\hline 4 & -0.11 & -0.14 & 0.00 & -0.14 & -0.25 & -0.07 & -0.14 & -0.13 & -0.42 \\
\hline 5 & -4.54 & -4.50 & -4.71 & -4.61 & -4.89 & -4.86 & -4.85 & -4.70 & -4.98 \\
\hline 6 & -4.43 & -4.40 & -4.63 & -4.53 & -4.81 & -4.73 & -4.76 & -4.56 & -4.86 \\
\hline 7 & -4.55 & -4.54 & -4.78 & -4.68 & -4.95 & -4.84 & -4.86 & -4.62 & -4.99 \\
\hline 8 & -4.69 & -4.67 & -4.96 & -4.81 & -5.11 & -5.15 & -5.12 & -4.86 & -5.09 \\
\hline Mic. & DI & DI & DI & DI & DI & DI & DI & DI & DI \\
Location & $180^{\circ}$ & $200^{\circ}$ & $220^{\circ}$ & $240^{\circ}$ & $260^{\circ}$ & $280^{\circ}$ & $300^{\circ}$ & $320^{\circ}$ & $340^{\circ}$ \\
\hline 1 & -2.28 & -2.53 & -2.28 & -2.46 & -2.44 & -2.65 & -2.82 & -2.50 & -2.67 \\
\hline 2 & -1.21 & -1.42 & -1.25 & -1.35 & -1.37 & -1.56 & -1.75 & -1.39 & -1.63 \\
\hline 3 & -0.45 & -0.63 & -0.48 & -0.56 & -0.61 & -0.77 & -0.96 & -0.63 & -0.86 \\
\hline 4 & -0.17 & -0.43 & -0.30 & -0.35 & -0.40 & -0.57 & -0.83 & -0.50 & -0.77 \\
\hline 5 & -4.49 & -4.87 & -4.80 & -5.21 & -5.06 & -5.18 & -5.47 & -5.41 & -5.41 \\
\hline 6 & -4.38 & -4.73 & -4.64 & -4.94 & -4.80 & -4.92 & -5.22 & -5.19 & -5.18 \\
\hline 7 & -4.51 & -4.83 & -4.74 & -5.03 & -4.93 & -5.05 & -5.36 & -5.31 & -5.29 \\
\hline 8 & -4.67 & -4.96 & -4.81 & -5.38 & -5.19 & -5.24 & -5.50 & -5.67 & -5.53 \\
\hline
\end{tabular}


Table E.15: Directivity index values (dB) at all microphone locations, $1 / 3$ octave band center frequency: $500 \mathrm{~Hz}$, maximum SPL in $1 / 3$ octave frequency band: $48 \mathrm{~dB}$ ref $20 \mu \mathrm{Pa}$.

\begin{tabular}{|c|c|c|c|c|c|c|c|c|c|}
\hline $\begin{array}{c}\text { Mic. } \\
\text { Location }\end{array}$ & DI $0^{\circ}$ & DI $20^{\circ}$ & DI $40^{\circ}$ & DI $60^{\circ}$ & DI $80^{\circ}$ & $\begin{array}{c}\text { DI } \\
100^{\circ}\end{array}$ & $\begin{array}{c}\text { DI } \\
120^{\circ}\end{array}$ & $\begin{array}{c}\text { DI } \\
140^{\circ}\end{array}$ & $\begin{array}{c}\text { DI } \\
160^{\circ}\end{array}$ \\
\hline 1 & -2.24 & -2.46 & -2.54 & -2.58 & -2.40 & -2.48 & -2.50 & -2.74 & -2.66 \\
\hline 2 & -1.41 & -1.56 & -1.69 & -1.80 & -1.59 & -1.69 & -1.70 & -1.97 & -1.85 \\
\hline 3 & -0.72 & -0.83 & -0.94 & -1.06 & -0.91 & -0.96 & -0.93 & -1.26 & -1.13 \\
\hline 4 & 0 & -0.17 & -0.22 & -0.33 & -0.19 & -0.26 & -0.36 & -0.52 & -0.46 \\
\hline 5 & -2.96 & -3.29 & -3.15 & -3.09 & -3.07 & -3.12 & -3.43 & -3.34 & -3.32 \\
\hline 6 & -2.61 & -2.96 & -2.81 & -2.75 & -2.74 & -2.77 & -3.10 & -2.96 & -2.96 \\
\hline 7 & -2.55 & -2.90 & -2.77 & -2.73 & -2.69 & -2.70 & -3.01 & -2.85 & -2.82 \\
\hline 8 & -2.52 & -2.85 & -2.76 & -2.67 & -2.62 & -2.61 & -2.89 & -2.74 & -2.61 \\
\hline Mic. & DI & DI & DI & DI & DI & DI & DI & DI & DI \\
Location & $180^{\circ}$ & $200^{\circ}$ & $220^{\circ}$ & $240^{\circ}$ & $260^{\circ}$ & $280^{\circ}$ & $300^{\circ}$ & $320^{\circ}$ & $340^{\circ}$ \\
\hline 1 & -2.64 & -2.91 & -2.71 & -2.80 & -3.26 & -3.03 & -3.15 & -3.07 & -3.36 \\
\hline 2 & -1.82 & -2.08 & -1.92 & -1.88 & -2.21 & -2.07 & -2.13 & -2.11 & -2.39 \\
\hline 3 & -1.10 & -1.32 & -1.19 & -1.04 & -1.31 & -1.24 & -1.24 & -1.26 & -1.48 \\
\hline 4 & -0.41 & -0.69 & -0.47 & -0.29 & -0.64 & -0.47 & -0.52 & -0.45 & -0.73 \\
\hline 5 & -3.31 & -3.75 & -3.29 & -3.30 & -3.67 & -3.38 & -3.67 & -3.36 & -3.76 \\
\hline 6 & -2.92 & -3.36 & -2.91 & -3.01 & -3.36 & -3.08 & -3.38 & -3.05 & -3.46 \\
\hline 7 & -2.76 & -3.20 & -2.78 & -2.91 & -3.27 & -2.99 & -3.30 & -2.97 & -3.39 \\
\hline 8 & -2.58 & -3.07 & -2.68 & -2.72 & -3.07 & -2.82 & -3.22 & -2.93 & -3.34 \\
\hline
\end{tabular}

Table E.16: Directivity index values $(\mathrm{dB})$ at all microphone locations, $1 / 3$ octave band center frequency: $630 \mathrm{~Hz}$, maximum SPL in $1 / 3$ octave frequency band: $48 \mathrm{~dB}$ ref $20 \mu \mathrm{Pa}$.

\begin{tabular}{|c|c|c|c|c|c|c|c|c|c|}
\hline $\begin{array}{c}\text { Mic. } \\
\text { Location }\end{array}$ & DI $0^{\circ}$ & DI $20^{\circ}$ & DI $40^{\circ}$ & DI $60^{\circ}$ & DI $80^{\circ}$ & $\begin{array}{c}\text { DI } \\
100^{\circ}\end{array}$ & $\begin{array}{c}\text { DI } \\
120^{\circ}\end{array}$ & $\begin{array}{c}\text { DI } \\
140^{\circ}\end{array}$ & $\begin{array}{c}\text { DI } \\
160^{\circ}\end{array}$ \\
\hline 1 & -3.32 & -3.78 & -3.66 & -3.84 & -3.74 & -3.68 & -3.96 & -4.01 & -3.99 \\
\hline 2 & -2.35 & -2.81 & -2.75 & -2.89 & -2.78 & -2.82 & -3.02 & -3.05 & -3.00 \\
\hline 3 & -1.38 & -1.90 & -1.91 & -2.07 & -1.98 & -2.17 & -2.20 & -2.21 & -2.08 \\
\hline 4 & 0 & -0.55 & -0.61 & -0.86 & -0.82 & -1.05 & -1.00 & -0.95 & -0.85 \\
\hline 5 & -1.78 & -2.26 & -2.26 & -2.64 & -2.71 & -2.75 & -2.71 & -2.61 & -2.54 \\
\hline 6 & -0.93 & -1.41 & -1.45 & -1.87 & -1.95 & -1.97 & -1.95 & -1.79 & -1.74 \\
\hline 7 & -0.88 & -1.38 & -1.44 & -1.85 & -1.96 & -1.96 & -1.92 & -1.77 & -1.70 \\
\hline 8 & -0.81 & -1.27 & -1.32 & -1.72 & -1.80 & -1.76 & -1.70 & -1.57 & -1.48 \\
\hline Mic. & DI & DI & DI & DI & DI & DI & DI & DI & DI \\
Location & $180^{\circ}$ & $200^{\circ}$ & $220^{\circ}$ & $240^{\circ}$ & $260^{\circ}$ & $280^{\circ}$ & $300^{\circ}$ & $320^{\circ}$ & $340^{\circ}$ \\
\hline 1 & -3.85 & -3.78 & -3.56 & -3.60 & -3.51 & -3.97 & -3.88 & -4.39 & -3.74 \\
\hline 2 & -2.82 & -2.72 & -2.57 & -2.75 & -2.63 & -2.98 & -3.03 & -3.54 & -2.93 \\
\hline 3 & -1.92 & -1.72 & -1.72 & -1.95 & -1.71 & -2.03 & -2.14 & -2.64 & -2.10 \\
\hline 4 & -0.62 & -0.33 & -0.35 & -0.66 & -0.40 & -0.84 & -0.91 & -1.42 & -0.76 \\
\hline 5 & -2.30 & -1.98 & -1.95 & -2.42 & -2.10 & -2.82 & -2.76 & -3.16 & -2.36 \\
\hline 6 & -1.48 & -1.19 & -1.14 & -1.61 & -1.35 & -2.07 & -1.95 & -2.27 & -1.51 \\
\hline 7 & -1.44 & -1.15 & -1.10 & -1.60 & -1.38 & -2.06 & -1.93 & -2.24 & -1.47 \\
\hline 8 & -1.29 & -0.98 & -0.94 & -1.48 & -1.23 & -1.91 & -1.81 & -2.10 & -1.34 \\
\hline
\end{tabular}


Table E.17: Directivity index values (dB) at all microphone locations, $1 / 3$ octave band center frequency: $800 \mathrm{~Hz}$, maximum SPL in $1 / 3$ octave frequency band: $50 \mathrm{~dB}$ ref $20 \mu \mathrm{Pa}$.

\begin{tabular}{|c|c|c|c|c|c|c|c|c|c|}
\hline $\begin{array}{c}\text { Mic. } \\
\text { Location }\end{array}$ & DI $0^{\circ}$ & DI $20^{\circ}$ & DI $40^{\circ}$ & DI $60^{\circ}$ & DI $80^{\circ}$ & $\begin{array}{c}\text { DI } \\
100^{\circ}\end{array}$ & $\begin{array}{c}\text { DI } \\
120^{\circ}\end{array}$ & $\begin{array}{c}\text { DI } \\
140^{\circ}\end{array}$ & $\begin{array}{c}\text { DI } \\
160^{\circ}\end{array}$ \\
\hline 1 & -0.56 & -0.78 & -0.98 & -0.71 & -1.00 & -0.92 & -1.10 & -1.26 & -1.21 \\
\hline 2 & 0 & -0.31 & -0.47 & -0.19 & -0.49 & -0.37 & -0.56 & -0.63 & -0.55 \\
\hline 3 & -0.16 & -0.52 & -0.65 & -0.39 & -0.66 & -0.55 & -0.73 & -0.72 & -0.59 \\
\hline 4 & -0.69 & -0.97 & -1.14 & -0.98 & -1.20 & -1.13 & -1.22 & -1.14 & -0.97 \\
\hline 5 & -3.83 & -4.18 & -4.47 & -4.58 & -4.89 & -4.79 & -4.65 & -4.50 & -4.31 \\
\hline 6 & -1.96 & -2.44 & -2.90 & -3.18 & -3.66 & -3.61 & -3.45 & -3.21 & -2.92 \\
\hline 7 & -0.37 & -0.87 & -1.45 & -1.72 & -2.25 & -2.21 & -2.02 & -1.80 & -1.42 \\
\hline 8 & -0.30 & -0.80 & -1.39 & -1.67 & -2.14 & -2.09 & -1.88 & -1.73 & -1.36 \\
\hline Mic. & DI & DI & DI & DI & DI & DI & DI & DI & DI \\
Location & $180^{\circ}$ & $200^{\circ}$ & $220^{\circ}$ & $240^{\circ}$ & $260^{\circ}$ & $280^{\circ}$ & $300^{\circ}$ & $320^{\circ}$ & $340^{\circ}$ \\
\hline 1 & -0.98 & -0.70 & -0.79 & -0.99 & -1.26 & -1.59 & -1.05 & -1.35 & -1.43 \\
\hline 2 & -0.27 & -0.01 & -0.17 & -0.26 & -0.53 & -0.81 & -0.36 & -0.67 & -0.72 \\
\hline 3 & -0.36 & -0.03 & -0.22 & -0.38 & -0.68 & -0.90 & -0.47 & -0.76 & -0.84 \\
\hline 4 & -0.70 & -0.36 & -0.47 & -0.88 & -1.25 & -1.47 & -1.05 & -1.34 & -1.39 \\
\hline 5 & -3.85 & -3.60 & -3.60 & -4.46 & -4.82 & -5.31 & -4.77 & -4.85 & -4.89 \\
\hline 6 & -2.35 & -2.21 & -2.24 & -3.08 & -3.50 & -3.94 & -3.16 & -3.16 & -3.17 \\
\hline 7 & -0.93 & -0.72 & -0.87 & -1.48 & -1.86 & -2.23 & -1.50 & -1.46 & -1.39 \\
\hline 8 & -0.94 & -0.73 & -0.89 & -1.39 & -1.68 & -2.02 & -1.40 & -1.32 & -1.22 \\
\hline
\end{tabular}

Table E.18: Directivity index values $(\mathrm{dB})$ at all microphone locations, $1 / 3$ octave band center frequency: $1 \mathrm{kHz}$, maximum SPL in $1 / 3$ octave frequency band: $55 \mathrm{~dB}$ ref $20 \mu \mathrm{Pa}$.

\begin{tabular}{|c|c|c|c|c|c|c|c|c|c|}
\hline $\begin{array}{c}\text { Mic. } \\
\text { Location }\end{array}$ & DI $0^{\circ}$ & DI $20^{\circ}$ & DI $40^{\circ}$ & DI $60^{\circ}$ & DI $80^{\circ}$ & $\begin{array}{c}\text { DI } \\
100^{\circ}\end{array}$ & $\begin{array}{c}\text { DI } \\
120^{\circ}\end{array}$ & $\begin{array}{c}\text { DI } \\
140^{\circ}\end{array}$ & $\begin{array}{c}\text { DI } \\
160^{\circ}\end{array}$ \\
\hline 1 & -1.56 & -1.35 & -1.62 & -1.55 & -2.03 & -1.75 & -1.94 & -1.60 & -1.96 \\
\hline 2 & -1.13 & -1.01 & -1.31 & -1.27 & -1.75 & -1.52 & -1.67 & -1.27 & -1.58 \\
\hline 3 & -1.14 & -1.04 & -1.47 & -1.47 & -2.02 & -1.75 & -1.85 & -1.38 & -1.56 \\
\hline 4 & -0.06 & 0.00 & -0.52 & -0.65 & -1.24 & -1.00 & -0.96 & -0.42 & -0.45 \\
\hline 5 & -2.23 & -2.25 & -2.91 & -3.17 & -3.73 & -3.52 & -3.34 & -2.66 & -2.52 \\
\hline 6 & -4.37 & -4.48 & -5.23 & -5.67 & -6.30 & -5.97 & -5.68 & -4.78 & -4.47 \\
\hline 7 & -4.75 & -5.00 & -5.95 & -6.55 & -7.41 & -7.03 & -6.51 & -5.47 & -4.95 \\
\hline 8 & -2.99 & -3.28 & -4.29 & -4.97 & -5.86 & -5.46 & -4.95 & -3.86 & -3.39 \\
\hline Mic. & DI & DI & DI & DI & DI & DI & DI & DI & DI \\
Location & $180^{\circ}$ & $200^{\circ}$ & $220^{\circ}$ & $240^{\circ}$ & $260^{\circ}$ & $280^{\circ}$ & $300^{\circ}$ & $320^{\circ}$ & $340^{\circ}$ \\
\hline 1 & -1.73 & -1.72 & -2.06 & -2.41 & -2.25 & -2.52 & -2.25 & -2.50 & -2.37 \\
\hline 2 & -1.31 & -1.25 & -1.57 & -1.92 & -1.77 & -2.01 & -1.77 & -2.04 & -1.93 \\
\hline 3 & -1.24 & -1.18 & -1.51 & -1.86 & -1.72 & -1.92 & -1.73 & -1.98 & -1.88 \\
\hline 4 & -0.07 & -0.05 & -0.40 & -0.84 & -0.75 & -0.98 & -0.75 & -0.95 & -0.85 \\
\hline 5 & -2.10 & -2.12 & -2.59 & -3.16 & -3.10 & -3.31 & -3.08 & -3.23 & -3.18 \\
\hline 6 & -4.01 & -4.05 & -4.71 & -5.46 & -5.52 & -5.71 & -5.44 & -5.51 & -5.40 \\
\hline 7 & -4.49 & -4.58 & -5.29 & -6.27 & -6.46 & -6.82 & -6.25 & -6.16 & -5.79 \\
\hline 8 & -2.89 & -2.98 & -3.74 & -4.67 & -4.82 & -5.10 & -4.45 & -4.33 & -4.01 \\
\hline
\end{tabular}


Table E.19: Directivity index values (dB) at all microphone locations, $1 / 3$ octave band center frequency: $1.25 \mathrm{kHz}$, maximum SPL in $1 / 3$ octave frequency band: $57 \mathrm{~dB}$ ref $20 \mu \mathrm{Pa}$.

\begin{tabular}{|c|c|c|c|c|c|c|c|c|c|}
\hline $\begin{array}{c}\text { Mic. } \\
\text { Location }\end{array}$ & DI $0^{\circ}$ & DI $20^{\circ}$ & DI $40^{\circ}$ & DI $60^{\circ}$ & DI $80^{\circ}$ & $\begin{array}{c}\text { DI } \\
100^{\circ}\end{array}$ & $\begin{array}{c}\text { DI } \\
120^{\circ}\end{array}$ & $\begin{array}{c}\text { DI } \\
140^{\circ}\end{array}$ & $\begin{array}{c}\text { DI } \\
160^{\circ}\end{array}$ \\
\hline 1 & -3.28 & -3.59 & -3.95 & -3.63 & -4.06 & -3.84 & -4.01 & -4.08 & -4.16 \\
\hline 2 & -2.56 & -3.00 & -3.43 & -3.21 & -3.66 & -3.48 & -3.68 & -3.63 & -3.65 \\
\hline 3 & -1.91 & -2.57 & -3.21 & -3.17 & -3.62 & -3.44 & -3.51 & -3.23 & -3.07 \\
\hline 4 & 0 & -0.82 & -1.63 & -1.91 & -2.45 & -2.25 & -2.18 & -1.63 & -1.29 \\
\hline 5 & -1.40 & -2.35 & -3.30 & -3.77 & -4.44 & -4.30 & -4.01 & -3.21 & -2.76 \\
\hline 6 & -1.76 & -2.71 & -3.81 & -4.44 & -5.29 & -5.19 & -4.64 & -3.70 & -3.00 \\
\hline 7 & -3.46 & -4.51 & -5.79 & -6.62 & -7.46 & -7.24 & -6.38 & -5.13 & -4.24 \\
\hline 8 & -3.74 & -4.91 & -6.45 & -7.48 & -8.48 & -8.24 & -7.15 & -5.68 & -4.75 \\
\hline Mic. & DI & DI & DI & DI & DI & DI & DI & DI & DI \\
Location & $180^{\circ}$ & $200^{\circ}$ & $220^{\circ}$ & $240^{\circ}$ & $260^{\circ}$ & $280^{\circ}$ & $300^{\circ}$ & $320^{\circ}$ & $340^{\circ}$ \\
\hline 1 & -3.95 & -4.05 & -4.25 & -4.40 & -4.40 & -4.47 & -4.77 & -4.32 & -4.43 \\
\hline 2 & -3.34 & -3.38 & -3.47 & -3.58 & -3.52 & -3.62 & -3.90 & -3.48 & -3.59 \\
\hline 3 & -2.67 & -2.79 & -2.71 & -3.01 & -2.82 & -2.92 & -3.19 & -2.71 & -2.84 \\
\hline 4 & -0.80 & -0.96 & -0.86 & -1.31 & -1.07 & -1.18 & -1.31 & -0.81 & -0.86 \\
\hline 5 & -2.14 & -2.29 & -2.32 & -2.80 & -2.63 & -2.83 & -2.80 & -2.32 & -2.34 \\
\hline 6 & -2.30 & -2.48 & -2.64 & -3.24 & -3.26 & -3.51 & -3.50 & -2.93 & -2.87 \\
\hline 7 & -3.64 & -3.98 & -4.32 & -5.19 & -5.23 & -5.51 & -5.48 & -4.83 & -4.62 \\
\hline 8 & -4.12 & -4.54 & -5.28 & -6.33 & -6.60 & -6.80 & -6.37 & -5.47 & -5.10 \\
\hline
\end{tabular}

Table E.20: Directivity index values (dB) at all microphone locations, $1 / 3$ octave band center frequency: $1.6 \mathrm{kHz}$, maximum SPL in $1 / 3$ octave frequency band: $58 \mathrm{~dB}$ ref $20 \mu \mathrm{Pa}$.

\begin{tabular}{|c|c|c|c|c|c|c|c|c|c|}
\hline $\begin{array}{c}\text { Mic. } \\
\text { Location }\end{array}$ & DI $0^{\circ}$ & DI $20^{\circ}$ & DI $40^{\circ}$ & DI $60^{\circ}$ & DI $80^{\circ}$ & $\begin{array}{c}\text { DI } \\
100^{\circ}\end{array}$ & $\begin{array}{c}\text { DI } \\
120^{\circ}\end{array}$ & $\begin{array}{c}\text { DI } \\
140^{\circ}\end{array}$ & $\begin{array}{c}\text { DI } \\
160^{\circ}\end{array}$ \\
\hline 1 & -5.09 & -5.30 & -5.41 & -5.62 & -5.62 & -5.36 & -5.70 & -5.61 & -5.70 \\
\hline 2 & -4.28 & -4.68 & -4.95 & -5.30 & -5.31 & -5.06 & -5.24 & -5.09 & -4.99 \\
\hline 3 & -3.81 & -4.30 & -4.69 & -5.23 & -5.45 & -5.08 & -5.02 & -4.63 & -4.34 \\
\hline 4 & -1.65 & -2.41 & -3.19 & -4.23 & -4.60 & -4.41 & -4.07 & -3.40 & -2.73 \\
\hline 5 & -1.05 & -2.02 & -3.25 & -4.78 & -5.53 & -5.26 & -4.67 & -3.45 & -2.50 \\
\hline 6 & -0.03 & -1.09 & -2.55 & -4.30 & -5.25 & -4.92 & -4.15 & -2.73 & -1.56 \\
\hline 7 & 0 & -1.02 & -2.32 & -3.81 & -4.58 & -4.10 & -3.46 & -2.10 & -0.95 \\
\hline 8 & -1.79 & -2.81 & -3.90 & -5.08 & -5.73 & -5.25 & -4.79 & -3.53 & -2.27 \\
\hline Mic. & DI & DI & DI & DI & DI & DI & DI & DI & DI \\
Location & $180^{\circ}$ & $200^{\circ}$ & $220^{\circ}$ & $240^{\circ}$ & $260^{\circ}$ & $280^{\circ}$ & $300^{\circ}$ & $320^{\circ}$ & $340^{\circ}$ \\
\hline 1 & -5.53 & -5.32 & -5.56 & -5.93 & -5.92 & -6.01 & -5.95 & -6.17 & -6.18 \\
\hline 2 & -4.72 & -4.43 & -4.74 & -5.11 & -5.00 & -5.17 & -5.19 & -5.39 & -5.33 \\
\hline 3 & -3.88 & -3.77 & -4.13 & -4.57 & -4.64 & -4.86 & -4.70 & -4.94 & -4.78 \\
\hline 4 & -2.15 & -1.93 & -2.34 & -2.95 & -3.08 & -3.20 & -2.91 & -2.84 & -2.58 \\
\hline 5 & -1.69 & -1.49 & -2.13 & -2.88 & -3.05 & -3.01 & -2.53 & -2.24 & -2.02 \\
\hline 6 & -0.63 & -0.57 & -1.30 & -2.14 & -2.24 & -2.17 & -1.62 & -1.29 & -1.02 \\
\hline 7 & -0.16 & -0.09 & -0.77 & -1.52 & -1.53 & -1.52 & -1.11 & -1.00 & -0.87 \\
\hline 8 & -1.48 & -1.62 & -2.31 & -3.18 & -3.14 & -3.29 & -3.09 & -3.04 & -2.86 \\
\hline
\end{tabular}


Table E.21: Directivity index values (dB) at all microphone locations, $1 / 3$ octave band center frequency: $2 \mathrm{kHz}$, maximum SPL in $1 / 3$ octave frequency band: $60 \mathrm{~dB}$ ref $20 \mu \mathrm{Pa}$.

\begin{tabular}{|c|c|c|c|c|c|c|c|c|c|}
\hline $\begin{array}{c}\text { Mic. } \\
\text { Location }\end{array}$ & DI $0^{\circ}$ & DI $20^{\circ}$ & DI $40^{\circ}$ & DI $60^{\circ}$ & DI $80^{\circ}$ & $\begin{array}{c}\text { DI } \\
100^{\circ}\end{array}$ & $\begin{array}{c}\text { DI } \\
120^{\circ}\end{array}$ & $\begin{array}{c}\text { DI } \\
140^{\circ}\end{array}$ & $\begin{array}{c}\text { DI } \\
160^{\circ}\end{array}$ \\
\hline 1 & -4.79 & -4.89 & -4.93 & -4.94 & -5.05 & -4.99 & -4.98 & -4.92 & -4.85 \\
\hline 2 & -2.75 & -3.16 & -3.64 & -3.93 & -4.34 & -4.38 & -4.28 & -4.08 & -3.70 \\
\hline 3 & -4.28 & -5.04 & -5.66 & -6.15 & -6.49 & -6.60 & -6.39 & -5.99 & -5.33 \\
\hline 4 & -2.85 & -3.79 & -4.76 & -5.64 & -6.32 & -6.50 & -6.10 & -5.16 & -4.09 \\
\hline 5 & -4.17 & -5.37 & -6.72 & -8.25 & -8.89 & -8.86 & -8.38 & -6.72 & -4.97 \\
\hline 6 & -2.20 & -3.60 & -5.54 & -7.64 & -8.33 & -8.47 & -7.72 & -5.55 & -3.28 \\
\hline 7 & 0 & -1.50 & -3.61 & -5.62 & -6.74 & -6.97 & -5.87 & -3.61 & -1.28 \\
\hline 8 & -0.30 & -2.12 & -4.16 & -5.69 & -6.04 & -5.95 & -5.07 & -3.07 & -1.12 \\
\hline Mic. & DI & DI & DI & DI & DI & DI & DI & DI & DI \\
Location & $180^{\circ}$ & $200^{\circ}$ & $220^{\circ}$ & $240^{\circ}$ & $260^{\circ}$ & $280^{\circ}$ & $300^{\circ}$ & $320^{\circ}$ & $340^{\circ}$ \\
\hline 1 & -4.92 & -5.00 & -5.09 & -5.48 & -5.54 & -5.24 & -5.54 & -5.65 & -5.62 \\
\hline 2 & -3.37 & -3.20 & -3.25 & -3.31 & -3.31 & -3.01 & -3.38 & -3.50 & -3.44 \\
\hline 3 & -4.94 & -4.63 & -4.28 & -4.45 & -4.20 & -3.85 & -4.16 & -4.35 & -4.63 \\
\hline 4 & -3.34 & -3.13 & -2.99 & -3.21 & -2.94 & -2.49 & -2.82 & -2.92 & -3.17 \\
\hline 5 & -4.30 & -4.44 & -5.05 & -5.87 & -5.79 & -5.42 & -5.50 & -5.33 & -5.21 \\
\hline 6 & -2.44 & -2.76 & -3.99 & -5.43 & -5.79 & -5.51 & -5.02 & -4.28 & -3.57 \\
\hline 7 & -0.34 & -0.71 & -2.13 & -3.57 & -4.12 & -3.70 & -3.06 & -2.10 & -1.14 \\
\hline 8 & -0.50 & -1.16 & -2.44 & -3.48 & -3.34 & -2.74 & -2.22 & -1.66 & -1.15 \\
\hline
\end{tabular}

Table E.22: Directivity index values (dB) at all microphone locations, $1 / 3$ octave band center frequency: $2.5 \mathrm{kHz}$, maximum SPL in $1 / 3$ octave frequency band: $61 \mathrm{~dB}$ ref $20 \mu \mathrm{Pa}$.

\begin{tabular}{|c|c|c|c|c|c|c|c|c|c|}
\hline $\begin{array}{c}\text { Mic. } \\
\text { Location }\end{array}$ & DI $0^{\circ}$ & DI $20^{\circ}$ & DI $40^{\circ}$ & DI $60^{\circ}$ & DI $80^{\circ}$ & $\begin{array}{c}\text { DI } \\
100^{\circ}\end{array}$ & $\begin{array}{c}\text { DI } \\
120^{\circ}\end{array}$ & $\begin{array}{c}\text { DI } \\
140^{\circ}\end{array}$ & $\begin{array}{c}\text { DI } \\
160^{\circ}\end{array}$ \\
\hline 1 & -6.54 & -6.48 & -6.37 & -6.54 & -6.67 & -6.50 & -6.62 & -6.45 & -6.57 \\
\hline 2 & -4.50 & -4.93 & -5.17 & -5.43 & -5.59 & -5.41 & -5.51 & -5.20 & -5.13 \\
\hline 3 & -4.99 & -5.76 & -6.32 & -6.64 & -6.86 & -6.63 & -6.62 & -6.06 & -5.70 \\
\hline 4 & -1.89 & -2.82 & -3.41 & -3.72 & -3.75 & -3.78 & -3.90 & -3.46 & -2.73 \\
\hline 5 & -2.27 & -3.30 & -3.90 & -3.94 & -3.55 & -3.88 & -4.68 & -4.34 & -3.30 \\
\hline 6 & -2.29 & -3.97 & -4.90 & -3.99 & -2.61 & -2.92 & -4.68 & -5.16 & -3.58 \\
\hline 7 & -1.03 & -3.09 & -4.34 & -3.32 & -1.96 & -2.62 & -4.72 & -4.53 & -2.17 \\
\hline 8 & 0 & -2.22 & -4.39 & -4.74 & -4.45 & -4.89 & -5.67 & -4.09 & -1.46 \\
\hline Mic. & DI & DI & DI & DI & DI & DI & DI & DI & DI \\
Location & $180^{\circ}$ & $200^{\circ}$ & $220^{\circ}$ & $240^{\circ}$ & $260^{\circ}$ & $280^{\circ}$ & $300^{\circ}$ & $320^{\circ}$ & $340^{\circ}$ \\
\hline 1 & -6.49 & -6.56 & -6.98 & -6.92 & -7.14 & -7.05 & -7.22 & -7.25 & -7.04 \\
\hline 2 & -4.74 & -4.50 & -4.65 & -4.32 & -4.43 & -4.46 & -4.81 & -5.04 & -4.89 \\
\hline 3 & -5.07 & -4.77 & -4.71 & -4.36 & -4.23 & -4.17 & -4.63 & -5.12 & -5.29 \\
\hline 4 & -1.85 & -1.61 & -1.74 & -1.52 & -1.36 & -1.38 & -1.75 & -2.15 & -2.26 \\
\hline 5 & -2.40 & -2.08 & -2.24 & -1.91 & -1.77 & -1.76 & -2.19 & -2.57 & -2.79 \\
\hline 6 & -2.35 & -2.48 & -2.98 & -2.37 & -1.82 & -1.90 & -2.69 & -3.30 & -3.18 \\
\hline 7 & -1.05 & -1.67 & -2.95 & -2.63 & -2.20 & -2.39 & -2.97 & -3.04 & -2.26 \\
\hline 8 & -0.30 & -0.92 & -2.52 & -2.88 & -3.12 & -3.03 & -2.85 & -2.30 & -1.09 \\
\hline
\end{tabular}


Table E.23: Directivity index values (dB) at all microphone locations, $1 / 3$ octave band center frequency: $3.15 \mathrm{kHz}$, maximum SPL in $1 / 3$ octave frequency band: $60 \mathrm{~dB}$ ref $20 \mu \mathrm{Pa}$.

\begin{tabular}{|c|c|c|c|c|c|c|c|c|c|}
\hline $\begin{array}{c}\text { Mic. } \\
\text { Location }\end{array}$ & DI $0^{\circ}$ & DI $20^{\circ}$ & DI $40^{\circ}$ & DI $60^{\circ}$ & DI $80^{\circ}$ & $\begin{array}{c}\text { DI } \\
100^{\circ}\end{array}$ & $\begin{array}{c}\text { DI } \\
120^{\circ}\end{array}$ & $\begin{array}{c}\text { DI } \\
140^{\circ}\end{array}$ & $\begin{array}{c}\text { DI } \\
160^{\circ}\end{array}$ \\
\hline 1 & -1.08 & -0.77 & -0.94 & -1.05 & -1.15 & -1.09 & -1.08 & -0.95 & -1.11 \\
\hline 2 & -0.44 & -0.57 & -0.79 & -0.60 & -0.56 & -0.40 & -0.45 & -0.21 & -0.36 \\
\hline 3 & -3.44 & -3.78 & -3.69 & -2.77 & -2.19 & -1.86 & -2.06 & -2.00 & -2.59 \\
\hline 4 & -3.25 & -4.10 & -3.80 & -2.54 & -1.76 & -1.49 & -2.01 & -2.64 & -3.28 \\
\hline 5 & -3.44 & -4.60 & -4.50 & -3.51 & -2.80 & -2.58 & -3.48 & -4.38 & -4.36 \\
\hline 6 & -1.54 & -3.63 & -3.85 & -2.46 & -2.27 & -2.61 & -3.86 & -4.54 & -3.04 \\
\hline 7 & -0.58 & -3.00 & -3.47 & -0.92 & -0.07 & -0.53 & -2.46 & -4.16 & -1.93 \\
\hline 8 & -0.36 & -3.16 & -3.26 & -0.74 & 0.00 & -0.68 & -3.39 & -4.15 & -1.16 \\
\hline Mic. & DI & DI & DI & DI & DI & DI & DI & DI & DI \\
Location & $180^{\circ}$ & $200^{\circ}$ & $220^{\circ}$ & $240^{\circ}$ & $260^{\circ}$ & $280^{\circ}$ & $300^{\circ}$ & $320^{\circ}$ & $340^{\circ}$ \\
\hline 1 & -1.23 & -1.05 & -1.21 & -1.41 & -1.65 & -1.52 & -1.40 & -1.64 & -1.60 \\
\hline 2 & -0.29 & -0.13 & -0.11 & -0.20 & -0.21 & -0.24 & -0.28 & -0.58 & -0.52 \\
\hline 3 & -2.49 & -2.17 & -1.47 & -1.38 & -1.12 & -1.14 & -1.40 & -2.20 & -2.77 \\
\hline 4 & -2.74 & -2.05 & -1.04 & -0.48 & 0.24 & 0.56 & 0.35 & -0.78 & -2.16 \\
\hline 5 & -3.51 & -2.94 & -2.35 & -1.79 & -0.96 & -0.72 & -0.92 & -1.97 & -3.33 \\
\hline 6 & -1.55 & -1.31 & -1.45 & -1.22 & -1.15 & -1.01 & -1.02 & -1.67 & -2.04 \\
\hline 7 & -0.34 & -1.08 & -1.14 & -0.06 & 0.31 & 0.02 & -0.98 & -2.21 & -1.86 \\
\hline 8 & 0.02 & -1.07 & -1.60 & -0.56 & -0.13 & -0.60 & -1.48 & -1.96 & -1.28 \\
\hline
\end{tabular}

Table E.24: Directivity index values (dB) at all microphone locations, $1 / 3$ octave band center frequency: $4 \mathrm{kHz}$, maximum SPL in $1 / 3$ octave frequency band: $63 \mathrm{~dB}$ ref $20 \mu \mathrm{Pa}$.

\begin{tabular}{|c|c|c|c|c|c|c|c|c|c|}
\hline $\begin{array}{c}\text { Mic. } \\
\text { Location }\end{array}$ & DI $0^{\circ}$ & DI $20^{\circ}$ & DI $40^{\circ}$ & DI $60^{\circ}$ & DI $80^{\circ}$ & $\begin{array}{c}\text { DI } \\
100^{\circ}\end{array}$ & $\begin{array}{c}\text { DI } \\
120^{\circ}\end{array}$ & $\begin{array}{c}\text { DI } \\
140^{\circ}\end{array}$ & $\begin{array}{c}\text { DI } \\
160^{\circ}\end{array}$ \\
\hline 1 & -0.07 & 0.00 & -0.05 & -0.42 & -0.17 & -0.23 & -0.36 & -0.25 & -0.25 \\
\hline 2 & -1.81 & -2.70 & -3.34 & -3.76 & -3.85 & -4.09 & -4.15 & -3.77 & -3.73 \\
\hline 3 & -3.29 & -4.12 & -5.36 & -6.14 & -5.57 & -4.67 & -4.02 & -3.31 & -3.38 \\
\hline 4 & -5.57 & -6.27 & -6.21 & -6.75 & -6.23 & -4.91 & -3.46 & -3.13 & -4.19 \\
\hline 5 & -4.75 & -6.63 & -5.70 & -5.06 & -4.76 & -3.90 & -3.26 & -3.77 & -5.47 \\
\hline 6 & -7.76 & -9.48 & -5.26 & -3.74 & -4.26 & -4.24 & -3.67 & -5.05 & -8.93 \\
\hline 7 & -4.21 & -6.92 & -2.51 & -0.77 & -1.65 & -2.24 & -2.78 & -5.22 & -6.47 \\
\hline 8 & -6.40 & -10.04 & -3.48 & -1.51 & -2.80 & -3.40 & -4.01 & -8.14 & -9.02 \\
\hline Mic. & DI & DI & DI & DI & DI & DI & DI & DI & DI \\
Location & $180^{\circ}$ & $200^{\circ}$ & $220^{\circ}$ & $240^{\circ}$ & $260^{\circ}$ & $280^{\circ}$ & $300^{\circ}$ & $320^{\circ}$ & $340^{\circ}$ \\
\hline 1 & -0.17 & -0.15 & -0.47 & -0.65 & -0.88 & -1.21 & -0.98 & -0.86 & -1.07 \\
\hline 2 & -3.21 & -3.05 & -2.86 & -2.61 & -2.33 & -2.62 & -2.48 & -2.12 & -2.21 \\
\hline 3 & -3.63 & -3.96 & -4.09 & -4.31 & -4.05 & -3.69 & -2.93 & -2.80 & -3.25 \\
\hline 4 & -4.88 & -4.72 & -4.12 & -4.25 & -3.91 & -3.23 & -2.34 & -2.64 & -4.20 \\
\hline 5 & -5.00 & -4.20 & -3.03 & -2.79 & -2.09 & -1.75 & -1.43 & -2.15 & -3.85 \\
\hline 6 & -7.36 & -6.25 & -3.45 & -2.45 & -2.85 & -3.26 & -2.98 & -4.25 & -6.89 \\
\hline 7 & -3.88 & -3.20 & -0.89 & 0.29 & -0.58 & -1.59 & -1.86 & -3.08 & -3.90 \\
\hline 8 & -5.76 & -4.97 & -1.37 & -0.30 & -1.54 & -2.57 & -3.78 & -7.31 & -7.82 \\
\hline
\end{tabular}


Table E.25: Directivity index values (dB) at all microphone locations, $1 / 3$ octave band center frequency: $5 \mathrm{kHz}$, maximum SPL in $1 / 3$ octave frequency band: $65 \mathrm{~dB}$ ref $20 \mu \mathrm{Pa}$.

\begin{tabular}{|c|c|c|c|c|c|c|c|c|c|}
\hline $\begin{array}{c}\text { Mic. } \\
\text { Location }\end{array}$ & DI $0^{\circ}$ & DI $20^{\circ}$ & DI $40^{\circ}$ & DI $60^{\circ}$ & DI $80^{\circ}$ & $\begin{array}{c}\text { DI } \\
100^{\circ}\end{array}$ & $\begin{array}{c}\text { DI } \\
120^{\circ}\end{array}$ & $\begin{array}{c}\text { DI } \\
140^{\circ}\end{array}$ & $\begin{array}{c}\text { DI } \\
160^{\circ}\end{array}$ \\
\hline 1 & -1.28 & -1.42 & -1.43 & -2.11 & -2.21 & -2.36 & -2.21 & -2.19 & -2.39 \\
\hline 2 & -1.38 & -2.25 & -2.60 & -2.98 & -3.20 & -3.18 & -3.14 & -2.80 & -3.22 \\
\hline 3 & -1.40 & -2.57 & -3.76 & -4.08 & -3.85 & -3.53 & -2.61 & -1.69 & -1.65 \\
\hline 4 & -2.42 & -3.10 & -3.74 & -4.72 & -4.32 & -3.40 & -1.94 & -1.06 & -1.85 \\
\hline 5 & -4.76 & -5.37 & -5.10 & -6.08 & -4.44 & -2.79 & -1.30 & -1.27 & -4.33 \\
\hline 6 & -10.86 & -10.84 & -6.66 & -5.89 & -6.83 & -5.24 & -3.95 & -5.66 & -12.56 \\
\hline 7 & -9.64 & -9.41 & -1.50 & 0.00 & -2.49 & -2.01 & -0.72 & -3.39 & -12.44 \\
\hline 8 & -7.75 & -8.26 & -1.75 & -0.80 & -3.00 & -3.45 & -4.16 & -8.06 & -12.71 \\
\hline Mic. & DI & DI & DI & DI & DI & DI & DI & DI & DI \\
Location & $180^{\circ}$ & $200^{\circ}$ & $220^{\circ}$ & $240^{\circ}$ & $260^{\circ}$ & $280^{\circ}$ & $300^{\circ}$ & $320^{\circ}$ & $340^{\circ}$ \\
\hline 1 & -2.49 & -1.99 & -2.49 & -2.40 & -2.53 & -2.82 & -2.76 & -3.04 & -3.00 \\
\hline 2 & -2.83 & -2.66 & -3.23 & -3.13 & -3.13 & -3.45 & -3.43 & -3.04 & -2.82 \\
\hline 3 & -1.41 & -1.99 & -3.08 & -3.86 & -4.05 & -3.50 & -2.31 & -1.91 & -1.87 \\
\hline 4 & -2.46 & -2.56 & -2.87 & -3.52 & -3.77 & -3.29 & -1.39 & -0.90 & -1.51 \\
\hline 5 & -6.09 & -5.83 & -3.26 & -2.68 & -2.64 & -2.70 & -1.34 & -1.66 & -3.96 \\
\hline 6 & -13.58 & -10.66 & -4.72 & -3.25 & -3.99 & -4.52 & -3.61 & -5.31 & -8.75 \\
\hline 7 & -10.72 & -6.51 & 0.64 & 1.91 & 0.13 & -0.57 & -0.23 & -3.52 & -6.99 \\
\hline 8 & -9.20 & -5.79 & -0.07 & 0.99 & -0.57 & -1.85 & -2.69 & -7.11 & -8.10 \\
\hline
\end{tabular}

Table E.26: Directivity index values (dB) at all microphone locations, $1 / 3$ octave band center frequency: $6.3 \mathrm{kHz}$, maximum SPL in $1 / 3$ octave frequency band: $67 \mathrm{~dB}$ ref $20 \mu \mathrm{Pa}$.

\begin{tabular}{|c|c|c|c|c|c|c|c|c|c|}
\hline $\begin{array}{c}\text { Mic. } \\
\text { Location }\end{array}$ & DI $0^{\circ}$ & DI $20^{\circ}$ & DI $40^{\circ}$ & DI $60^{\circ}$ & DI $80^{\circ}$ & $\begin{array}{c}\text { DI } \\
100^{\circ}\end{array}$ & $\begin{array}{c}\text { DI } \\
120^{\circ}\end{array}$ & $\begin{array}{c}\text { DI } \\
140^{\circ}\end{array}$ & $\begin{array}{c}\text { DI } \\
160^{\circ}\end{array}$ \\
\hline 1 & -5.44 & -5.48 & -5.46 & -6.04 & -6.08 & -6.28 & -6.10 & -6.24 & -6.10 \\
\hline 2 & -5.01 & -5.02 & -4.36 & -3.55 & -3.18 & -3.16 & -3.93 & -4.50 & -5.33 \\
\hline 3 & -5.72 & -5.84 & -5.32 & -3.48 & -2.46 & -2.60 & -4.30 & -5.65 & -6.40 \\
\hline 4 & -3.14 & -3.42 & -4.74 & -2.94 & -0.21 & 0.00 & -1.51 & -2.63 & -4.01 \\
\hline 5 & -4.74 & -5.27 & -8.33 & -7.73 & -3.16 & -2.86 & -4.10 & -6.08 & -9.20 \\
\hline 6 & -10.83 & -7.80 & -9.08 & -9.65 & -5.57 & -4.77 & -5.64 & -8.89 & -12.74 \\
\hline 7 & -8.69 & -6.12 & -4.76 & -3.43 & -2.13 & -1.22 & -3.09 & -8.79 & -8.29 \\
\hline 8 & -9.33 & -9.16 & -4.91 & -3.88 & -3.86 & -3.37 & -6.49 & -12.22 & -9.55 \\
\hline Mic. & DI & DI & DI & DI & DI & DI & DI & DI & DI \\
Location & $180^{\circ}$ & $200^{\circ}$ & $220^{\circ}$ & $240^{\circ}$ & $260^{\circ}$ & $280^{\circ}$ & $300^{\circ}$ & $320^{\circ}$ & $340^{\circ}$ \\
\hline 1 & -6.37 & -6.00 & -6.14 & -6.15 & -6.87 & -6.81 & -6.71 & -6.61 & -6.45 \\
\hline 2 & -5.42 & -5.56 & -5.49 & -5.47 & -6.02 & -6.97 & -8.18 & -8.20 & -7.48 \\
\hline 3 & -6.09 & -6.33 & -5.43 & -4.59 & -3.91 & -5.24 & -7.57 & -8.30 & -7.54 \\
\hline 4 & -4.43 & -4.92 & -3.72 & -1.83 & -0.77 & -2.59 & -3.98 & -3.99 & -4.01 \\
\hline 5 & -8.69 & -7.38 & -5.52 & -3.92 & -1.31 & -3.27 & -4.72 & -5.14 & -6.82 \\
\hline 6 & -12.51 & -10.80 & -7.18 & -5.75 & -2.85 & -4.29 & -5.22 & -7.78 & -15.02 \\
\hline 7 & -11.10 & -10.92 & -2.38 & -1.36 & 0.61 & -0.71 & -1.85 & -4.22 & -12.08 \\
\hline 8 & -9.00 & -12.17 & -2.90 & -2.58 & -1.13 & -2.87 & -3.82 & -6.72 & -13.90 \\
\hline
\end{tabular}


Table E.27: Directivity index values (dB) at all microphone locations, $1 / 3$ octave band center frequency: $8 \mathrm{kHz}$, maximum SPL in $1 / 3$ octave frequency band: $68 \mathrm{~dB}$ ref $20 \mu \mathrm{Pa}$.

\begin{tabular}{|c|c|c|c|c|c|c|c|c|c|}
\hline $\begin{array}{c}\text { Mic. } \\
\text { Location }\end{array}$ & DI $0^{\circ}$ & DI $20^{\circ}$ & DI $40^{\circ}$ & DI $60^{\circ}$ & DI $80^{\circ}$ & $\begin{array}{c}\text { DI } \\
100^{\circ}\end{array}$ & $\begin{array}{c}\text { DI } \\
120^{\circ}\end{array}$ & $\begin{array}{c}\text { DI } \\
140^{\circ}\end{array}$ & $\begin{array}{c}\text { DI } \\
160^{\circ}\end{array}$ \\
\hline 1 & -3.03 & -2.61 & -2.81 & -3.39 & -3.33 & -3.29 & -2.86 & -2.87 & -2.90 \\
\hline 2 & -4.22 & -4.54 & -4.27 & -3.54 & -3.22 & -3.15 & -4.50 & -5.38 & -6.96 \\
\hline 3 & -7.77 & -7.04 & -3.91 & -1.05 & -0.01 & -0.33 & -2.40 & -5.07 & -8.86 \\
\hline 4 & -5.97 & -9.22 & -6.25 & -2.20 & 0.00 & -0.42 & -2.10 & -4.27 & -8.93 \\
\hline 5 & -3.81 & -6.19 & -7.85 & -4.25 & -1.14 & -2.76 & -5.91 & -7.27 & -8.09 \\
\hline 6 & -12.95 & -7.04 & -9.58 & -11.15 & -5.01 & -6.78 & -11.02 & -12.41 & -11.59 \\
\hline 7 & -5.82 & -3.67 & -3.95 & -10.14 & -0.64 & -2.59 & -7.17 & -6.00 & -7.04 \\
\hline 8 & -5.47 & -8.55 & -9.04 & -12.39 & -3.86 & -6.07 & -9.79 & -7.70 & -7.97 \\
\hline Mic. & DI & DI & DI & DI & DI & DI & DI & DI & DI \\
Location & $180^{\circ}$ & $200^{\circ}$ & $220^{\circ}$ & $240^{\circ}$ & $260^{\circ}$ & $280^{\circ}$ & $300^{\circ}$ & $320^{\circ}$ & $340^{\circ}$ \\
\hline 1 & -3.15 & -2.35 & -2.78 & -2.73 & -3.57 & -3.41 & -3.21 & -3.44 & -3.59 \\
\hline 2 & -7.62 & -7.88 & -7.24 & -6.23 & -5.42 & -5.31 & -5.11 & -5.01 & -4.41 \\
\hline 3 & -10.59 & -9.61 & -4.14 & -2.13 & -1.63 & -2.98 & -4.86 & -6.32 & -7.74 \\
\hline 4 & -10.34 & -10.12 & -3.76 & -1.14 & -0.85 & -3.88 & -7.32 & -7.08 & -6.73 \\
\hline 5 & -7.28 & -8.25 & -6.18 & -2.94 & -1.51 & -5.30 & -9.37 & -9.03 & -5.74 \\
\hline 6 & -11.32 & -8.82 & -10.51 & -7.78 & -3.75 & -6.21 & -10.79 & -11.43 & -13.45 \\
\hline 7 & -14.26 & -5.72 & -5.11 & -5.67 & 1.32 & -0.48 & -2.96 & -4.55 & -8.14 \\
\hline 8 & -8.58 & -10.33 & -9.05 & -6.93 & -1.50 & -3.97 & -5.60 & -6.17 & -9.06 \\
\hline
\end{tabular}

Table E.28: Directivity index values $(\mathrm{dB})$ at all microphone locations, $1 / 3$ octave band center frequency: $10 \mathrm{kHz}$, maximum SPL in $1 / 3$ octave frequency band: $68 \mathrm{~dB}$ ref $20 \mu \mathrm{Pa}$.

\begin{tabular}{|c|c|c|c|c|c|c|c|c|c|}
\hline $\begin{array}{c}\text { Mic. } \\
\text { Location }\end{array}$ & DI $0^{\circ}$ & DI $20^{\circ}$ & DI $40^{\circ}$ & DI $60^{\circ}$ & DI $80^{\circ}$ & $\begin{array}{c}\text { DI } \\
100^{\circ}\end{array}$ & $\begin{array}{c}\text { DI } \\
120^{\circ}\end{array}$ & $\begin{array}{c}\text { DI } \\
140^{\circ}\end{array}$ & $\begin{array}{c}\text { DI } \\
160^{\circ}\end{array}$ \\
\hline 1 & -3.39 & -3.12 & -3.06 & -4.12 & -4.38 & -4.66 & -4.31 & -4.71 & -4.06 \\
\hline 2 & -3.01 & -2.77 & -1.83 & -1.48 & -1.41 & -1.05 & -2.35 & -3.39 & -5.33 \\
\hline 3 & -5.09 & -5.19 & -4.67 & -3.81 & -2.56 & -1.52 & -1.18 & -3.01 & -7.40 \\
\hline 4 & -9.86 & -8.03 & -5.58 & -4.31 & -3.11 & -2.71 & -3.46 & -7.00 & -11.46 \\
\hline 5 & -5.06 & -6.09 & -3.00 & -1.29 & 0.00 & -0.46 & -6.40 & -9.53 & -9.74 \\
\hline 6 & -14.57 & -6.71 & -7.52 & -10.58 & -6.18 & -6.20 & -16.12 & -15.90 & -7.47 \\
\hline 7 & -2.09 & -4.71 & -4.26 & -12.17 & -2.30 & -1.82 & -12.85 & -2.05 & -8.91 \\
\hline 8 & -3.12 & -10.28 & -9.49 & -13.81 & -5.08 & -4.31 & -14.99 & -4.56 & -4.42 \\
\hline Mic. & DI & DI & DI & DI & DI & DI & DI & DI & DI \\
Location & $180^{\circ}$ & $200^{\circ}$ & $220^{\circ}$ & $240^{\circ}$ & $260^{\circ}$ & $280^{\circ}$ & $300^{\circ}$ & $320^{\circ}$ & $340^{\circ}$ \\
\hline 1 & -4.58 & -3.66 & -4.15 & -3.92 & -5.25 & -4.99 & -4.62 & -4.76 & -4.96 \\
\hline 2 & -6.00 & -6.45 & -5.54 & -4.86 & -4.53 & -4.64 & -4.68 & -4.65 & -3.75 \\
\hline 3 & -7.60 & -9.96 & -5.21 & -3.92 & -3.22 & -4.56 & -5.40 & -5.46 & -5.36 \\
\hline 4 & -13.88 & -10.00 & -4.37 & -2.49 & -2.70 & -4.78 & -8.98 & -9.89 & -8.13 \\
\hline 5 & -8.36 & -6.61 & -3.55 & -1.80 & -0.99 & -2.45 & -8.04 & -8.36 & -6.24 \\
\hline 6 & -9.13 & -10.53 & -9.79 & -7.75 & -3.87 & -5.55 & -12.43 & -11.93 & -10.94 \\
\hline 7 & -10.34 & -7.17 & -9.06 & -5.04 & 0.43 & 0.33 & -4.18 & -7.28 & -5.93 \\
\hline 8 & -5.99 & -10.92 & -10.05 & -5.87 & -2.83 & -2.20 & -6.24 & -11.14 & -9.86 \\
\hline
\end{tabular}


Table E.29: Background SPL measurements (dB ref $20 \mu \mathrm{Pa}$ ) for directivity testing. *Multiple types of microphones were utilized in this testing accounting for the differences in the background levels measured.

\begin{tabular}{|c|c|c|c|c|c|c|c|c|c|}
\hline $\begin{array}{c}\text { Mic. } \\
\text { Location }\end{array}$ & $20 \mathrm{~Hz}$ & $25 \mathrm{~Hz}$ & $\begin{array}{c}31.5 \\
\mathrm{~Hz}\end{array}$ & $40 \mathrm{~Hz}$ & $50 \mathrm{~Hz}$ & $63 \mathrm{~Hz}$ & $80 \mathrm{~Hz}$ & $100 \mathrm{~Hz}$ & $125 \mathrm{~Hz}$ \\
\hline 1 & 45.15 & 44.18 & 42.43 & 42.50 & 43.67 & 44.98 & 44.91 & 44.80 & 44.42 \\
\hline 2 & 46.75 & 45.96 & 44.37 & 44.60 & 45.73 & 47.15 & 47.03 & 46.90 & 46.53 \\
\hline 3 & 47.66 & 47.10 & 45.54 & 45.93 & 47.04 & 48.54 & 48.41 & 48.28 & 47.93 \\
\hline 4 & 47.66 & 46.79 & 45.17 & 45.39 & 46.51 & 47.91 & 477.87 & 47.67 & 47.36 \\
\hline 5 & 39.63 & 37.73 & 33.21 & 31.04 & 32.28 & 33.38 & 33.48 & 32.87 & 32.62 \\
\hline 6 & 39.44 & 37.72 & 33.29 & 31.05 & 31.71 & 32.64 & 33.00 & 32.20 & 31.95 \\
\hline 7 & 39.67 & 37.87 & 33.22 & 30.81 & 32.32 & 33.16 & 34.06 & 32.65 & 32.34 \\
\hline 8 & 37.65 & 36.83 & 31.27 & 24.36 & 24.32 & 24.25 & 23.27 & 17.43 & 15.54 \\
\hline $\begin{array}{c}\text { Mic. } \\
\text { Location }\end{array}$ & $160 \mathrm{~Hz}$ & $200 \mathrm{~Hz}$ & $250 \mathrm{~Hz}$ & $315 \mathrm{~Hz}$ & $400 \mathrm{~Hz}$ & $500 \mathrm{~Hz}$ & $630 \mathrm{~Hz}$ & $800 \mathrm{~Hz}$ & $1 \mathrm{kHz}$ \\
\hline 1 & 43.43 & 42.45 & 42.12 & 41.36 & 40.40 & 39.88 & 38.31 & 37.39 & 36.62 \\
\hline 2 & 45.52 & 44.57 & 44.25 & 43.48 & 42.51 & 42.05 & 40.43 & 39.49 & 38.73 \\
\hline 3 & 46.94 & 45.98 & 45.64 & 44.88 & 43.92 & 43.43 & 41.84 & 40.87 & 40.10 \\
\hline 4 & 46.33 & 45.34 & 45.06 & 44.31 & 43.32 & 42.87 & 41.28 & 40.26 & 39.56 \\
\hline 5 & 31.54 & 30.51 & 30.20 & 29.44 & 28.50 & 28.03 & 26.41 & 25.49 & 24.67 \\
\hline 6 & 30.79 & 29.78 & 29.58 & 28.72 & 27.86 & 27.37 & 25.74 & 24.73 & 24.01 \\
\hline 7 & 31.24 & 30.30 & 30.26 & 29.18 & 28.60 & 28.10 & 26.61 & 25.52 & 24.79 \\
\hline 8 & 8.50 & 7.74 & 11.12 & 3.54 & 10.70 & 10.42 & 9.79 & 9.40 & 10.02 \\
\hline $\begin{array}{c}\text { Mic. } \\
\text { Location }\end{array}$ & $\begin{array}{l}1.25 \\
\mathrm{kHz}\end{array}$ & $\begin{array}{c}1.6 \\
\mathrm{kHz}\end{array}$ & $2 \mathrm{kHz}$ & $\begin{array}{c}2.5 \\
\mathrm{kHz}\end{array}$ & $3 \mathrm{kHz}$ & $4 \mathrm{kHz}$ & $5 \mathrm{kHz}$ & $\begin{array}{c}6.3 \\
\mathrm{kHz}\end{array}$ & $8 \mathrm{kHz}$ \\
\hline 1 & 35.57 & 34.61 & 33.56 & 32.77 & 31.78 & 30.84 & 29.86 & 29.22 & 28.54 \\
\hline 2 & 37.66 & 36.68 & 35.74 & 34.87 & 33.84 & 32.99 & 31.98 & 31.39 & 30.72 \\
\hline 3 & 39.04 & 38.21 & 37.14 & 36.25 & 35.30 & 34.32 & 33.43 & 32.80 & 32.05 \\
\hline 4 & 38.42 & 37.51 & 36.54 & 35.69 & 34.71 & 33.67 & 32.72 & 32.06 & 31.47 \\
\hline 5 & 23.62 & 22.77 & 21.73 & 20.92 & 20.03 & 19.18 & 18.43 & 17.87 & 17.37 \\
\hline 6 & 22.96 & 22.10 & 21.19 & 20.33 & 19.53 & 18.51 & 17.68 & 17.12 & 16.44 \\
\hline 7 & 24.18 & 23.41 & 22.60 & 21.84 & 21.05 & 20.09 & 18.98 & 18.44 & 17.76 \\
\hline 8 & 10.13 & 10.65 & 10.70 & 10.80 & 10.87 & 10.84 & 10.99 & 11.37 & 11.76 \\
\hline $\begin{array}{c}\text { Mic. } \\
\text { Location }\end{array}$ & $10 \mathrm{kHz}$ & & & & & & & & \\
\hline 1 & 28.28 & & & & & & & & \\
\hline 2 & 30.43 & & & & & & & & \\
\hline 3 & 31.70 & & & & & & & & \\
\hline 4 & 31.20 & & & & & & & & \\
\hline 5 & 17.23 & & & & & & & & \\
\hline 6 & 16.32 & & & & & & & & \\
\hline 7 & 17.30 & & & & & & & & \\
\hline 8 & 12.23 & & & & & & & & \\
\hline
\end{tabular}




\section{Appendix F — CNT Hot-film Microphone Experimentation}

\section{Results}

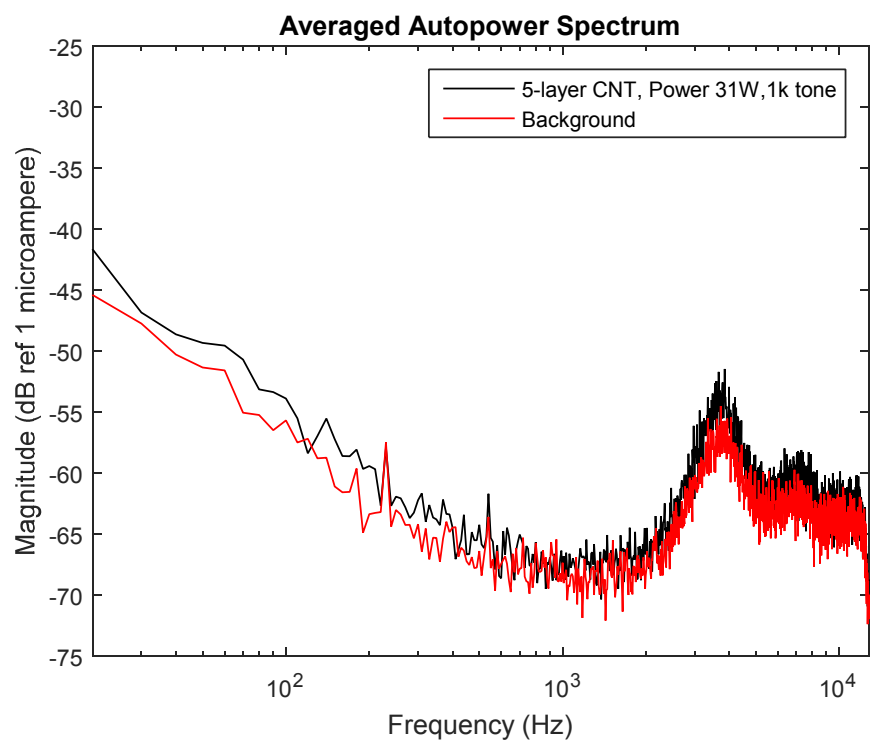

Figure F.1: Averaged autopower spectra of current signals through CNT assembly. 5-layer CNT, Power 31W, 1 kHz tone, Amplitude @ 1 kHz: -69 dB ref 1mA Background, Amplitude@1 kHz:-67 dB ref 1 mA

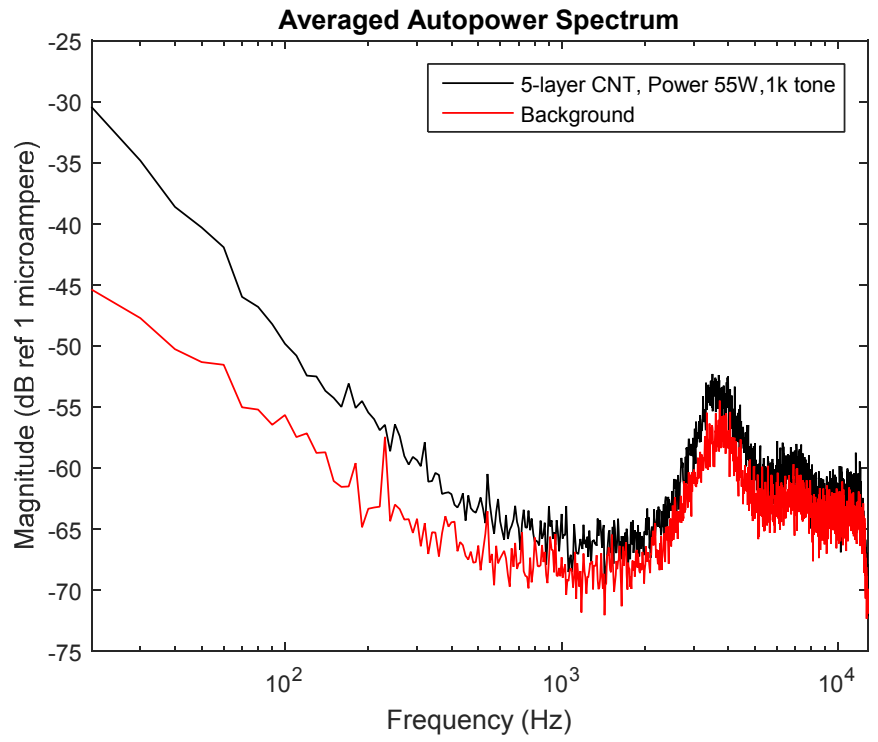

Figure F.2: Averaged autopower spectra of current signals through CNT assembly. 5-layer CNT, Power 55W, 1 kHz tone, Amplitude @ 1 kHz: -64 dB ref 1mA Background, Amplitude@1 kHz:-67 dB ref 1 mA 


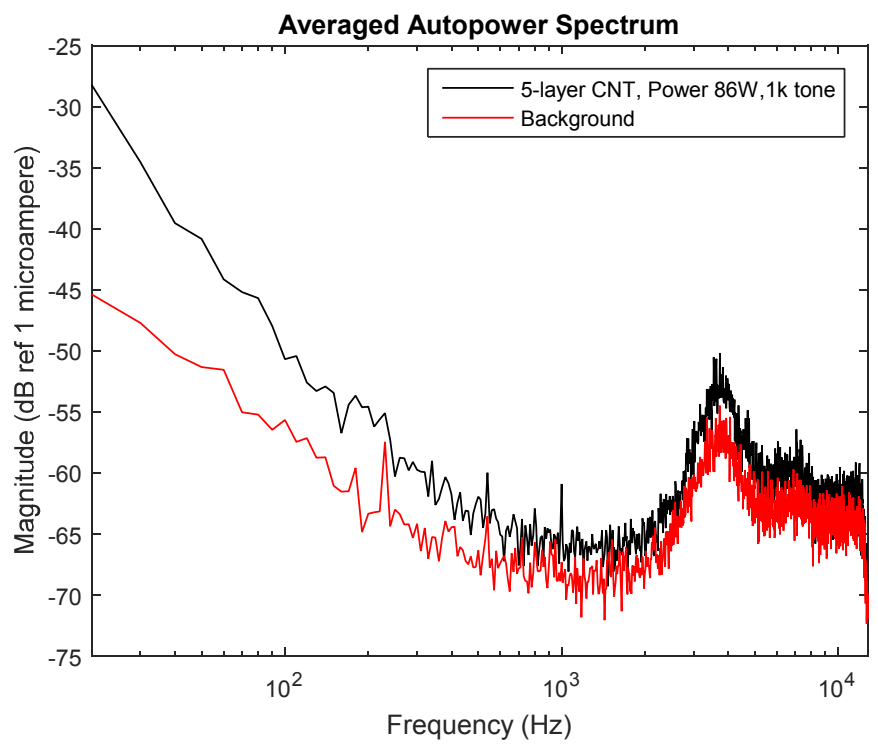

Figure F.3: Averaged autopower spectra of current signals through CNT assembly. 5-layer CNT, Power 86W, $1 \mathrm{kHz}$ tone, Amplitude @ $1 \mathrm{kHz}$ - $61 \mathrm{~dB}$ ref 1mA Background, Amplitude @ 1 kHz: -67 dB ref 1 mA 


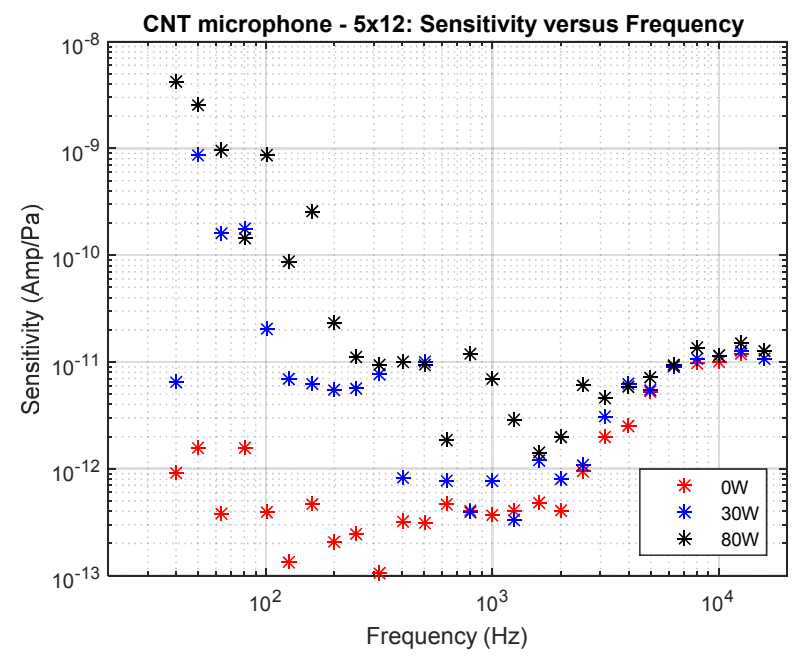

Figure F.4: Sensitivity versus frequency tone played, $5 \mathrm{~cm} \mathrm{x} 12 \mathrm{~cm}$ CNT assembly.

Table F.1: Amplitudes of current signals ( $\mathrm{dB}$ ref $1 \mathrm{~mA})$ at the frequency of the pure tone played for $5 \mathrm{~cm} \times 12 \mathrm{~cm}$ CNT assembly.

\begin{tabular}{|c|c|c|c|c|c|c|}
\hline $\begin{array}{c}\text { Frequency tone } \\
\text { played/ } \\
\text { Frequency at } \\
\text { which } \\
\text { current } \\
\text { amplitude occurs } \\
\end{array}$ & $\begin{array}{c}\text { Background } \\
\text { no tone } \\
\text { played, } \\
5 \times 12 \mathrm{CNT} \text {, } \\
\text { 0W }\end{array}$ & $\begin{array}{c}5 \times 12 \\
\text { CNT, } \\
0 \mathrm{~W}\end{array}$ & $\begin{array}{c}\text { Background } \\
\text { no tone } \\
\text { played, } \\
5 \times 12 \mathrm{CNT} \text {, } \\
30 \mathrm{~W}\end{array}$ & $\begin{array}{l}5 \times 12 \\
\text { CNT, } \\
30 \mathrm{~W}\end{array}$ & $\begin{array}{l}\text { Background } \\
\text { no tone } \\
\text { played, } \\
5 \text { x } 12 \mathrm{CNT} \text {, } \\
80 \mathrm{~W}\end{array}$ & $\begin{array}{c}5 \times 12 \\
\text { CNT, } 80 \mathrm{~W}\end{array}$ \\
\hline $40 \mathrm{~Hz}$ & -80.96 & -84.61 & -33.23 & -67.58 & -25.61 & -11.13 \\
\hline $50 \mathrm{~Hz}$ & -94.18 & -81.07 & -37.55 & -26.23 & -29.65 & -16.84 \\
\hline $63 \mathrm{~Hz}$ & -83.13 & -93.02 & -40.66 & -40.65 & -33.04 & -25.25 \\
\hline $80 \mathrm{~Hz}$ & -92.25 & -78.59 & -45.11 & -37.45 & -38.10 & -39.10 \\
\hline $100 \mathrm{~Hz}$ & -93.32 & -89.33 & -48.86 & -54.98 & -41.72 & -22.61 \\
\hline $125 \mathrm{~Hz}$ & -91.02 & -98.69 & -53.08 & -64.57 & -45.08 & -42.52 \\
\hline $160 \mathrm{~Hz}$ & -90.05 & -87.81 & -56.69 & -65.27 & -50.22 & -33.06 \\
\hline $200 \mathrm{~Hz}$ & -97.82 & -94.55 & -59.75 & -66.10 & -53.22 & -53.35 \\
\hline $250 \mathrm{~Hz}$ & -95.77 & -92.36 & -65.88 & -65.04 & -57.07 & -59.40 \\
\hline $315 \mathrm{~Hz}$ & -111.90 & -99.36 & -68.29 & -62.29 & -61.93 & -60.53 \\
\hline $400 \mathrm{~Hz}$ & -96.47 & -89.46 & -73.09 & -81.39 & -65.59 & -59.47 \\
\hline $500 \mathrm{~Hz}$ & -107.07 & -89.79 & -77.76 & -59.68 & -68.46 & -60.07 \\
\hline $630 \mathrm{~Hz}$ & -97.24 & -85.90 & -79.66 & -81.65 & -72.31 & -73.90 \\
\hline $800 \mathrm{~Hz}$ & -102.73 & -87.17 & -83.78 & -87.47 & -76.95 & -57.72 \\
\hline $1 \mathrm{kHz}$ & -93.51 & -87.74 & -89.30 & -81.45 & -80.59 & -62.44 \\
\hline $1.25 \mathrm{kHz}$ & -102.16 & -87.39 & -86.31 & -89.00 & -80.28 & -70.28 \\
\hline $1.6 \mathrm{kHz}$ & -94.99 & -85.60 & -93.18 & -77.59 & -94.86 & -76.26 \\
\hline $2 \mathrm{kHz}$ & -92.06 & -86.56 & -78.80 & -80.70 & -86.93 & -72.95 \\
\hline $2.5 \mathrm{kHz}$ & -92.72 & -79.98 & -77.87 & -78.85 & -73.89 & -63.95 \\
\hline $3.15 \mathrm{kHz}$ & -79.72 & -74.28 & -74.85 & -70.64 & -64.22 & -66.98 \\
\hline $4 \mathrm{kHz}$ & -71.86 & -71.39 & -80.93 & -63.49 & -80.42 & -64.04 \\
\hline $5 \mathrm{kHz}$ & -82.48 & -64.52 & -84.77 & -64.41 & -87.35 & -62.14 \\
\hline $6.3 \mathrm{kHz}$ & -87.96 & -60.97 & -99.95 & -61.05 & -92.69 & -60.53 \\
\hline $8 \mathrm{kHz}$ & -97.54 & -59.99 & -108.48 & -59.21 & -97.37 & -57.13 \\
\hline $10 \mathrm{kHz}$ & -87.53 & -59.51 & -117.26 & -58.38 & -116.19 & -58.51 \\
\hline $12.5 \mathrm{kHz}$ & -88.00 & -58.35 & -110.20 & -57.69 & -107.80 & -56.26 \\
\hline $16 \mathrm{kHz}$ & -92.95 & -57.67 & -109.74 & -59.27 & -104.37 & -57.67 \\
\hline
\end{tabular}




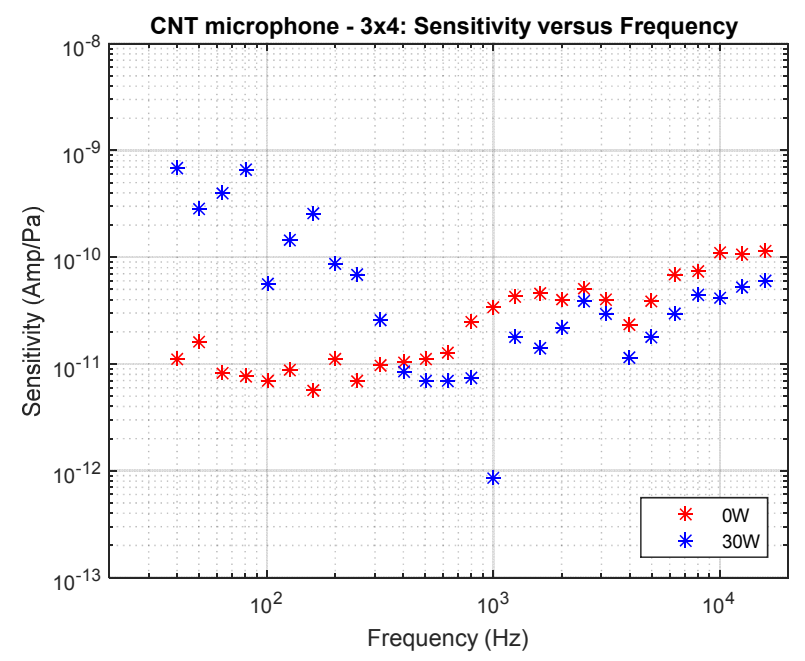

Figure F.5: Sensitivity versus frequency tone played, $3 \mathrm{~cm} \mathrm{x} 4 \mathrm{~cm}$ CNT assembly.

Table F.2: Amplitudes of current signals ( $\mathrm{dB}$ ref $1 \mathrm{~mA})$ at the frequency of the pure tone played for $3 \mathrm{~cm} \mathrm{x} 4 \mathrm{~cm}$ CNT assembly.

\begin{tabular}{|c|c|c|c|c|}
\hline $\begin{array}{l}\text { Frequency tone } \\
\text { played/ } \\
\text { Frequency at which } \\
\text { current amplitude } \\
\text { occurs }\end{array}$ & $\begin{array}{c}\text { Background } \\
\text { no tone played, } \\
3 \times 4 \text { CNT, } \\
\text { 0W }\end{array}$ & $\begin{array}{c}3 \times 4 \\
\text { CNT, } 0 \mathrm{~W}\end{array}$ & $\begin{array}{c}\text { Background } \\
\text { no tone played, } \\
3 \times 4 \mathrm{CNT}, \\
30 \mathrm{~W}\end{array}$ & $\begin{array}{c}3 \times 4 \\
\mathrm{CNT}, 30 \mathrm{~W}\end{array}$ \\
\hline $40 \mathrm{~Hz}$ & -82.62 & -62.72 & -42.94 & -27.18 \\
\hline $50 \mathrm{~Hz}$ & -88.08 & -60.61 & -47.13 & -35.85 \\
\hline $63 \mathrm{~Hz}$ & -89.48 & -66.51 & -51.13 & -32.78 \\
\hline $80 \mathrm{~Hz}$ & -96.17 & -64.66 & -54.40 & -25.91 \\
\hline $100 \mathrm{~Hz}$ & -90.24 & -64.38 & -60.00 & -46.31 \\
\hline $125 \mathrm{~Hz}$ & -93.27 & -62.55 & -61.21 & -37.97 \\
\hline $160 \mathrm{~Hz}$ & -91.16 & -66.00 & -68.47 & -32.96 \\
\hline $200 \mathrm{~Hz}$ & -95.92 & -59.85 & -68.47 & -42.16 \\
\hline $250 \mathrm{~Hz}$ & -103.50 & -63.43 & -77.93 & -43.45 \\
\hline $315 \mathrm{~Hz}$ & -98.26 & -60.08 & -78.29 & -51.45 \\
\hline $400 \mathrm{~Hz}$ & -96.02 & -59.11 & -81.78 & -61.05 \\
\hline $500 \mathrm{~Hz}$ & -110.22 & -58.54 & -87.58 & -62.70 \\
\hline $630 \mathrm{~Hz}$ & -98.25 & -57.36 & -91.90 & -62.53 \\
\hline $800 \mathrm{~Hz}$ & -107.23 & -51.26 & -92.84 & -61.87 \\
\hline $1 \mathrm{kHz}$ & -101.78 & -48.54 & -91.76 & -80.67 \\
\hline $1.25 \mathrm{kHz}$ & -99.29 & -46.80 & -94.18 & -54.37 \\
\hline $1.6 \mathrm{kHz}$ & -103.41 & -45.85 & -88.08 & -56.09 \\
\hline $2 \mathrm{kHz}$ & -105.22 & -46.90 & -83.75 & -52.18 \\
\hline $2.5 \mathrm{kHz}$ & -101.40 & -45.51 & -73.82 & -47.81 \\
\hline $3.15 \mathrm{kHz}$ & -94.15 & -48.25 & -77.13 & -50.85 \\
\hline $4 \mathrm{kHz}$ & -88.14 & -51.94 & -78.53 & -58.23 \\
\hline $5 \mathrm{kHz}$ & -96.64 & -47.25 & -90.09 & -54.00 \\
\hline $6.3 \mathrm{kHz}$ & -93.25 & -43.35 & -96.79 & -50.60 \\
\hline $8 \mathrm{kHz}$ & -93.06 & -42.28 & -99.14 & -46.78 \\
\hline $10 \mathrm{kHz}$ & -101.21 & -38.62 & -103.12 & -47.37 \\
\hline $12.5 \mathrm{kHz}$ & -101.63 & -39.25 & -102.49 & -45.43 \\
\hline $16 \mathrm{kHz}$ & -106.56 & -38.72 & -106.71 & -44.31 \\
\hline
\end{tabular}




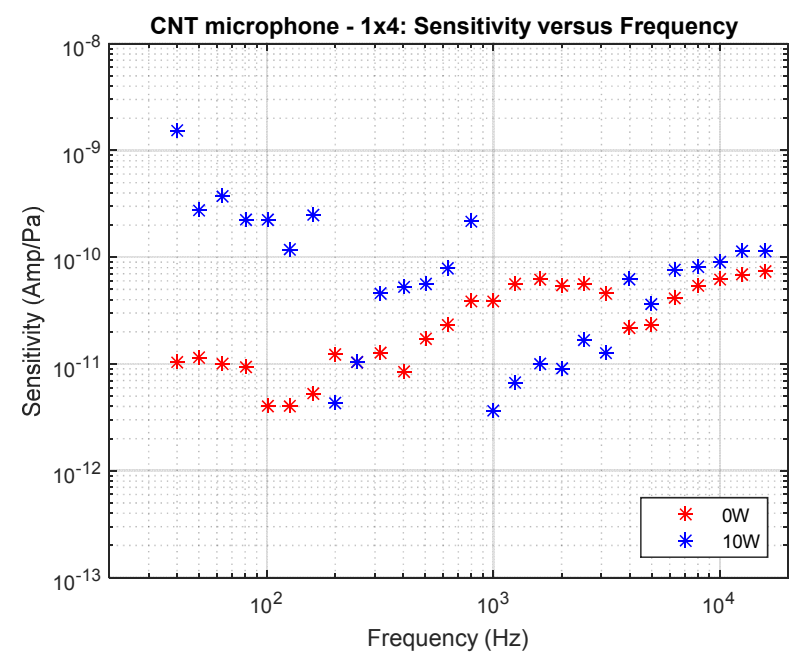

Figure F.6: Sensitivity versus frequency tone played, $1 \mathrm{~cm} \mathrm{x} 4 \mathrm{~cm}$ CNT assembly.

Table F.3: Amplitudes of current signals (dB ref $1 \mathrm{~mA})$ at the frequency of the pure tone played for $1 \mathrm{~cm} \mathrm{x} 4 \mathrm{~cm}$ CNT assembly.

\begin{tabular}{|c|c|c|c|c|}
\hline $\begin{array}{l}\text { Frequency tone } \\
\text { played/ } \\
\text { Frequency at which } \\
\text { current amplitude } \\
\text { occurs }\end{array}$ & $\begin{array}{c}\text { Background } \\
\text { no tone played, } \\
1 \times 4 \mathrm{CNT}, \\
0 \mathrm{~W}\end{array}$ & $\begin{array}{c}1 \times 4 \\
\text { CNT, } 0 \mathrm{~W}\end{array}$ & $\begin{array}{c}\text { Background } \\
\text { no tone played, } \\
1 \times 4 \mathrm{CNT} \\
10 \mathrm{~W}\end{array}$ & $\begin{array}{c}1 \times 4 \\
\text { CNT, } 10 \mathrm{~W}\end{array}$ \\
\hline $40 \mathrm{~Hz}$ & -91.73 & -63.39 & -31.63 & -20.07 \\
\hline $50 \mathrm{~Hz}$ & -90.34 & -63.70 & -36.17 & -36.25 \\
\hline $63 \mathrm{~Hz}$ & -89.09 & -64.66 & -39.31 & -33.38 \\
\hline $80 \mathrm{~Hz}$ & -88.00 & -62.95 & -43.93 & -35.28 \\
\hline $100 \mathrm{~Hz}$ & -90.37 & -69.21 & -47.53 & -34.28 \\
\hline $125 \mathrm{~Hz}$ & -91.96 & -69.25 & -51.46 & -39.77 \\
\hline $160 \mathrm{~Hz}$ & -96.65 & -66.61 & -56.10 & -33.18 \\
\hline $200 \mathrm{~Hz}$ & -99.68 & -58.91 & -60.83 & -68.09 \\
\hline $250 \mathrm{~Hz}$ & -98.26 & -59.77 & -62.99 & -59.92 \\
\hline $315 \mathrm{~Hz}$ & -93.85 & -57.77 & -67.39 & -46.51 \\
\hline $400 \mathrm{~Hz}$ & -106.52 & -61.07 & -72.81 & -45.08 \\
\hline $500 \mathrm{~Hz}$ & -97.56 & -54.94 & -74.97 & -44.63 \\
\hline $630 \mathrm{~Hz}$ & -96.61 & -52.06 & -79.46 & -41.35 \\
\hline $800 \mathrm{~Hz}$ & -96.69 & -47.50 & -83.90 & -32.57 \\
\hline $1 \mathrm{kHz}$ & -105.27 & -47.29 & -87.57 & -67.84 \\
\hline $1.25 \mathrm{kHz}$ & -102.03 & -44.52 & -85.57 & -62.88 \\
\hline $1.6 \mathrm{kHz}$ & -101.29 & -43.21 & -90.23 & -59.18 \\
\hline $2 \mathrm{kHz}$ & -98.53 & -44.04 & -80.62 & -59.67 \\
\hline $2.5 \mathrm{kHz}$ & -104.60 & -44.63 & -73.53 & -55.16 \\
\hline $3.15 \mathrm{kHz}$ & -93.63 & -46.90 & -73.18 & -58.24 \\
\hline $4 \mathrm{kHz}$ & -88.87 & -52.57 & -84.77 & -43.50 \\
\hline $5 \mathrm{kHz}$ & -97.46 & -51.80 & -87.02 & -47.97 \\
\hline $6.3 \mathrm{kHz}$ & -106.14 & -47.88 & -106.80 & -42.58 \\
\hline $8 \mathrm{kHz}$ & -93.49 & -45.04 & $\begin{array}{l}-103.98 \\
\end{array}$ & -41.54 \\
\hline $10 \mathrm{kHz}$ & -95.15 & -43.79 & -114.73 & -40.52 \\
\hline $12.5 \mathrm{kHz}$ & -94.75 & -42.94 & -104.96 & -38.75 \\
\hline $16 \mathrm{kHz}$ & -105.01 & -42.42 & -104.86 & -38.47 \\
\hline
\end{tabular}

